\title{
Dataflows de tempo real como abstração para ferramentas de processamento de Big Data
}

Fernanda de Camargo Magano

\author{
DisSERTAÇÃO APRESENTADA \\ AO \\ Instituto DE MATEMÁticA E EstatísticA \\ DA \\ Universidade DE SÃo PAUlo \\ PARA \\ OBTENÇÃO DO TÍTULO \\ $\mathrm{DE}$ \\ Mestre em CIÊNCIAS \\ Programa: Ciência da Computação \\ Orientadora: Profa. Dra. Kelly Rosa Braghetto
}

Durante o desenvolvimento deste trabalho a autora recebeu auxílio financeiro do CNPq

São Paulo, abril de 2020 


\section{Dataflows de tempo real como abstração para ferramentas de processamento de Big Data}

Esta versão da dissertação/tese contém as correções e alterações sugeridas pela Comissão Julgadora durante a defesa da versão original do trabalho, realizada em 29/04/2020. Uma cópia da versão original está disponível no

Instituto de Matemática e Estatística da Universidade de São Paulo.

Comissão Julgadora:

- Prof ${ }^{a}$. Dr ${ }^{a}$. Kelly Rosa Braghetto (orientadora) - IME-USP

- Prof. Dr. André Luis Schwerz - UTFPR

- Prof. Dr. José de Jesús Pérez Alcázar - EACH-USP 


\section{Agradecimentos}

Gostaria de agradecer primeiramente a Deus pelas bênçãos que tem me proporcionado na vida e pela saúde, força e persistência que tem me dado para chegar até aqui.

Agradeço aos meus pais, Maria e Fernando, por todo o amor, carinho, suporte, conversas e conselhos que me deram desde sempre, sendo fundamentais em cada conquista de minha vida. Agradeço também aos meus avós e a toda minha família.

À minha orientadora, Kelly Rosa, pelo suporte, sugestões e apoio neste trabalho. Aos professores Alfredo Goldman e Daniel Batista pelas sugestões dadas na qualificação do meu projeto de mestrado, as quais ajudaram a melhorá-lo. Aos professores e alunos do grupo de sistemas, os quais deram dicas durante os relatos e apresentações realizadas nas reuniões do grupo.

Aos meus amigos IMEanos, alguns dos quais me conhecem desde o começo da minha Graduação. Citarei alguns que acompanharam minha trajetória e me trouxeram muitos momentos de alegria, união, companheirismo, risadas e empatia: Alyssa Shibata, Eduardo Bier, Fernando Freire, Giuliano Belinassi, Ivo Terek, Renato Cordeiro, Shayenne Moura e Vinícius Bittencourt.

Aos amigos que fiz ao longo de minha vida e que torcem por mim, me proporcionam momentos de descontração, boas conversas e risadas.

Ao IME como um todo, incluindo professores, colegas e todos os funcionários que tornam o ambiente acolhedor e garantem o bom funcionamento do instituto. Aprendi muito no IME, desde a graduação, a qual foi uma base essencial na concretização deste trabalho de mestrado.

Foram muitos aprendizados, não somente acadêmicos, como também lições de vida: aprendi a ser uma pessoa ainda mais persistente, forte e a continuar seguindo em frente, acreditando que sonhos são possíveis de serem alcançados. 


\section{Resumo}

\section{MAGANO, F. C. Dataflows de tempo real como abstração para ferramentas de proces-}

samento de Big Data. 2020. Dissertação (Mestrado) - Instituto de de Matemática e Estatística, Universidade de São Paulo, São Paulo, 2020.

Grandes volumes de dados, provenientes de diversas fontes, são gerados continuamente nas cidades. O processamento e análise desses dados desempenham um papel fundamental na implementação de iniciativas para cidades inteligentes. Para processar Big Data urbano, é fundamental o uso de ferramentas de alto desempenho, que possam se beneficiar de computação paralela e distribuída para acelerar o processamento e prover respostas rápidas. Entretanto, esse uso não é trivial, pois as ferramentas, geralmente, não são interoperáveis e demandam que seus usuários tenham conhecimentos de computação paralela e distribuída e bancos de dados. Além disso, em cidades inteligentes, uma aplicação precisa ser capaz de se adaptar ao contexto atual de sua execução. Por exemplo, uma aplicação que mostra a situação atual do trânsito, em um contexto de indisponibilidade momentânea de dados coletados em tempo real, deve poder mostrar uma previsão do trânsito baseada em dados históricos, sendo necessária a combinação de processamento de dados em tempo real e em lotes. O objetivo deste trabalho é facilitar o uso de ferramentas de processamento de Big Data para desenvolvedores de software. Para isso, foi criada uma interface para especificação de workflows para o processamento de dados (ou dataflows) e um sistema de software que possibilita a execução deles em diferentes ferramentas de Big Data. Por um lado, a interface sintetiza os principais recursos dessas ferramentas, abstraindo suas especificidades e fornecendo uma representação padronizada para eles. Por outro lado, o sistema de software mapeia os dataflows definidos por meio da interface em modelos inteligíveis às ferramentas. A interface e o sistema propostos formam uma camada de abstração sobre os arcabouços de Big Data. Ambos foram validados e avaliados por meio da implementação de uma aplicação no domínio de mobilidade urbana, que processa dados reais da cidade de São Paulo. A aplicação escrita com o auxílio da interface foi analisada por meio de métricas de código-fonte. A partir da análise, foi possível concluir que houve ganhos com o uso da interface, como a redução no número de linhas, métodos, atributos, bem como a diminuição da complexidade ciclomática do código-fonte.

Palavras-chaves: Workflows, Dataflows, Processamento de Big Data, Cidades Inteligentes. 


\section{Abstract}

MAGANO, F. C. Real time dataflows as abstraction for Big Data processing tools 2020. Thesis (Master) - Instituto de de Matemática e Estatística, Universidade de São Paulo, São Paulo, 2020.

Large volumes of data, from different sources, are continuously generated in cities. Processing and analyzing these data play a key role in implementing smart city initiatives. In order to process urban Big Data, it is essential to use high performance tools, which can benefit from parallel and distributed computing to accelerate the processing and provide quick answers. However, this use is not trivial, as the tools are not interoperable and require knowledge of parallel and distributed computing and databases from their users. In addition, in smart cities, applications need to be able to self-adapt to the current context of their execution. For example, an application that shows the current traffic situation, in a context of momentary unavailability of data collected in real time, should be able to show a traffic forecast based on historical data, using a combination of real time and batch data processing. In this work, the goal is to facilitate the use of Big Data processing tools for software developers and, for that, we created an interface to specify workflows for data processing (or dataflows) and a software system that makes it possible to run them in different Big Data tools. On the one hand, the interface summarizes the main features of these tools, abstracting their specificities and providing a standardized representation for them. On the other hand, the software system maps the dataflows defined through the interface to intelligible models for the tools. The developed interface and system form an abstraction layer over the Big Data frameworks. Both were validated and evaluated through the implementation of an application in the field of urban mobility, using real data collected from the city of São Paulo. The application written with the aid of the interface was analyzed using source code metrics. From the analysis, it was possible to conclude that there was gain from the use of the interface, such as reducing the number of lines, methods, attributes, as well as decreasing the cyclomatic complexity of its source code.

Keywords: Workflows, Dataflows, Big Data Processing, Smart Cities. 


\section{Sumário}

Lista de Abreviaturas $\quad$ xi

Lista de Figuras $\quad$ xiii

Lista de Tabelas $\quad$ xv

1 Introdução $\quad 1$

1.1 Motivação . . . . . . . . . . . . . . . . . . . . . . . . . . 1

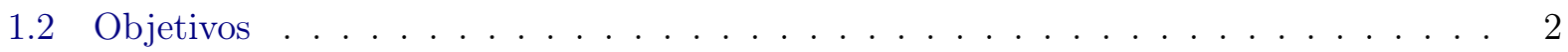

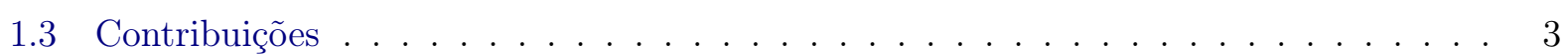

1.4 Organização do trabalho . . . . . . . . . . . . . . . . . . . 4

2 Fundamentação teórica $\quad 5$

2.1 Big Data . . . . . . . . . . . . . . . . . . . . . . . 5

2.1 .1 Processamento de dados . . . . . . . . . . . . . . . . . . . . . . 5

2.1.2 Arquiteturas de Big Data para processamento em tempo real . . . . . . . . 7

2.2 Ferramentas de processamento de Big Data . . . . . . . . . . . . . . . 7

2.2 .1 Modelo de processamento . . . . . . . . . . . . . . . . . 8

2.2.2 Camada de transporte de mensagens . . . . . . . . . . . . . . . . . . 9

2.2 .3 Formato dos dados . . . . . . . . . . . . . . . . . . . . . . . . . 11

2.2.4 Tolerância a falhas e persistência de estado . . . . . . . . . . . . . . . . . 12

2.2 .5 Janelas . . . . . . . . . . . . . . . . . . . . . . . . . . . . . . . . . 13

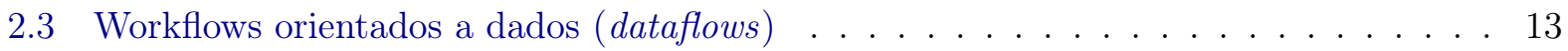

2.3.1 Estruturas dos workflows orientados a dados . . . . . . . . . . . . . . . 13

2.3.2 Dataflow process networks . . . . . . . . . . . . . . . . . . . 15

2.3.3 Sistemas Gerenciadores de Workflows . . . . . . . . . . . . . . . 16

2.4 Camadas de abstração de software . . . . . . . . . . . . . . . . . 16

2.4.1 Abstração para processamento de stream . . . . . . . . . . . . . . . . . 17

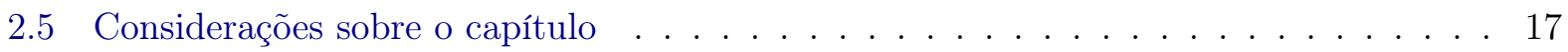

3 Trabalhos relacionados $\quad 18$

3.1 Processamento de Big Data em tempo real . . . . . . . . . . . . . . . . . . . . 18

3.2 Camada de abstração e modelo de dataflows . . . . . . . . . . . . . . . . . . . . 19

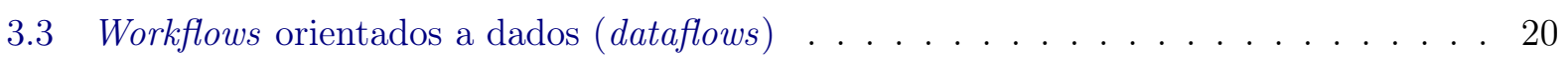

3.4 Considerações sobre o capítulo . . . . . . . . . . . . . . . . . . . . 21 
4 Ferramentas de Big Data e suas características

4.1 Comparação de ferramentas . . . . . . . . . . . . . . . . . . . . . 22

4.2 Operadores para processamento de Big Data . . . . . . . . . . . . . . . . . . 25

4.3 Estudo do Apache Flink . . . . . . . . . . . . . . . . . . . . . 26

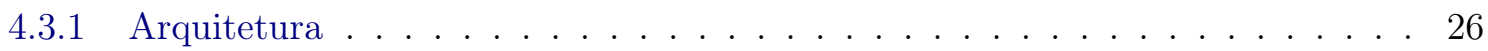

4.3.2 Streams, operadores e janelas . . . . . . . . . . . . . . . . 27

4.3 .3 Representação dos dataflows . . . . . . . . . . . . . . . . . . . . . 28

4.4 Estudo do Apache Apex . . . . . . . . . . . . . . . . . . . . . . 28

4.4 Arquitetura . . . . . . . . . . . . . . . . . . . . 29

4.4.2 Streams, operadores e janelas . . . . . . . . . . . . . . . . 30

4.4 .3 Representação dos dataflows . . . . . . . . . . . . . . . . . . . 30

4.5 Estrutura geral dos projetos no Flink e Apex . . . . . . . . . . . . . . . 31

4.6 Considerações sobre o estudo das ferramentas . . . . . . . . . . . . . . . . . 33

5 Interface para representação de dataflows $\quad 34$

5.1 Arquitetura desenvolvida . . . . . . . . . . . . . . . . . . 34

5.2 Estrutura de classes da API . . . . . . . . . . . . . . . . . . . . 34

5.3 Interface para construção de dataflows: componentes abstraídos . . . . . . . . . . . 37

5.3 .1 Tipo de parâmetro . . . . . . . . . . . . . . . . . . . . . . . 38

5.3 .2 ProjectSettings . . . . . . . . . . . . . . . . . . . 38

5.3.3 Operadores de entrada e saída de dados . . . . . . . . . . . . . . . . . . . . 39

5.3 .4 Data . . . . . . . . . . . . . . . . . . . . . 41

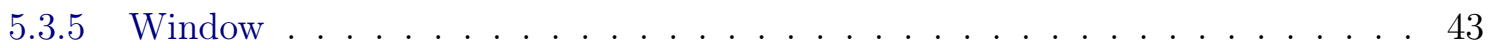

5.3 .6 Sequência das classes da interface . . . . . . . . . . . . . . . . . . . 44

5.4 Considerações sobre a interface desenvolvida . . . . . . . . . . . . . . . . . . 44

6 Análise e mapeamento de dataflows $\quad 46$

6.1 Analisador de código . . . . . . . . . . . . . . . . . . . . . 47

6.1 .1 JavaParser: analisador léxico e sintático . . . . . . . . . . . . . . . . 48

6.1 .2 Estrutura do analisador desenvolvido . . . . . . . . . . . . . . . . . . 49

6.2 Serviços de mapeamento . . . . . . . . . . . . . . . . . . . . . 51

6.2 .1 Tratamento dos tipos de dados . . . . . . . . . . . . . 55

6.3 Considerações sobre o capítulo . . . . . . . . . . . . . . . . . . 55

$\begin{array}{lll}7 & \text { Experimentos e estudo de caso } & 57\end{array}$

7.1 Dados coletados da SPTrans . . . . . . . . . . . . . . . . . . . . . 57

7.2 Preparação dos dados . . . . . . . . . . . . . . . . . . . . . . . 59

7.3 Experimentos realizados . . . . . . . . . . . . . . . . . . 60

7.3.1 Experimento 1: diferenças de previsão de chegada entre paradas consecutivas $\quad 60$

7.3.2 Experimento 2: menores e maiores tempos previstos entre paradas consecutivas 65

7.4 Estudo de caso: sistema de previsão de horários de chegadas de ônibus . . . . . . . . . 68

7.4.1 Análises dos resultados das execuções . . . . . . . . . . . . . . . . 72

7.5 Considerações sobre o capítulo . . . . . . . . . . . . . . . . . . 73 
8 Análise dos códigos-fonte do estudo de caso $\quad 76$

8.1 Métricas de código-fonte selecionadas . . . . . . . . . . . . . . . . 76

8.2 Métricas quantitativas . . . . . . . . . . . . . . . . . . 77

8.3 Métricas de complexidade . . . . . . . . . . . . . . . . . 78

8.4 Métricas de acoplamento e coesão . . . . . . . . . . . . . . . . . 78

8.5 Métricas relacionadas a herança . . . . . . . . . . . . . . . . . 79

8.6 Métricas relacionadas a métodos e seus parâmetros . . . . . . . . . . . . . . 79

8.7 Considerações sobre o capítulo atual . . . . . . . . . . . . . . . . 80

9 Conclusões $\quad \mathbf{8 2}$

9.1 Pesquisas futuras $\ldots \ldots \ldots \ldots \ldots \ldots \ldots \ldots$

$\begin{array}{ll}\text { A Mapeamento de código } & 84\end{array}$

B Tempo de execução de dataflows mapeados $\quad 89$

$\begin{array}{ll}\text { Referências Bibliográficas } & 91\end{array}$ 


\title{
Lista de Abreviaturas
}

\author{
API Interface de Programação de Aplicações (Application Programming Interface) \\ AVL Localização Automática do Veículo (Automatic Vehicle Location) \\ $\mathrm{CBO} \quad$ Acoplamento Entre Objetos (Coupling Between Objects) \\ CC / V(G) Complexidade Ciclomática de McCabe (McCabe Cyclomatic Complexity) \\ DAG Grafo Acíclico Dirigido (Directed Acyclic Graph) \\ DIT Profundidade da Árvore de Herança (Depth of Inheritance Tree) \\ FIFO Fila (First In First Out) \\ HDFS Sistema de Arquivos Distribuído do Hadoop (Hadoop Distributed File System) \\ IoT Internet das Coisas (Internet of Things) \\ INCT Instituto Nacional de Ciência e Tecnologia \\ IME Instituto de Matemática e Estatística \\ JSON Notação de Objeto JavaScript (JavaScript Object Notation) \\ LOC Linhas de Código (Lines of Code) \\ LCOM Falta de Coesão em Métodos 4 (Lack of Cohesion in Methods 4) \\ NOA Número de Atributos (Number of Attributes) \\ NOC Número de Filhos (Number of Children) \\ NOM Número de Métodos (Number of Methods) \\ POM Modelo de Objeto do Projeto (Project Object Model) \\ RDD Dados Resilientes e Distribuídos (Resilient Distributed Dataset) \\ RFC Resposta para uma Classe (Response for a Class) \\ SGW Sistema Gerenciador de Workflows \\ SPTrans São Paulo Transporte \\ SQL Linguagem de Consulta Estruturada (Structured Query Language) \\ UDF $\quad$ Função Definida pelo Usuário (User Defined Function) \\ UML Linguagem de Modelagem Unificada (Unified Modeling Language) \\ XML Linguagem Extensível de Marcação Genérica (Extensible Markup Language) \\ YARN Ainda Outro Gerenciador de Recursos (Yet Another Resource Negotiator)
}




\section{Lista de Figuras}

1.1 Exemplo de aplicação para cidades inteligentes $\ldots \ldots \ldots$. . . . . . . . . . 2

2.1 Arquitetura Lambda (figura adaptada de Lambda (2020)) . . . . . . . . . . . . . . 7

2.2 Arquitetura Kappa (figura adaptada de Kappa (2016)) . . . . . . . . . . . . . . . . . 8

2.3 Fases do MapReduce (figura adaptada de Dean e Ghemawat (2008)) . . . . . . . . . 9

2.4 Janelas fixas, deslizantes e de sessão . . . . . . . . . . . . . . . . . . . . . . . 14

2.5 Exemplo de workflow orientado a dados . . . . . . . . . . . . . . . . . . 14

2.6 Tipos de estruturas de workflows (figura adaptada de Bharathi et al. (2008)) . . . . 15

4.1 Exemplo de redução de dados, utilizando como lógica a adição dos elementos . . 26

4.2 Arquitetura ${ }^{1}$ do Apache Flink . . . . . . . . . . . . . . . . . . 27

4.3 Dataflow do Apache Flink para um contador de palavras . . . . . . . . . . . . . . . 29

4.4 Arquitetura ${ }^{2}$ do Apache Apex . . . . . . . . . . . . . . . . . . . . 29

4.5 Dataflow do Apache Apex para um contador de palavras . . . . . . . . . . . . . . 31

4.6 Método main - Apache Flink . . . . . . . . . . . . . . . . . . . . 32

4.7 Método populateDAG-Apache Apex . . . . . . . . . . . . . . . . 32

5.1 Arquitetura do sistema de abstração de ferramentas de Big Data . . . . . . . . . . . 35

5.2 Diagrama UML com as classes presentes na interface desenvolvida . . . . . . . . . 36

5.3 Diagrama de sequência ilustrando os passos na criação de um dataflow com a interface desenvolvida . . . . . . . . . . . . . . . . . . . . . . 45

6.1 Fluxo de conversão do arquivo inicial do usuário aos arquivos finais . . . . . . . . . 46

6.2 Visão das classes da interface e daquelas criadas para realizar o mapeamento de código 52

7.1 Tempo médio (com intervalo de confiança de 99\%) que os ônibus das linhas 32772, 1651 e 1465 levam entre duas paradas consecutivas nos meses de abril, maio e junho de $2019 \ldots \ldots \ldots \ldots$

7.2 Tempo médio (com intervalo de confiança de 99\%) que os ônibus das linhas 34694, 1450 e 198 levam entre duas paradas consecutivas nos meses de abril, maio e junho

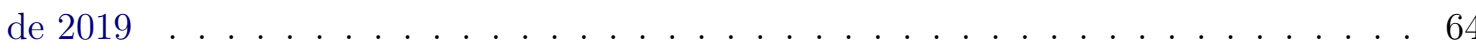

7.3 Tempos mínimo, médio e máximo que os ônibus da linha 1450 levam entre duas paradas consecutivas, analisados com dados do mês de abril de 2019 . . . . . . . . 67

7.4 Tempos mínimo, médio e máximo que os ônibus da linha 1450 levam entre duas paradas consecutivas, analisados com dados do mês de maio de 2019 . . . . . . . . 67 
7.5 Tempos mínimo, médio e máximo que os ônibus da linha 1450 levam entre duas paradas consecutivas, analisados com dados do mês de junho de 2019 . . . . . . . . . 68

7.6 Dataflow do sistema servidor da aplicação de mobilidade urbana. . . . . . . . . . . . . 69

7.7 Quantidade média de ônibus ao longo do dia para seis linhas de ônibus em setembro de 2019, considerando-se apenas dias úteis

7.8 Quantidade média de ônibus ao longo do dia para seis linhas de ônibus em setembro de 2019, considerando-se apenas finais de semana e feriados . . . . . . . . . . . . . 73

7.9 Quantidade média de ônibus que passam nas paradas ao longo do dia, para as três linhas analisadas, em julho, agosto e setembro de 2019 . . . . . . . . . . . . . . 74

B.1 Tempo médio de execução (com intervalo de confiança de 99\%) do Experimento 1 nos arcabouços Apex e Flink . . . . . . . . . . . . . . . . . . . . . . . . 90 


\section{Lista de Tabelas}

3.1 Comparação de trabalhos relacionados ao processamento de Big Data em tempo real 19

3.2 Comparação de trabalhos relacionados à camada de abstração e modelo de dataflows 20

3.3 Comparação entre trabalhos relacionados a workflows orientados a dados . . . . . . . 21

4.1 Comparação entre ferramentas - análise quantitativa (atualizada em agosto de 2019) 23

4.2 Comparação entre ferramentas - linguagens de programação e conectores . . . . . . . 23

4.3 Comparação entre ferramentas - modelo de processamento e consistência . . . . . . . 24

5.1 Métodos públicos da API para a classe ProjectSettings . . . . . . . . . . . . . . 39

5.2 Métodos públicos da API para a classe Kafka . . . . . . . . . . . . . . . . . 39

5.3 Propriedades utilizadas para a leitura e escrita no Kafka . . . . . . . . . . . . 40

5.4 Métodos públicos da API para a classe FileIo . . . . . . . . . . . . . . . . 40

5.5 Métodos públicos da API para a classe Data . . . . . . . . . . . . . . . 41

7.1 Número de registros dos três datasets utilizados no Experimento $1 \ldots$. . . . . . . 61

7.2 Cenários de execução do Experimento $1 \ldots \ldots$. . . . . . . . . . . . 61

7.3 Número de registros dos três datasets utilizados no Experimento $2 \ldots \ldots$. . . . . . 65

7.4 Cenários de execução do Experimento $2 \ldots \ldots$. . . . . . . . . . . . . 66

8.1 Comparação da quantidade de linhas, atributos, métodos, classes e arquivos nos

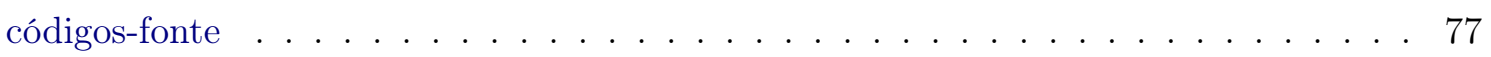

8.2 Comparação das complexidades ciclomática e cognitiva dos códigos-fonte . . . . . . . 78

8.3 Comparação do acoplamento entre objetos nos códigos-fonte . . . . . . . . . . . 79

8.4 Comparação da profundidade da árvore de herança dos códigos-fonte . . . . . . . . . 79

8.5 Comparação da resposta para uma classe (RFC) dos códigos-fontes . . . . . . . . . . 80

8.6 Comparação da quantidade média de parâmetros dos métodos (ANPM) dos códigos-

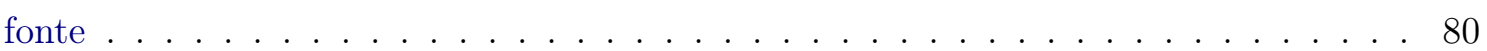




\section{Capítulo 1}

\section{Introdução}

Grandes volumes de dados, provenientes de diversas fontes, são gerados continuamente nas cidades. Com a evolução da infraestrutura para Internet das Coisas (IoT, do termo em inglês Internet of Things) e o barateamento da tecnologia, os dispositivos eletrônicos com capacidades de sensoriamento estão cada vez mais presentes no ambiente urbano, monitorando temperatura, tráfego, qualidade do ar, poluição sonora, alagamentos, entre outros (Zanella et al., 2014). Há também o sensoriamento participativo, em que cidadãos comuns coletam e compartilham informações que estão à sua volta, por meio de celulares ou de redes sociais, por exemplo. Celulares podem ser usados como sensores através de recursos como câmera, microfone, GPS e acelerômetro (Kanhere, 2011). Além disso, redes sociais podem ser combinadas com dispositivos móveis e redes de sensores, de modo a se obter informações contextuais de um usuário ou de um grupo deles, podendo-se ter ciência de sua localização, preferências e relacionamentos (Beach et al., 2010). Isso permite levar em consideração dados dos cidadãos e de seus arredores, para propor soluções que sejam compatíveis com suas necessidades e com os ambientes nos quais estão inseridos.

O processamento e análise desses dados desempenham um papel fundamental na implementação de iniciativas para cidades inteligentes, pois permitem um melhor entendimento do que ocorre nas cidades. Eles possibilitam a identificação de problemas e suas possíveis causas, podendo também, consequentemente, contribuir para propostas de soluções e para tomada de melhores decisões nesse contexto, refletindo na qualidade de vida dos cidadãos. Embora não haja uma definição clara e consensual para cidades inteligentes, pode-se dizer que uma das características presentes nessas cidades é a melhoria da qualidade de vida dos cidadãos por meio da utilização de tecnologia e serviços em diferentes setores da cidade, como de transporte, educação, saúde, governo, segurança, entre outros (Al Nuaimi et al., 2015).

O volume dos dados urbanos em geral é bem grande. Por exemplo, a frota de ônibus de São Paulo possui cerca de 14.500 ônibus distribuídos em mais de 1.300 linhas, 28 terminais municipais e 19,5 mil pontos de parada, de acordo com dados da São Paulo Transporte (SPTrans) (SPTrans, 2020), responsável pela gestão de transporte público por ônibus do município de São Paulo. Como os ônibus estão em movimento em suas rotas, a posição deles é diferente a cada instante e esses dados são atualizados várias vezes por minuto. O grande volume dos dados urbanos, combinado à heterogeneidade de suas fontes e estruturas e ao seu valor econômico e social, permitem que esse tipo de dado seja classificado como Big Data.

\subsection{Motivação}

Processamentos de Big Data, como esses citados anteriormente, podem ser feitos em lotes ou em tempo real (Zhang et al., 2016). No processamento em lotes (batch processing), dados previamente coletados e armazenados são processados, o que pode levar horas no caso dos lotes serem grandes. Já no processamento em tempo real (stream processing), os dados são processados à medida que chegam à aplicação, gerando resultados com baixa latência. Algumas aplicações requerem o uso combinado de processamento em lotes e em tempo real. Isso pode ser útil, por exemplo, em um sistema de 
monitoramento de trânsito, que precisa tanto identificar e reportar com rapidez a ocorrência de acidentes, como também ser capaz de prever as zonas mais perigosas e evitar novas situações de risco por meio do cruzamento de informações históricas.

A Figura 1.1 mostra um exemplo de aplicação para cidades inteligentes que utiliza processamento de dados: um sistema que indica a melhor rota para o motorista tendo como base mapas e dados de tráfego da cidade coletados em tempo real. Para prover a melhor rota, pode-se considerar diferentes fatores, tais como os caminhos mais curtos em termos de distância percorrida e as vias menos congestionadas no momento, entre outros. Também pode-se usar dados históricos, em caso de falta de dados em tempo real, para fazer previsões.

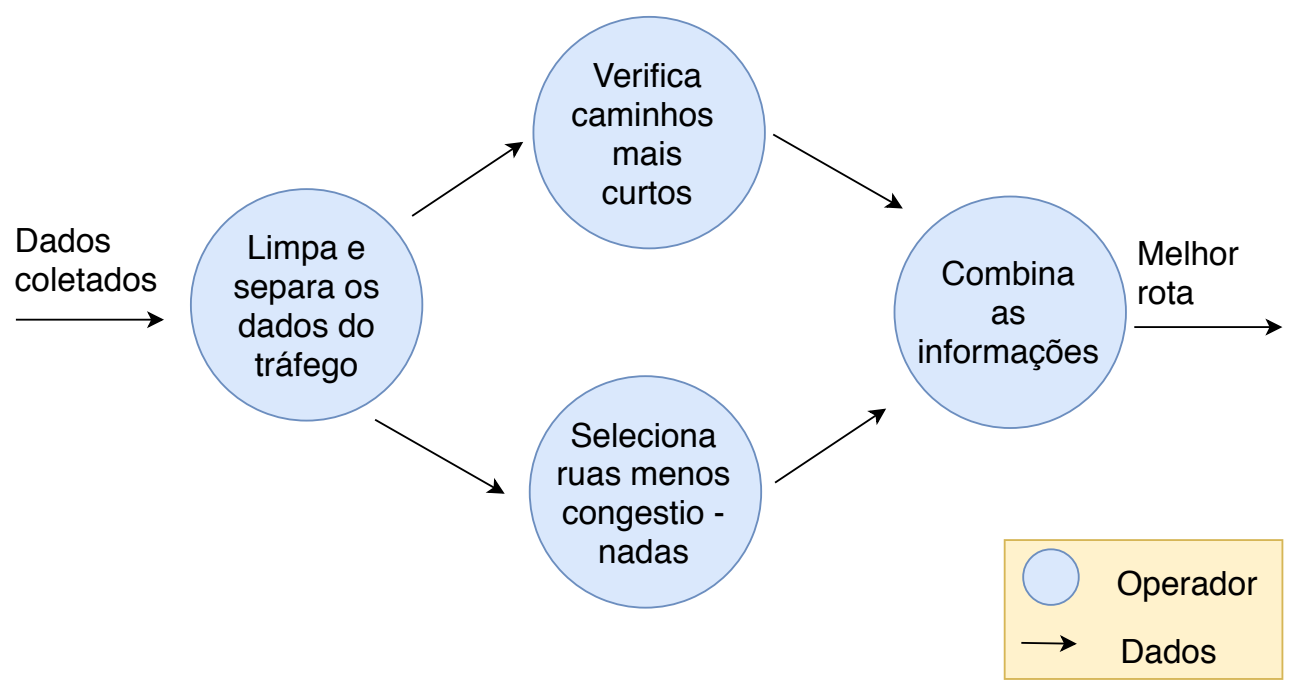

Figura 1.1: Exemplo de aplicação para cidades inteligentes

Para tratar e processar Big Data, é fundamental o uso de ferramentas de alto desempenho, que possam se beneficiar de recursos de computação paralela e distribuída para acelerar o processamento dos dados e prover respostas rápidas. Existem várias ferramentas com tais recursos (Zhang et al., 2016) e, embora sejam bastante poderosas, essas ferramentas não são triviais de serem utilizadas pois exigem de seus usuários conhecimentos sobre programação, computação paralela e distribuída e bancos de dados. Além disso, cada uma delas tem suas particularidades na forma como recebem, armazenam e processam os dados. Apesar de geralmente lidarem com formatos abertos de dados, não usam linguagens padronizadas para a especificação dos modelos de processamento e, portanto, não são completamente interoperáveis.

Ademais, é comum que sistemas de grande escala, como os utilizados em cidades inteligentes, precisem usar benchmarks para avaliar como o desempenho é modificado conforme algumas condições (como a carga de trabalho) variam, de forma a identificar possíveis gargalos. Trabalhos de benchmarking e levantamento que fazem análises comparativas no uso de recursos, tempo de resposta, vazão e latência no processamento de dados, como os de Samosir et al. (2016) e Inoubli et al. (2018), seriam facilitados se houvesse alguma abstração que abrangesse as ferramentas de Big Data.

\subsection{Objetivos}

Este projeto de mestrado tem como objetivo facilitar o uso de ferramentas de processamento de Big Data para desenvolvedores de aplicações diversas, como as de cidades inteligentes, abstraindo as especificidades dos modelos de processamento das ferramentas. Para isso, foram criados:

- Uma Interface de Programação de Aplicações (API) para a especificação de workflows para o processamento de dados em tempo real e em lotes (denotados como dataflows neste trabalho). A interface sintetiza os recursos de roteamento e processamento de dados mais frequentemente encontrados nas ferramentas de Big Data, provendo uma representação padronizada para eles. 
- Um sistema de software que possui serviços que analisam especificações de dataflows e as mapeiam para programas com a sintaxe empregada nas ferramentas de Big Data.

A interface e o sistema desenvolvidos compõem a abstração, responsável por reduzir a complexidade de desenvolvimento de soluções usando Big Data. O modelo de dataflow - citado anteriormente - representa o fluxo de dados entre atividades de um processamento por intermédio de um grafo dirigido. Dessa forma, são expressas as dependências entre essas atividades (Yu e Buyya, 2005). Como as ferramentas de Big Data utilizam modelos de dados próprios para expressar como os dados se movimentam entre os componentes de processamento, é viável usar dataflows para criar uma camada de abstração sobre tais ferramentas.

Com o sistema de abstração, os dataflows especificados por meio da interface aqui proposta podem ser executados em diferentes ferramentas de processamento de dados, bastando para isso que sejam implementados componentes de mapeamento para os modelos específicos usados nas ferramentas escolhidas.

O sistema implementado foi validado com dados reais coletados da SPTrans (SPTrans, 2020), inserindo-se em uma das frentes de pesquisa do Instituto Nacional de Ciência e Tecnologia da Internet do Futuro para Cidades Inteligentes (InterSCity) (InterSCity, 2020): a que dedica-se a desenvolver novos mecanismos para gerenciamento e análise do grande volume de dados gerado nas cidades. Dessa forma, espera-se que aplicações desenvolvidas para Big Data, como aquelas associadas ao InterSCity e ao contexto de cidades inteligentes, possam se beneficiar da eficiência no processamento dos dados provida pelas ferramentas de Big Data sem o ônus de ter que lidar com elas diretamente.

Como prova de conceito, este trabalho implementou mapeamentos para duas ferramentas de Big Data: Apache Flink (Flink, 2020) e Apache Apex (Apex, 2020). Foram desenvolvidos experimentos e uma aplicação para cidades inteligentes no domínio de mobilidade urbana, como estudo de caso. Por meio da implementação e da execução deles, foi possível avaliar a interface e o sistema construídos. Além disso, foram aplicadas métricas sobre o código do estudo de caso para comparar o código implementado usando-se a interface com aquele desenvolvido para executar sobre o Flink e Apex, visando a mostrar as vantagens do uso da API desenvolvida.

As questões de pesquisa que nortearam o desenvolvimento do trabalho foram as seguintes:

- Quais operações de manipulação de dados as ferramentas de Big Data têm em comum e que, portanto, são possíveis de se abstrair?

- Como essas operações comuns podem ser abstraídas e apresentadas aos usuários de forma independente de ferramentas, a fim de facilitar a especificação de dataflows?

- Como mapear as especificações abstratas de dataflows em programas nas linguagens específicas das ferramentas de Big Data?

\subsection{Contribuições}

As principais contribuições deste trabalho foram:

- Produção de uma interface que provê a abstração de especificidades dos arcabouços de Big Data, podendo ser generalizada para várias ferramentas de processamento. A API desenvolvida permite especificar dataflows para o processamento de dados em tempo real e em lotes.

- Realização de um mapeamento da interface criada para duas ferramentas de processamento de Big Data, são elas: Apache Flink e Apache Apex.

- Produção de uma metodologia para expandir a abstração desenvolvida para novas ferramentas de Big Data. 
- Implementação de uma aplicação para cidades inteligentes, como estudo de caso, no domínio de mobilidade urbana, com dados reais coletados da SPTrans.

Parte dos resultados do presente trabalho foram apresentados e publicados no Workshop on the Distributed Smart City (WDSC'2018) inserido no 37th IEEE International Symposium on Reliable Distributed Systems (de Camargo Magano e Braghetto, 2018).

\subsection{Organização do trabalho}

O restante deste texto está organizado da seguinte forma: o Capítulo 2 contém os fundamentos necessários para o entendimento da pesquisa e o Capítulo 3 faz uma revisão bibliográfica de trabalhos relacionados. O Capítulo 4 apresenta os resultados de um levantamento sobre ferramentas de Big Data, comparando-as e justificando a escolha do Flink e do Apex para a prova de conceito. Os capítulos 5 e 6 descrevem em detalhes a interface e o sistema desenvolvidos, ilustrando o seu uso por meio de exemplos. O Capítulo 7 contém os experimentos realizados e o detalhamento do estudo de caso desenvolvido, enquanto o Capítulo 8 tem o detalhamento das métricas obtidas a partir do estudo de caso. Por fim, o Capítulo 9 apresenta as considerações finais, discutindo os resultados obtidos a partir do trabalho. 


\section{Capítulo 2}

\section{Fundamentação teórica}

Este trabalho visou a criação de uma abstração composta pelo desenvolvimento de uma interface e um sistema de software para especificação e mapeamento de dataflows para o processamento de dados em tempo real e em lotes. O intuito foi prover uma generalização que facilite o uso de diferentes ferramentas de processamento de grandes volumes de dados para aplicações que precisem manipular e transformar dados, como ocorre no cenário de cidades inteligentes. As seções a seguir introduzem conceitos relacionados a Big Data, workflows orientados a dados (dataflows) e camadas de abstração de software que são fundamentais para o entendimento do trabalho.

\section{$2.1 \quad$ Big Data}

O termo Big Data se refere a um grande volume de dados coletados de fontes heterogêneas, dos quais se pode extrair informações úteis por meio de processamento e análise, demandando tecnologias avançadas para captura, armazenamento, gerenciamento e análise dos dados (Al Nuaimi et al., 2015; Gandomi e Haider, 2015). Por "grande volume de dados" entende-se uma quantidade que excede a capacidade infraestrutural dos softwares monolíticos tradicionalmente usados para gerenciamento de dados (como os sistemas de bancos de dados relacionais).

Além do grande volume, há outras características inerentes a Big Data, tais como: a velocidade com a qual os dados são produzidos, analisados e processados; a variedade dos tipos de dados, que se refere tanto à estrutura quanto à procedência; a variabilidade, que se refere à variação das taxas de fluxo de dados, as quais podem apresentar picos periódicos, e ao fato de que a estrutura e o significado dos dados estão em constante mudança; o valor obtido de uma boa análise e processamento, agregando conhecimentos que antes não eram conhecidos; a veracidade, que se refere à qualidade variável dos dados, que podem ter origens não confiáveis, vieses e incertezas (Gandomi e Haider, 2015).

Um sistema que lida com Big Data precisa ser tolerante a falhas, ter suporte a processamento de dados em tempo real, apresentar baixa latência, ser escalável (isto é, manter bom desempenho mesmo com o aumento de carga de processamento), ser genérico o suficiente para permitir que uma gama de aplicações possa ser desenvolvida usando o sistema e ser flexível para que novas funcionalidades possam ser adicionadas no futuro, permitindo a evolução do sistema (Marz e Warren, 2015).

O processamento e a análise de Big Data têm alto custo computacional. Assim, ferramentas para Big Data dependem de plataformas de computação de alto desempenho para sua execução. A Seção 2.2 fornece uma visão geral dessas ferramentas.

\subsubsection{Processamento de dados}

Há três abordagens principais para o processamento de dados: processamento em lotes, microlotes e de streams (Lopez et al., 2016). Essas estratégias são detalhadas a seguir: 
- Processamento em lotes: opera sobre grandes coleções de dados estáticas e devolve o resultado posteriormente, quando a computação completa está concluída. Sistemas para esse tipo de processamento têm sido estudados e aperfeiçoados há décadas. Todavia, nos dias atuais, com a facilidade de se coletar mais dados em menos tempo, há cada vez mais aplicações que demandam respostas rápidas para apoiar a tomada de decisão em tempo real (Zhang et al., 2016). O processamento em lotes não é capaz de atender a esse tipo de demanda satisfatoriamente.

- Processamento em micro-lotes: o processamento é realizado em tempo próximo ao real. Micro-lotes dividem os streams em blocos menores de dados (Lopez et al., 2016) e os processa continuamente. Apresenta maior vazão de dados em relação ao processamento em lotes.

- Processamento de streams: atua sobre quantidades ilimitadas de dados, gerados continuamente. Os resultados são obtidos de forma rápida e interativa, de modo que os dados que chegam sejam processados sem a necessidade de serem armazenados.

Sistemas de processamento em tempo real tratam os itens de dados assim que eles chegam, o que diminui a latência ${ }^{1}$ mas, por outro lado, aumenta a sobrecarga por item, porque os dados são tratados em quantidades menores. O processamento em lotes é mais eficiente, por utilizar buffer de armazenamento e processar os dados conjuntamente, mas a latência na geração dos resultados pode inviabilizar o seu uso em sistemas de tempo real (Wingerath et al., 2016).

As ferramentas de Big Data costumam explorar três estratégias diferentes para paralelizar a execução das operações de processamento de dados: (i) paralelismo de tarefas: execução em paralelo de operações de processamento que são independentes entre si; (ii) paralelismo de dados: ocorre sobre múltiplos itens de dados por meio de réplicas de tarefas que permitem lidar com partições dos dados de entrada separadamente;e (iii) paralelismo de pipeline: em que os itens de dados produzidos por uma operação são consumidos pela operação subsequente à medida em que vão sendo produzidos (Vydyanathan et al., 2007).

Garantir corretude dos resultados e apresentar ferramentas que permitam lidar com tempo são características necessárias para que sistemas de streaming se equiparem e até superem aqueles que fazem processamento em lote (Akidau, 2015). Há diferentes noções de tempo: de evento, de processamento e de ingestão (Friedman e Tzoumas, 2016).

- Tempo de evento: é o momento em que o evento ocorreu na sua origem e, normalmente, fica embutido como informação do próprio registro. Desse modo, o progresso do tempo depende do dado e não de relógios (wall clock), garantindo corretude de resultados mesmo para eventos atrasados ou fora de ordem.

- Tempo de processamento: depende do tempo da máquina que está executando a operação de processamento. Embora não garanta determinismo em suas respostas, provê melhor desempenho e mais baixa latência se comparado ao tempo de evento.

- Tempo de ingestão: é o momento em que o evento chega à ferramenta de processamento. Trata-se de um intermediário entre tempo de processamento e de evento, pois o tempo de ingestão oferece resultados mais previsíveis que o tempo de processamento, porém não consegue lidar com eventos atrasados ou fora de ordem.

Os tempos de evento e de processamento não costumam coincidir e, na prática, costumam desviar bastante, dependendo de fatores como o motor de execução do processamento, o hardware utilizado, as características do próprio dado processado, congestionamento na rede de transmissão, gargalos, entre outros. Esse desvio é resultante da latência inerente ao processamento. Para processar conjuntos ilimitados de dados, as ferramentas de processamento utilizam janelas, explicadas na Seção 2.2.5, que são formas de discretizar os dados em tamanhos finitos. Para garantir a corretude

\footnotetext{
${ }^{1}$ No contexto de workflows, a latência é o tempo necessário para processar cada item de dados ao longo de todos os componentes do workflow.
} 
no processamento do dado não é adequado utilizar o tempo de processamento (Akidau, 2015), visto que, como não há consistência na correlação entre os tempos de evento e processamento, os dados analisados podem ficar em janelas de tempo incorretas.

\subsubsection{Arquiteturas de Big Data para processamento em tempo real}

A necessidade de se processar dados em tempo real levou ao desenvolvimento de arquiteturas planejadas para esse tipo de processamento, uma vez que inicialmente as arquiteturas eram mais voltadas aos lotes. Duas arquiteturas se destacam e são detalhadas a seguir: Lambda e Kappa.

A arquitetura Lambda (Kiran et al., 2015; Lambda, 2020) unifica os processamentos em lote e em tempo real no mesmo arcabouço, sendo dividida em três camadas: a camada para processamento de lotes (batch layer), a de processamento em tempo real (speed layer) e a camada de serviço (serving layer) para responder e analisar consultas, provendo visualização dos resultados da camada de lote. Os novos dados que chegam ao sistema são enviados para ambas as camadas de lote e de tempo real para processamento, de modo que consultas são respondidas pela junção de ambos os resultados obtidos. A Figura 2.1 mostra as camadas dessa arquitetura.

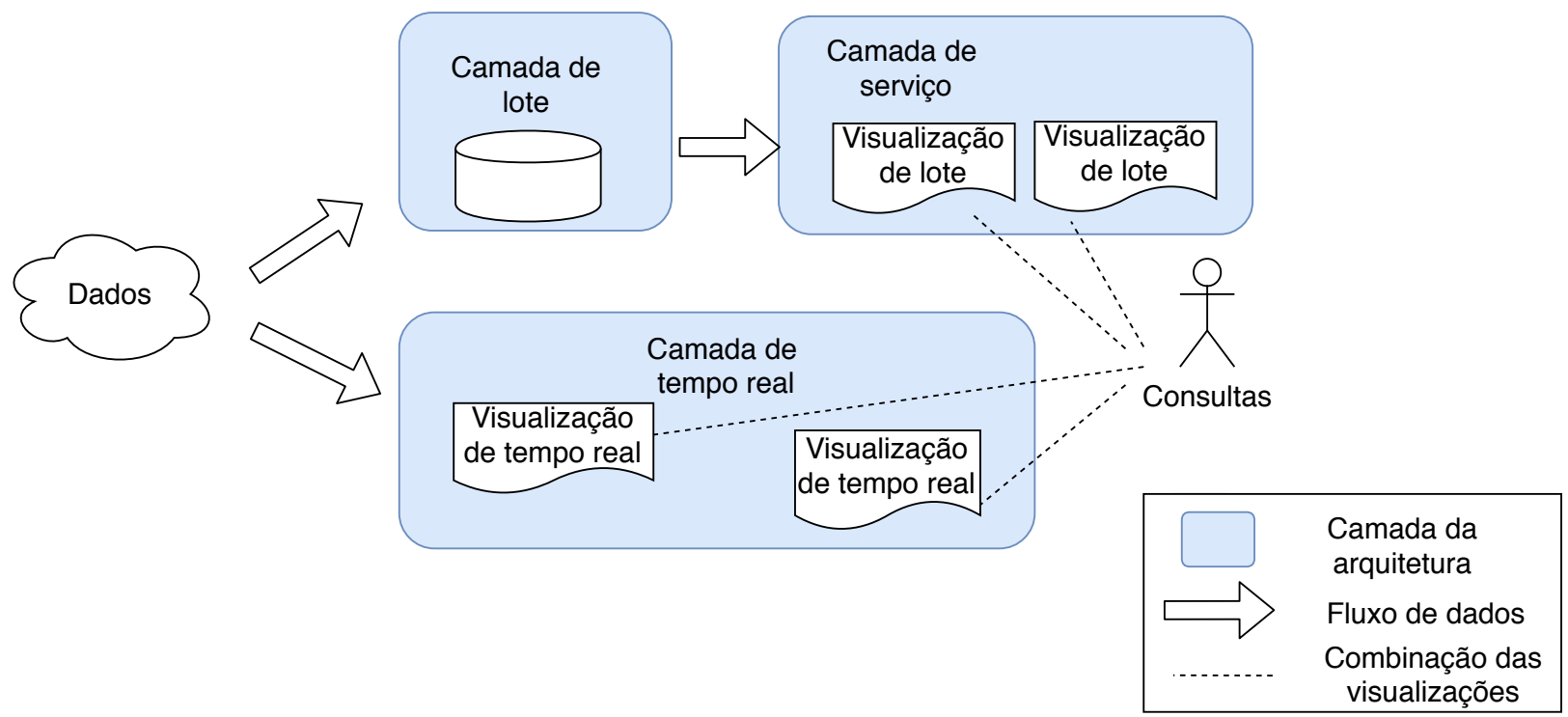

Figura 2.1: Arquitetura Lambda (figura adaptada de Lambda (2020))

Por apresentar camadas separadas para processar lotes e tempo real, é difícil a manutenção da arquitetura Lambda, já que envolve dois sistemas distribuídos complexos. A arquitetura Kappa, por outro lado, é mais simples que a Lambda por não apresentar a camada de processamento de lote. A camada de tempo real consegue lidar também com os lotes, havendo um único motor para ambos os tipos de processamento (Kappa, 2016), como indicado pela Figura 2.2. Nessa arquitetura os lotes são tratados como um subconjunto de streams, sendo possível fazer análises históricas. Os dados originais são persistidos e imutáveis, ou seja, embora os dados possam ser transformados e processados, os registros iniciais recebidos ficam intactos.

\subsection{Ferramentas de processamento de Big Data}

Existem diversas ferramentas de software voltadas ao processamento de grandes volumes de dados, sendo algumas mais dedicadas a lotes, enquanto outras enfocam o tempo real. Para amparar o desenvolvimento da interface de especificação de fluxos de processamento de dados proposta neste trabalho, as seguintes ferramentas de Big Data foram analisadas: Storm (2020), Spark (2020), Flink (2020), Apex (2020) e Samza (2020), todas elas da Apache Foundation. Este trabalho optou por analisar somente ferramentas de software livre e, dentre elas, foram escolhidas as mais usadas no momento em que a análise foi conduzida (2018). Além disso, no momento da escolha, constatou-se 


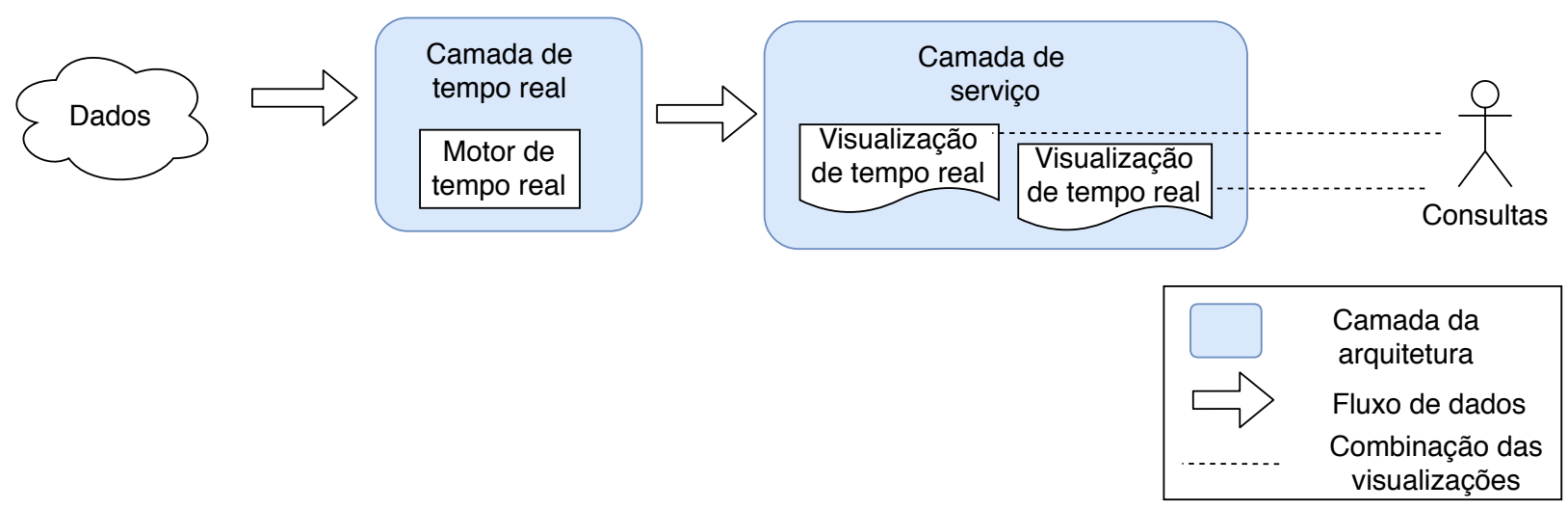

Figura 2.2: Arquitetura Kappa (figura adaptada de Kappa (2016))

que possuíam comunidades ativas responsáveis pela manutenção e melhorias dos arcabouços. Na sequência, são definidos alguns conceitos comuns importantes às ferramentas estudadas, introduzindo também a nomenclatura utilizada por elas.

\subsubsection{Modelo de processamento}

As ferramentas recebem fluxos de dados de diferentes fontes - como banco de dados, arquivos, filas de mensagens - e realizam transformações e computações sobre eles. As unidades de processamento de dados recebem nomes que variam conforme a ferramenta utilizada; exemplos deles são: bolts, operadores e tasks. A saída produzida pode ser armazenada ou devolvida no que algumas ferramentas chamam de sinks ou destinos.

Os dados recebidos pelas ferramentas podem ser particionados para permitir processamento paralelo e distribuído. Por exemplo, o Spark usa uma abstração de dados chamada RDD (Resilient Distributed Dataset), uma coleção de dados distribuídos e resilientes.

A maioria das ferramentas de Big Data atuais (incluindo as estudadas neste trabalho) utilizam um modelo de processamento baseado em grafos dirigidos acíclicos (DAGs), em que os nós representam as unidades de processamento de dados e as arestas representam as transferências de dados entre as unidades de processamento. Poucas das ferramentas possuem suporte a grafos dirigidos cíclicos, o Samza é um exemplo delas. Para a construção do grafo que representa uma dada aplicação de processamento de dados, cada ferramenta de Big Data geralmente oferece uma API aos desenvolvedores (Misale et al., 2017).

\section{MapReduce}

Em algumas ferramentas (como Spark e Flink), o modelo de processamento apresenta muitas semelhanças com o MapReduce (Dean e Ghemawat, 2008; Zhang et al., 2016) ou é uma generalização dele. O MapReduce trata-se de um modelo de programação que apresenta, como indicado em seu nome, as fases de mapeamento e de redução, além de uma fase intermediária entre estas duas (como ilustrado na Figura 2.3). Essas etapas atuam sobre pares de chave e valor.

O MapReduce é aplicado sobre um conjunto de dados $X=\left\{x_{1}, x_{2}, \ldots x_{n}\right\}$. Os dados de entrada são particionados e são realizadas cópias do programa do usuário contendo o MapReduce, sendo uma delas para o nó mestre, o qual atribui tarefas para os nós trabalhadores. As divisões não são previamente atribuídas a máquinas, mas sim distribuídas pelo nó mestre de acordo com alguns critérios. Por exemplo, se uma máquina terminou de processar sua tarefa, o mestre lhe atribui um novo bloco para processamento. Se uma máquina falha, a sua tarefa é reatribuída a outra que possa executá-la.

A tarefa atribuída para cada nó pode ser de map ou de reduce, como visto na Figura 2.3. Cada trabalhador que recebe uma tarefa de map lê uma fatia de dados resultante da divisão inicial dos dados de entrada. A etapa de mapeamento aplica uma função $f$, definida pelo usuário, sobre cada 
$x_{i}$ de modo a produzir um conjunto de pares do tipo chave e valor $(k, v)$. A computação paralela $f\left(x_{i}\right)$ é possível se a função aplicada depender apenas de $x_{i}$.

Os pares de chave e valor intermediários, produzidos como saída da função, são armazenados na memória. Com regularidade, os pares armazenados são escritos no disco local e seus endereços são passados ao nó mestre, responsável por repassar esses locais aos nós trabalhadores aos quais foram atribuídos tarefas de redução (Dean e Ghemawat, 2008). Ao receberem esses endereços, os nós leem os dados intermediários de sua partição, os ordenando pelas chaves para que valores associados à mesma chave estejam agrupados. Essa ordenação é necessária, visto que chaves diferentes podem estar na mesma tarefa de redução. O nó trabalhador itera sobre os dados intermediários, passando cada chave com o conjunto correspondente de valores para a função de redução. A etapa de redução aplica uma função $\rho$ sobre cada lista produzida na etapa intermediária, de modo a produzir os valores finais. As listas devem ser independentes umas das outras, isto é, possuírem chaves $k$ diferentes para que o paralelismo seja possível.

O nó mestre faz verificações periódicas aos trabalhadores e considera que determinado nó falhou se não houver resposta dentro de um certo intervalo de tempo. Tarefas de map ou reduce que estavam em progresso em algum nó trabalhador com falha são definidas como ociosas e se tornam elegíveis a reexecução. Devido à importância do nó mestre no modelo MapReduce, esse nó precisa manter pontos de restauração periódicos de suas estruturas de dados de modo que, em caso de falhas, uma nova instância possa ser executada.

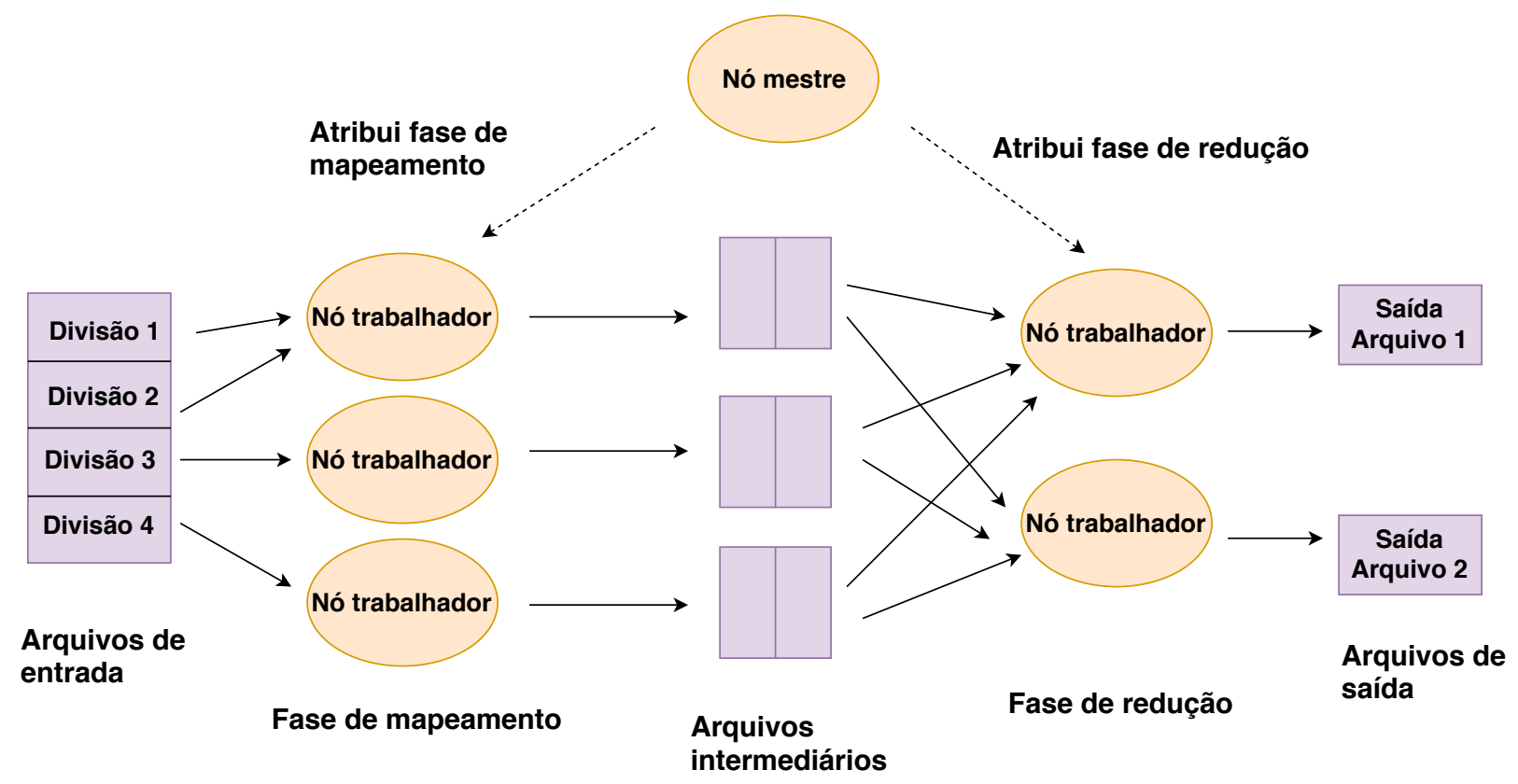

Figura 2.3: Fases do MapReduce (figura adaptada de Dean e Ghemawat (2008))

\subsubsection{Camada de transporte de mensagens}

A camada de transporte de mensagens também é importante em uma arquitetura baseada em streams, porque ferramentas de processamento precisam receber eventos contínuos, em tempo real. Os eventos chegam às ferramentas por meio de mensagens que são entregues pelo componente de transporte, o qual pode ser formado por filas de mensagens ou por brokers (detalhados nas próximas seções).

Um dos papéis da camada de transporte é funcionar como uma fila segura, para que, caso haja uma interrupção, seja possível recuperar as mensagens. A camada de transporte permite armazenar dados de eventos para o passo do processamento (Friedman e Tzoumas, 2016), tornando possível a retransmissão de mensagens. Isso permite computar novamente uma parte específica de um fluxo de eventos, garantindo o correto processamento. 


\section{Fila e broker de mensagens}

Considerando-se a forma como os dados são transmitidos dos seus respectivos produtores aos consumidores, há diferentes modelos que podem ser utilizados. Dois modelos bastante usados são as filas e os brokers de mensagens.

No primeiro modelo, a fila recebe as mensagens e garante que cada uma delas seja processada por apenas um consumidor, mesmo podendo haver diferentes consumidores da fila. Depois de recebida e processada por um consumidor, a mensagem é removida da fila. A escolha de determinado consumidor em detrimento dos demais depende da forma como foi realizada a implementação do algoritmo da fila. O elemento recuperado da fila é definido pela ordem de seu armazenamento ou com base na sua prioridade. Os consumidores obtêm as mensagens de forma síncrona, embora algumas filas tenham suporte limitado à entrega assíncrona de mensagens (Eugster et al., 2003). Contudo, esses mecanismos assíncronos não escalam bem para muitos consumidores, devido às interações adicionais necessárias para manter as garantias transacionais e de ordenação, por exemplo.

Brokers de mensagens são extensões das filas de mensagens, mediadores na comunicação entre aplicações, permitindo a troca de mensagens por meio da tradução do protocolo do remetente para o do seu respectivo receptor. Os brokers são cientes do conteúdo das mensagens que passam por eles, diferentemente das filas. Assim, aplicações de software podem se comunicar por troca de mensagens por intermédio de um broker, o qual valida e roteia as mensagens, garantindo o desacoplamento de aplicações, visto que elas não precisam estar completamente cientes umas das outras.

Além de rotear as mensagens aos seus destinos, um broker pode interagir com repositórios externos com o intuito de armazená-las, pode responder a eventos ou erros e usar o padrão publicaçãoassinatura (publish-subscribe) para roteamento de mensagens. Como exemplos de brokers de mensagens de código aberto, pode-se citar o Apache Kafka (2020) e RabbitMQ (2020), amplamente utilizados em grandes sistemas. Embora ambos utilizem o paradigma publicação-assinatura (explicado na Seção 2.2.2), eles apresentam modelos arquiteturais diferentes.

\section{Publicação-assinatura}

O padrão publicação-assinatura também utiliza o conceito de produtores e consumidores mas, diferentemente do modelo de filas, permite que a mesma mensagem seja recebida por múltiplos consumidores. Então, o modelo possui os publicadores e os assinantes dos dados, sendo os primeiros os produtores das mensagens e os últimos os consumidores que se inscreveram para recebê-las.

Esse padrão permite o desacoplamento entre os publicadores e os assinantes: além de não precisarem estar cientes uns dos outros, os participantes não precisam estar ativos ao mesmo tempo para que a interação funcione (Dobbelaere e Esmaili, 2017). Desse modo, mensagens não precisam ser lidas imediatamente, já que assinantes podem se inscrever para mensagens da fila, ou seja, o assinante não precisa estar em execução no momento em que a mensagem chegar (Friedman e Tzoumas, 2016).

Há dois tipos principais de lógica de roteamento utilizados para especificar quais os eventos de interesse: assinatura baseada em tópicos e assinatura baseada em conteúdo. A primeira utiliza um conjunto de etiquetas (tags) definidas pelo publicador que são úteis para filtrar quais mensagens vão para quais assinantes, os quais escolhem etiquetas de seu interesse. A segunda utiliza todos os campos de dados e metadados como filtros mais complexos e, portanto, com maior custo de processamento.

O padrão publicação-assinatura permite a construção de sistemas escaláveis e isso pode ser obtido considerando-se diferentes dimensões, por exemplo, aumento no número de produtores e consumidores, quantidade de tópicos e mensagens. A escalabilidade é alcançada por meio de algumas características desse padrão: o uso de operações paralelas (como o particionamento existente nos tópicos do Kafka), caching de mensagens, entre outras. 


\subsubsection{Formato dos dados}

Os dados podem estar disponíveis em vários formatos diferentes, tais como ORC, Avro, JSON, XML, CSV, SQL e fontes NoSQL, por exemplo. Eles podem ser divididos em três categorias: dados estruturados, semiestruturados e não estruturados (Gandomi e Haider, 2015).

- Dados estruturados apresentam um esquema sobre os dados, garantindo eficiência no armazenamento já que possuem estrutura bem definida. Por outro lado, isso traz rigidez, sendo um modelo menos flexível e dificultando modificações no esquema. Sistemas de bancos de dados relacionais e o Apache Avro (2020) - um sistema de seriação de dados - utilizam esse formato. Um exemplo de comando de definição de estrutura de uma tabela em SQL está ilustrado na Lista 2.1.

- Dados não estruturados são textos com formato livre ou objetos binários que não apresentam marcações nem metadados para organizá-los e normalmente precisam de contexto para que possam ser analisados. Um exemplo desse contexto pode ser o conhecimento da proveniência do dado. Há um custo associado para realizar as várias transformações e técnicas de extração necessárias para interpretar os dados. Exemplos desse formato são arquivos de texto e mídias sociais (como o texto de tweets publicados no Twitter).

- Dados semiestruturados apresentam alguma estrutura por registro mas não exigem um esquema global bem definido. São exemplos desse formato: JSON (Lista 2.2) e XML (Lista 2.3). Trata-se de um formato mais flexível e cada registro é auto-explicativo e de fácil compreensão pelos seres humanos. Por não apresentarem formato completamente estruturado, pode haver uma sobrecarga extra na análise desses dados em comparação com os estruturados.

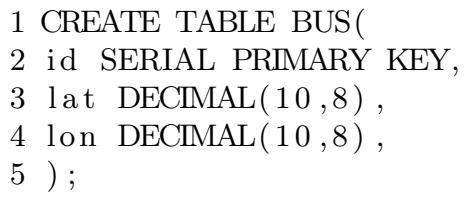

Lista 2.1: Exemplo de definição (em $S Q L$ ) da estrutura de uma tabela de um banco de dados relacional

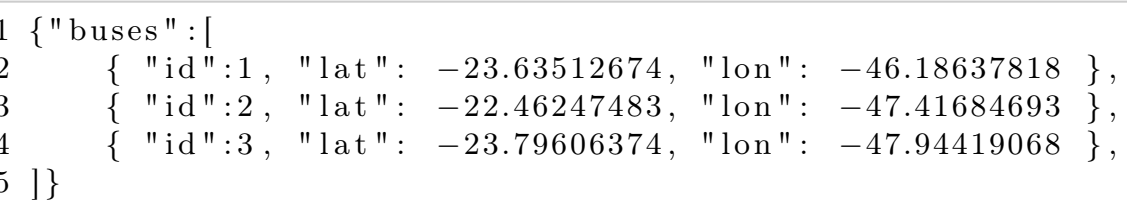

Lista 2.2: Exemplo de dados no formato JSON

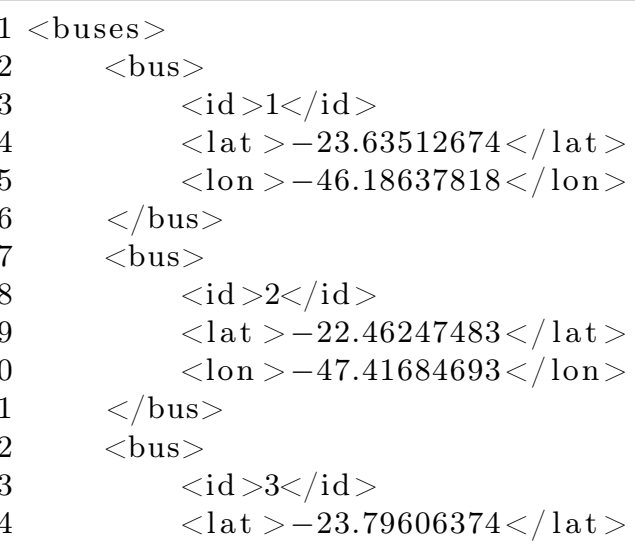




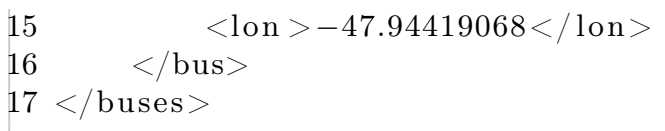

Lista 2.3: Exemplo de dados no formato $X M L$

As ferramentas Apache Apex, Flink, Samza, Spark e Storm conseguem lidar com os três tipos de dados, visto que todas têm suporte à leitura e escrita em arquivos de texto, JSON, Avro, entre outros conectores possíveis, como bancos NoSQL e brokers de mensagens. Essa flexibilidade de fontes de dados para as ferramentas de processamento de grande volume de dados é importante tendo-se em vista que uma das características de Big Data é a variedade, ou seja, as coleções de dados apresentam estruturas heterogêneas.

\subsubsection{Tolerância a falhas e persistência de estado}

Outras características importantes nas ferramentas são tolerância a falhas e persistência de estado (Misale et al., 2017). A capacidade de continuar processando os dados mesmo quando ocorrem falhas, como queda de energia por exemplo, é essencial para sistemas de tempo real, em que as respostas precisam ser fornecidas rapidamente. Com o intuito de se recuperar de falhas e garantir corretude dos resultados do processamento, um sistema precisa registrar seu estado periodicamente. As ferramentas atuais para processamento de streams persistem estado, guardando seu valor para registros já processados e realizando atualizações para cada nova entrada de dados (Friedman e Tzoumas, 2016).

Dependendo da ferramenta, a implementação da persistência de estado pode ser realizada na memória, em disco ou em ambos. Também pode ser feita utilizando-se sistemas de armazenamento como Redis (2020), HDFS (2020) ou Kafka. O Spark permite o armazenamento de dados em diferentes partições, replicando o estado das estruturas de dados para outros nós trabalhadores para conseguir recriar e recalcular os conjuntos de dados. O Samza restaura seu estado com base em snapshots. Em caso de falha em alguma máquina, o YARN (2020) permite transferir as tarefas para outra máquina. No Apex, quando ocorrem falhas, a recuperação automática garante que a computação continue no ponto em que parou, utilizando o YARN e snapshots. O Storm utiliza backups e mecanismo de confirmações (acknowledgments) para garantir que o reprocessamento foi realizado após uma falha, enquanto o Flink usa pontos de restauração (Lopez et al., 2016). Portanto, o Spark, Samza, Apex, Storm e Flink são tolerantes a falhas e possibilitam persistir o estado.

Há níveis de corretude dos resultados após uma recuperação bem-sucedida de uma falha quando se compara com resultados que seriam obtidos caso não houvesse falhas. Esse nível de corretude é chamado de consistência e pode ser dividido em três níveis, de acordo com a semântica de entrega dos dados: no máximo uma vez, pelo menos uma vez e exatamente uma vez.

- No máximo uma vez: os dados serão processados no máximo uma vez por todos os operadores da aplicação, sem haver retransmissão de eventos ou dados que possam ter sido perdidos em alguma falha. Desse modo, não há garantias de corretude.

- Pelo menos uma vez: permite retransmissão, mas com isso alguns dados podem ser processados mais de uma vez.

- Exatamente uma vez: é a garantia mais difícil de ser obtida pois, como indicada pelo próprio nome, os dados são processados "exatamente uma vez" por todos os operadores de uma aplicação.

Portanto, costuma ser difícil obter garantia "exatamente uma vez", alta vazão e baixa latência concomitantemente, por serem características conflitantes em um arcabouço. Por isso, a garantia "pelo menos uma vez" era a opção mais adotada entre os primeiros processadores de dados de tempo real, por ser mais facilmente implementada em comparação à "exatamente uma vez" e ser uma garantia melhor no quesito corretude em comparação a "no máximo uma vez". 


\subsubsection{Janelas}

Sistemas de tempo real recebem dados a todo momento e, desse modo, para realizar agregações sobre os dados - como média, soma, encontrar valor máximo ou mínimo, por exemplo - é necessário dividi-los em conjuntos finitos. Nesse contexto, o papel das janelas é fundamental (Misale et al., 2017), visto que elas permitem realizar essa tarefa.

Existem janelas de tempo e de contagem de elementos. Enquanto as primeiras consideram como métrica intervalos de tempo, possuindo uma marca de tempo inicial e final para delimitar as janelas, as últimas consideram como critério de divisão o número de elementos.

Três abordagens usuais para janelas de tempo são as janelas fixas, as deslizantes e as de sessões (Akidau, 2015), ilustradas na Figura 2.4 e detalhadas a seguir:

- Fixas: possuem tamanhos fixos de tempo e, uma vez avaliadas, todo o seu estado e seus registros são descartados. São úteis para discretizar os fluxos de dados em vários lotes.

- Deslizantes: generalizações das janelas fixas que permitem obter informações passadas dos dados, como por exemplo saber dos últimos cinco segundos, um minuto, entre outros. Assim, além da duração da janela, é indicado o fator deslizante, isto é, a quantidade de tempo deslizado de uma janela para outra. Com isso, é comum haver sobreposições entre elas e então um mesmo elemento pode aparecer em diferentes janelas.

- Sessões: são janelas dinâmicas, visto que sessões são formadas por períodos de atividade intercalados por intervalos de inatividade. Desse modo, os tamanhos dessas janelas não são pré-definidos e costumam ser diferentes entre si.

Para o caso de janelas de contagem, também é possível ter janelas fixas e deslizantes, com definição similar ao caso do tempo, mas com a diferença de que é considerado o número de elementos.

\subsection{Workflows orientados a dados (dataflows)}

Workflows orientados a fluxos de dados, também chamados de dataflows, são uma categoria de workflows usada para modelar e automatizar a execução de processos de análise de dados. Um modelo de dataflow estabelece as dependências entre atividades de processamento com base nos dados manipulados e transferidos por elas (Yu e Buyya, 2005) e, portanto, também pode ser representado por um DAG, como ilustrado na Figura 2.5. As atividades desempenham operações sobre os itens de dados, por meio das quais são acessados, modificados e novos itens são produzidos. Os dados que fluem pelas arestas (canais) são processados pelos nós. Pelo fato dos nós poderem processar dados de forma independente uns dos outros, os programas de dataflow apresentam bastante concorrência. Uma instância de um dataflow refere-se à sua execução e, assim, ele pode ser instanciado várias vezes, paralela ou concorrentemente.

A Figura 2.5 ilustra um dataflow que realiza agregações sobre dados coletados sobre a temperatura - média, cálculo do máximo e do mínimo - mostrando o fluxo de dados pelo dataflow até produzir um resultado como saída do processamento.

\subsubsection{Estruturas dos workflows orientados a dados}

As estruturas básicas componentes dos dataflows do ponto de vista de particionamento e agregação de dados são: processo, pipeline, distribuição, agregação e redistribuição de dados (Bharathi et al., 2008). Essas estruturas estão ilustradas na Figura 2.6.

- Processo: é o componente mais simples. Trata-se de uma transformação aplicada a um dado de entrada, gerando uma saída.

- Pipeline: é resultante da combinação sequencial de transformações, produzindo resultados intermediários utilizados pelo seu sucessor, sendo uma extensão do modelo de processo, mas considerada uma estrutura única, por ser recorrente em modelos de workflows. 


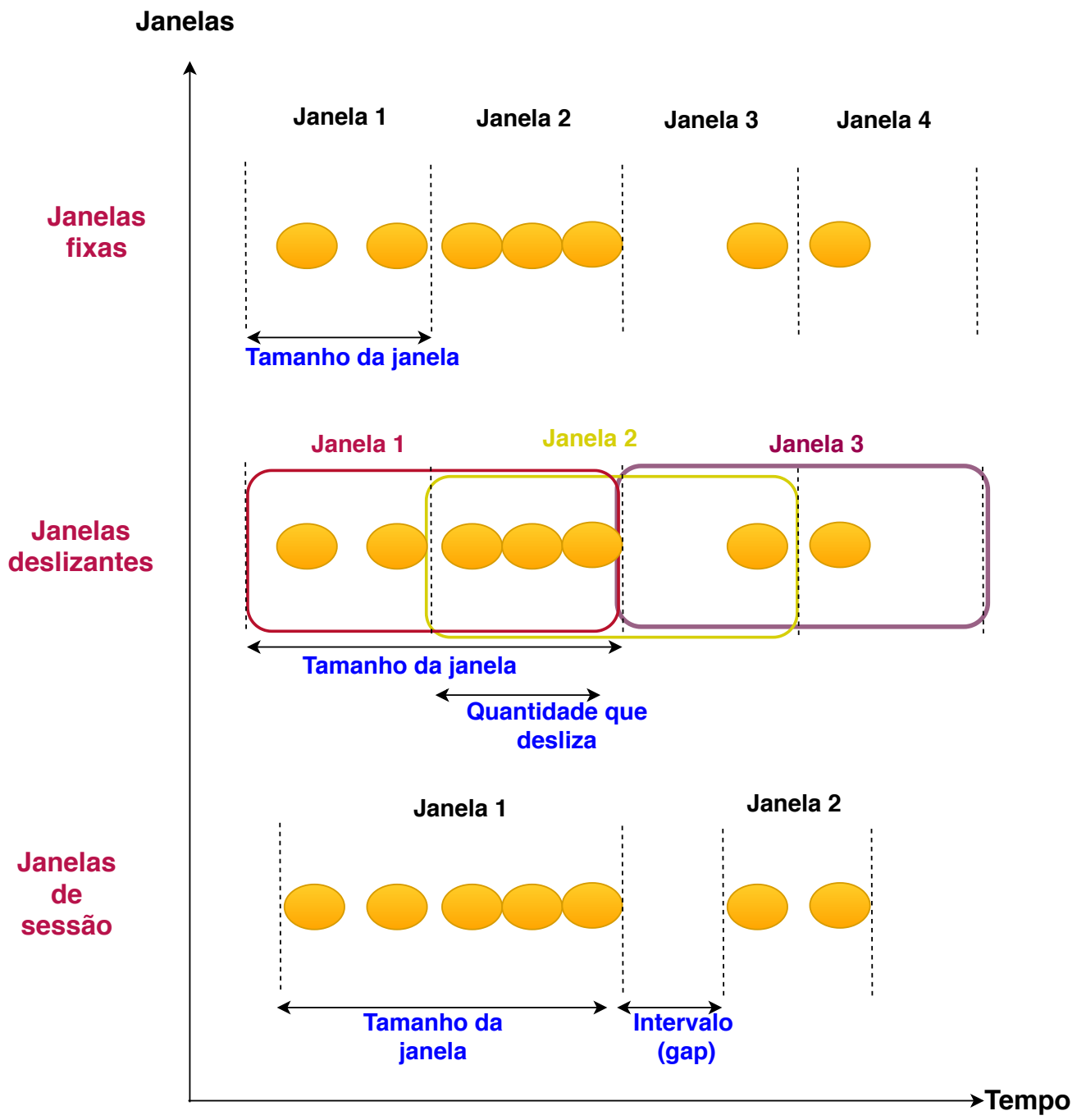

Figura 2.4: Janelas fixas, deslizantes e de sessão

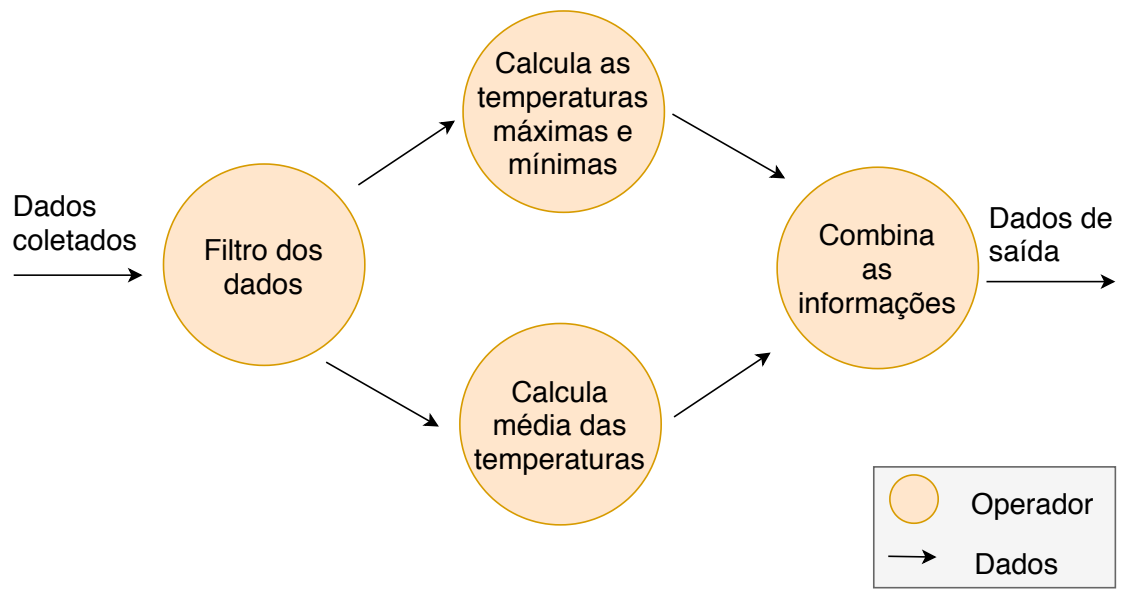

Figura 2.5: Exemplo de workflow orientado a dados 


\section{Processo}

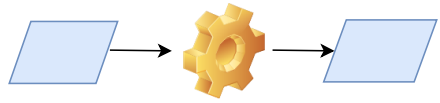

Pipeline

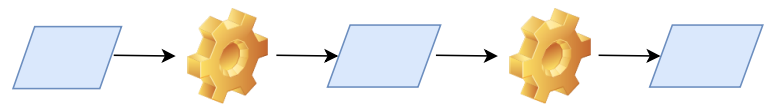

Agregação de dados

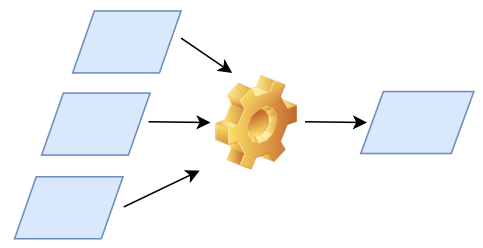

Redistribuição de dados

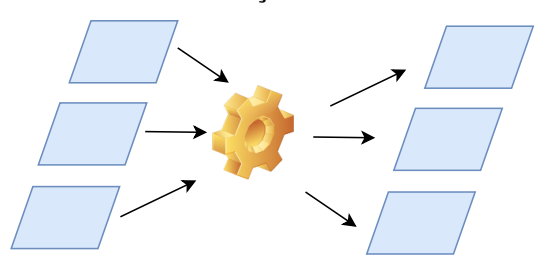

Distribuição de dados
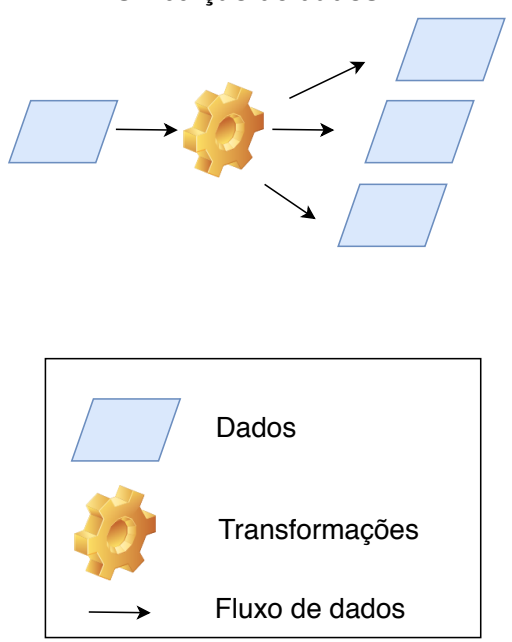

Figura 2.6: Tipos de estruturas de workflows (figura adaptada de Bharathi et al. (2008))

- Distribuição de dados: também referida como particionamento, gera dados de saída consumidos por outros jobs (transformações) ou divide um grande conjunto de dados em partições menores a serem processados por outras transformações, permitindo o uso de paralelismo sobre os dados. Um exemplo de particionamento é realizado pela operação de Map.

- Agregação: recebe mais de uma entrada de dados e, por meio da aplicação de agregações e processamentos sobre os dados, gera uma saída. Se por um lado a distribuição aumenta o paralelismo, a agregação diminui, já que várias entradas tornam-se uma única saída.

- Redistribuição de dados: dados previamente agregados são redistribuídos a vários jobs na etapa seguinte. É uma combinação de agregação com distribuição de dados. Desse modo, a redução inicial do paralelismo devido à agregação é recuperada no particionamento. A redistribuição dos dados funciona como um ponto de sincronização do processamento.

\subsubsection{Dataflow process networks}

Misale et al. (2017) comparam os modelos de processamento usados nas principais ferramentas de Big Data da atualidade, os quais podem ser generalizados por um modelo proposto em 1995, chamado dataflow process networks (Lee e Parks, 1995). É um modelo que descreve todos os níveis de abstração, desde a API até o modelo de execução, expressivo e genérico o suficiente para representar processamento em lote, micro-lote e tempo real, presentes nas ferramentas de processamento de Big Data, apenas mudando a semântica de atores e canais.

Um ator é uma unidade de computação, isto é, uma função que atua sobre tokens (fichas) e no geral não apresentam estado. Se possuírem estado, podem ser considerados como objetos com métodos que permitem alterar seu estado.

Quando recebem disparos, os atores consomem as fichas de entrada (pode ser uma ou mais) oriundas de streams e, como resultado, produzem uma ou mais fichas de saída. Uma ficha em uma rede de dataflow pode representar tanto um item de dado quanto um lote de dados. Pode haver um 
ou mais canais de entrada e saída e cada ficha produzida pode ser replicada para se espalhar para vários canais. Atores independentes podem ser rodados em paralelo, bem como serem replicados para explorar paralelismo sobre os dados. No caso em que atores são dependentes, pode-se utilizar paralelismo com pipeline.

Assim, no modelo de dataflow process networks as aplicações são representadas por meio de grafos dirigidos de atores e o processamento de dados consiste em disparos regulares dos atores. Uma rede de dataflow pode ser executada usando uma das duas abordagens a seguir (as demais são derivadas destas): baseada em processo ou em escalonamento (Misale et al., 2017). No primeiro modelo, cada ator é um processo e a comunicação ocorre por canais que seguem a estrutura de fila (FIFO, do inglês first in, first out). No segundo caso, o escalonador verifica a disponibilidade das fichas de entrada para os atores de modo a escaloná-los para executar tarefas de computação.

\subsubsection{Sistemas Gerenciadores de Workflows}

Um Sistema de Gerenciamento de Workflows (SGW) é um sistema que define, modifica, gerencia, monitora e executa workflows científicos (Lin et al., 2009). Alguns sistemas gerenciadores de workflows orientados a dados são amplamente usados especialmente pela comunidade científica, para automatizar experimentos in silico. Esses sistemas auxiliam usuários no projeto, execução e análise de workflows utilizando um nível de abstração que oculta as tecnicalidades envolvidas nessas tarefas. Uma função importante que esses sistemas podem assumir é a de prover execuções eficientes de workflows em plataformas de alto desempenho, cuidando do escalonamento e do gerenciamento da execução (paralela e distribuída) das atividades. Por essa razão, os SGWs costumam ser considerados mais fáceis de utilizar para usuários que as ferramentas de Big Data. Exemplos de SGWs bastante usados são o Pegasus ${ }^{2}$ e o Kepler ${ }^{3}$.

Contudo, os SGWs apresentam algumas limitações (Talia, 2013), para citar algumas:

- Embora existam operadores de alto nível nos SGWs para a construção de workflows, são operadores simples, sendo necessário que estruturas de alto nível mais complexas sejam incluídas nas ferramentas de programação de workflows.

- Os SGWs existentes possuem problemas de compatibilidade entre si. A interoperabilidade entre sistemas é uma característica fundamental para realizar experimentos de larga escala e, portanto, é necessário obter avanços nessa área para SGWs.

- Apenas alguns SGWs científicos provêm mecanismos explícitos para lidar com falhas de hardware ou software.

\subsection{Camadas de abstração de software}

No contexto deste trabalho, pode-se definir camada de abstração de software como sendo uma generalização de um conjunto de funcionalidades conceitualmente relacionadas. A camada de abstração esconde os detalhes de implementação das funcionalidades (que podem, inclusive, ser oferecidas por ferramentas de software diferentes) e provê uma interface que padroniza o acesso às mesmas, facilitando o seu uso e integração.

Uma camada de abstração de software frequentemente é implementada como uma interface de programação de aplicações (API, de Application Programming Interface). Uma API é um conjunto de funções, protocolos, objetos ou outros tipos de recursos que podem ser usados para a construção de aplicações de software ou para possibilitar a interação entre diferentes componentes de software. As APIs de arcabouços de Big Data disponibilizadas para a especificação dos dataflows podem ser divididas em declarativas e topológicas. Spark e Flink são exemplos de ferramentas que possuem APIs declarativas, enquanto Storm provê API topológica (Misale et al., 2017).

\footnotetext{
${ }^{2}$ https://pegasus.isi.edu/ Acesso em: 17 de fevereiro de 2020

${ }^{3}$ https://kepler-project.org/ Acesso em: 17 de fevereiro de 2020
} 
No modelo declarativo para processamento de dados, os programas são expressos por meio de uma álgebra sobre os dados. O processamento em lote é expresso de forma similar a métodos de objetos ou funções sobre valores. Os programas de processamento em tempo real são expressos por uma álgebra de operadores que atuam sobre dados, os quais normalmente são organizados em tuplas que apresentam um campo chave. Para este tipo de processamento também é importante considerar dois aspectos, presença de estado e de janelas (conforme explicado nas Subseções 2.2.4 e 2.2.5).

Por outro lado, no modelo topológico, os programas são expressos por grafos, explicitando as conexões dos nós de processamento e o código desses nós. Esse modelo de processamento provê operadores que devem ser conectados de modo a criar uma topologia. Assim, APIs declarativas são de mais alto nível se comparadas às topológicas, pela forma como são expressos os programas desenvolvidos com o uso delas.

\subsubsection{Abstração para processamento de stream}

A alta disponibilidade de dados em tempo real, seja por meio de sensores, mídias sociais, entre outras fontes, tornou crucial o processamento desses dados de modo a gerar informações que tragam valor. Com isso, tornou-se relevante a criação de abstrações para facilitar o desenvolvimento de código para processamento de dados de stream, como é o caso das linguagens de alto-nível. As abstrações trazem não somente facilidade na geração de código, mas também o torna mais fácil de ser compreendido por outras pessoas.

Existem diferentes tipos de linguagem de stream (Hirzel e Baudart, 2018) que podem ser divididas de acordo com seu foco principal: algumas têm o dado no centro, de forma que a linguagem é construída em torno do dado; outras têm como motivação o modelo de execução para processar os dataflows de forma eficiente, explorando até questões de hardware; há também linguagens focadas no usuário que irá desenvolver a aplicação de stream, buscando abstrair as complexidades. O projeto aqui desenvolvido encontra-se mais próximo desta última categoria de abstração.

\subsection{Considerações sobre o capítulo}

Este capítulo introduziu conceitos tais como o de Big Data, processamento de streams e arquiteturas utilizadas nesse tipo de processamento. Além disso, foram explicadas características importantes de ferramentas de Big Data como o modelo MapReduce, o transporte de mensagens, formato de dados, tolerância a falhas e janelas. As ferramentas utilizam modelos de workflows orientados a dados, os chamados dataflows e, considerando-se a variedade de arcabouços existentes, é relevante a construção de abstrações que facilitem o cotidiano dos usuários desses sistemas. Desse modo, foram descritos conceitos relevantes para a compreensão dos trabalhos relacionados, bem como do que foi proposto e desenvolvido neste trabalho, detalhados nos próximos capítulos. 


\section{Capítulo 3}

\section{Trabalhos relacionados}

Neste capítulo, são abordados os trabalhos mais relevantes ao tema deste projeto, ressaltando os principais aspectos em que se assemelham a este. As seções estão organizadas em três principais assuntos: processamento em tempo real [Aldinucci et al. (2018); Dissanayake e Jayasena (2017); Samosir et al. (2016); Stonebraker et al. (2005)], camada de abstração e modelo de dataflows [Cho et al. (2016); Crankshaw et al. (2017); Misale et al. (2017); Zhang (2016)] e workflows orientados a dados [Filgueira et al. (2016); Misale et al. (2018); Neophytou et al. (2011)].

\subsection{Processamento de Big Data em tempo real}

Com a tecnologia atual, o volume de dados produzidos em muitos sistemas é enorme e a necessidade de processá-los rapidamente para gerar resultados que viabilizem respostas rápidas está se tornando cada vez mais importante. Dessa forma, vários trabalhos têm estudado ou proposto arquiteturas voltadas ao processamento em tempo real (Stonebraker et al. (2005), Samosir et al. (2016)) ou que integrem processamento em lote com tempo real (Dissanayake e Jayasena, 2017). Há trabalhos que analisam requisitos desses sistemas de streaming (Stonebraker et al., 2005) ou fazem a comparação dos arcabouços existentes (Samosir et al. (2016), Aldinucci et al. (2018)).

Stonebraker et al. (2005) abordam sobre oito requisitos a serem observados em aplicações de processamento de streams, tais como lidar com dados atrasados ou desordenados, produzir como saída do processamento resultados determinísticos e passíveis de serem repetidos, se recuperar de falhas, processar dados com baixa latência, entre outros. Realizam também uma breve comparação sobre tecnologias que realizam o processamento de streams: sistemas gerenciadores de banco de dados, motores de regras e motores de processamento de streams.

Samosir et al. (2016) comparam ferramentas de processamento de streams: Storm, Samza e Spark Streaming. Implementam um protótipo para cada um dos arcabouços usando dados coletados de sensores usados no monitoramento de sistemas ferroviários de transporte pesado. Utilizam métricas qualitativas e quantitativas na análise das ferramentas. Aldinucci et al. (2018) também fazem uma comparação entre arcabouços de Big Data, mas considerando análises de dados em tempo real e em lotes, ressaltando como são as APIs e suas semânticas e como ocorre o paralelismo nessas ferramentas do ponto de vista da execução. O trabalho de Aldinucci et al. (2018) é mais teórico em comparação ao de Samosir et al. (2016).

O trabalho realizado por Dissanayake e Jayasena (2017) discute sobre um arcabouço capaz de analisar grandes volumes de dados em IoT, unificando os processamentos em lote e em tempo real no mesmo arcabouço. Em sua arquitetura, no lugar de se utilizar uma única camada de batch, como definido na arquitetura Lambda (Kiran et al., 2015), os autores propõem que sejam usadas duas sub-camadas. A tecnologia utilizada para distribuição dos lotes é HDFS (Hadoop Distributed File System). Para a camada de processamento em tempo real, o sistema utiliza Apache Storm.

Os trabalhos citados estão comparados na Tabela 3.1. 


\begin{tabular}{|c|c|c|c|}
\hline Trabalhos & Domínio & Teórico/Aplicado & $\begin{array}{c}\text { Diferenças/ } \\
\text { Pontos faltantes }\end{array}$ \\
\hline Stonebraker et al. (2005) & $\begin{array}{l}\text { Requisitos } \\
\text { para proces- } \\
\text { samento de } \\
\text { streams em } \\
\text { tempo real }\end{array}$ & Teórico & $\begin{array}{l}\text { Embora traga con- } \\
\text { ceitos relevantes para } \\
\text { o processamento em } \\
\text { tempo real, não os } \\
\text { apresenta na prática. }\end{array}$ \\
\hline Samosir et al. (2016) & $\begin{array}{l}\text { Comparação } \\
\text { qualitativa e } \\
\text { quantitativa } \\
\text { de plataformas } \\
\text { de streaming }\end{array}$ & $\begin{array}{l}\text { Teórico e aplicado } \\
\text { (avaliação por meio } \\
\text { de experimentos) }\end{array}$ & $\begin{array}{l}\text { Utilizou algumas mé- } \\
\text { tricas para análise dos } \\
\text { arcabouços, mas com } \\
\text { grande ênfase em mé- } \\
\text { tricas de desempenho }\end{array}$ \\
\hline Aldinucci et al. (2018) & $\begin{array}{l}\text { Comparação } \\
\text { de arcabouços } \\
\text { existentes para } \\
\text { análise de Big } \\
\text { Data }\end{array}$ & Teórico & $\begin{array}{l}\text { Trabalho teórico que, } \\
\text { embora apresente con- } \\
\text { ceitos relevantes, ex- } \\
\text { plora poucos critérios } \\
\text { de comparação das fer- } \\
\text { ramentas de Big Data }\end{array}$ \\
\hline $\begin{array}{l}\text { Dissanayake e Jayasena } \\
\text { (2017) }\end{array}$ & $\begin{array}{l}\text { Análise de Big } \\
\text { Data para IoT } \\
\text { de forma efici- } \\
\text { ente }\end{array}$ & $\begin{array}{l}\text { Teórico, com a pro- } \\
\text { posta de um modelo } \\
\text { para análise de da- } \\
\text { dos heterogêneos }\end{array}$ & $\begin{array}{l}\text { Apresenta um modelo } \\
\text { não implementado. Su- } \\
\text { gere o uso de Hadoop e } \\
\text { Storm, sem fazer aná- } \\
\text { lise para outros arca- } \\
\text { bouços de Big Data }\end{array}$ \\
\hline
\end{tabular}

Tabela 3.1: Comparação de trabalhos relacionados ao processamento de Big Data em tempo real

\subsection{Camada de abstração e modelo de dataflows}

Camadas de abstração de software são usadas nos mais variados domínios de aplicação computacionais. Por exemplo, Zhang (2016) e Crankshaw et al. (2017) discutem sobre camadas de abstração para o domínio de aprendizado de máquina. Algoritmos de aprendizado de máquina são bastantes utilizados, mas escalá-los é desafiador devido ao custo computacional, já que envolvem grande volume de dados de treinamento a serem processados e demandam comunicação contínua para convergir em um modelo. No trabalho de Zhang (2016), a camada provê abstração do modelo de dados e otimização nas operações de comunicação. Assim, algoritmos que se encaixam no modelo de computação iterativa podem ser paralelizados com uma camada única de comunicação para que a sincronização ocorra de forma eficiente. No trabalho de Crankshaw et al. (2017), fala-se sobre o Clipper, um sistema que se baseia em uma arquitetura em camadas para abstrair a heterogeneidade dos arcabouços e modelos existentes para aprendizado de máquina. Utilizando técnicas como caching e batching, o Clipper consegue reduzir a latência e melhorar o rendimento (taxa de transferência) das aplicações, sem modificar os arcabouços envolvidos.

O modelo de dataflow pode ser considerado uma forma de abstração por descrever bem os vários níveis das ferramentas de Big Data, abrangendo desde APIs a nível de usuário até o modelo de execução delas. Os trabalhos de Cho et al. (2016) e Misale et al. (2017) são relevantes por tratarem desse modelo sendo empregado como camada de abstração. O primeiro trabalho é mais prático, com desenvolvimento de um protótipo, enquanto o segundo é mais teórico, apresentando características e conceitos referentes aos arcabouços e ao modelo proposto.

O trabalho de Cho et al. (2016) buscou integrar processamento em tempo real e em lote em um único sistema propondo o arcabouço JsFlow, que abstrai os dados e provê um modelo de programação que utiliza álgebra de dataflow baseada em JSON. Para isso, estende a linguagem Jaql, uma linguagem declarativa e funcional, que provê vários operadores de processamento convertidos 
para código Hadoop e Spark: filter, join, sort, groupby, entre outros. Como Jaql não possui operadores para processamento em tempo real, o JsFlow adiciona operadores como window, tostream e append. JsFlow também escolhe automaticamente qual é o arcabouço de processamento de dados mais apropriado com base em estimativa de uso da memória principal. Para avaliar o arcabouço, foi construído um protótipo usando o Apache Spark para processamento de dados em lote e em tempo real. Contudo, a solução trata-se ainda de um protótipo e não houve testes para outros arcabouços além do Spark.

Misale et al. (2017) discorrem sobre o modelo de Dataflow Process Networks, formalização do modelo de dataflows utilizado pelos arcabouços de Big Data, por ser expressivo o suficiente para que possam ser representados lotes, micro-lotes e fluxos de dados em tempo real. Assim, além de explicar sobre conceitos desse modelo, o trabalho deles analisa e compara as ferramentas Spark, Storm, Flink e TensorFlow sob a ótica de dataflows. Os autores discutem também as APIs disponíveis para os usuários desses arcabouços.

Devido à importância das camadas de abstração para várias áreas da computação, é possível notar que é necessário colocar em prática os modelos teóricos existentes (como o de Misale et al. (2017)) e ampliar protótipos implementados (como o de Cho et al. (2016)) para outros arcabouços.

Os trabalhos citados estão comparados na Tabela 3.2.

\begin{tabular}{|c|l|l|l|}
\hline Trabalhos & Domínio & Teórico/Aplicado & \multicolumn{1}{|c|}{$\begin{array}{c}\text { Diferenças/ } \\
\text { Pontos faltantes }\end{array}$} \\
\hline Zhang (2016) & $\begin{array}{l}\text { Aprendizado } \\
\text { de máquina }\end{array}$ & $\begin{array}{l}\text { Aplicado (desenvol- } \\
\text { vido plugin para } \\
\text { Hadoop) }\end{array}$ & $\begin{array}{l}\text { Restringe-se ao Hadoop e } \\
\text { volta-se ao escopo de } \\
\text { aprendizado de máquina }\end{array}$ \\
\hline Crankshaw et al. (2017) & $\begin{array}{l}\text { Aprendizado } \\
\text { de máquina }\end{array}$ & Teórico e aplicado & $\begin{array}{l}\text { Escopo não abrange } \\
\text { arcabouços de Big Data }\end{array}$ \\
\hline Cho et al. $(2016)$ & $\begin{array}{l}\text { Modelo de } \\
\text { dataflow para } \\
\text { Big Data }\end{array}$ & Aplicado (protótipo) & $\begin{array}{l}\text { É um protótipo que } \\
\text { utiliza apenas o o } \\
\text { Apache Spark (não } \\
\text { abrange outros arca- } \\
\text { bouços) }\end{array}$ \\
\hline Misale et al. $(2017)$ & $\begin{array}{l}\text { Modelo de } \\
\text { dataflow para } \\
\text { Big Data }\end{array}$ & Teórico & $\begin{array}{l}\text { Falta aplicação dos } \\
\text { conceitos apresentados } \\
\text { no artigo }\end{array}$ \\
\hline
\end{tabular}

Tabela 3.2: Comparação de trabalhos relacionados à camada de abstração e modelo de dataflows

\subsection{Workflows orientados a dados (dataflows)}

Até há poucos anos, as pesquisas e as ferramentas de software desenvolvidas para workflows orientados a dados se restringiam ao processamento de dados em lotes. Contudo, devido à crescente demanda por resultados em tempo real, a modelagem e execução de workflows para processamento de streams começou a ser mais estudada e aprimorada recentemente. Um dos primeiros trabalhos a abordar o problema foi o desenvolvido por Neophytou et al. (2011). Os autores criaram o CONFLuEnCE (CONtinuous workFLow ExeCution Engine), um protótipo de sistema de execução de workflows para fluxos de dados contínuos, construído como uma extensão do SGW Kepler. Entretanto, tanto o CONFLuENCE quanto o Kepler não estão aptos a lidar com o processamento de grandes volumes de dados.

Uma proposta mais recente aborda o uso de workflows para processamento de streams com abordagens mais escaláveis: o Asterism (Filgueira et al. (2016)), o qual integra os recursos do SGW Pegasus (para processamentos de dados em lotes em plataformas computacionais heterogêneas) aos da ferramenta dispel4py, para processamento paralelo de dados em tempo real. O Asterism 
vem acompanhado de um modelo de "workflow como serviço" que pode facilitar a implantação de workflows em plataformas de nuvens, por meio do uso de contêineres.

Um outro trabalho relacionado é o PiCo (Misale et al., 2018), que utiliza o modelo de dataflows e visa a facilitar a programação dos modelos de dados, fornecendo uma API para o usuário e realizando o mapeamento da aplicação desenvolvida por ele. O mapeamento final é feito para ser executado no arcabouço Fast Flow (Aldinucci et al., 2014) de computação paralela. Embora se assemelhe ao presente trabalho pelo uso do modelo de dataflows e abstração de componentes para facilitar o desenvolvimento, difere-se porque o PiCo realiza o mapeamento para um único arcabouço, o Fast Flow.

A principal diferença entre as ferramentas de workflow para processamento de streams citadas aqui e a abordagem proposta neste projeto é que esses trabalhos se baseiam em um SGW ou arcabouço específico, estando portanto limitados às funcionalidades e à eficiência do sistema em questão. Já o objetivo do presente trabalho é criar uma camada de abstração - baseada em modelos de workflow - sobre diferentes sistemas de processamento de Big Data, para uniformizar o modo de uso dos mesmos e, dessa forma, facilitar o desenvolvimento de aplicações sobre eles.

Os trabalhos citados estão comparados na Tabela 3.3.

\begin{tabular}{|c|c|c|c|}
\hline Trabalhos & Domínio & Teórico/Aplicado & $\begin{array}{c}\text { Diferenças/ } \\
\text { Pontos faltantes }\end{array}$ \\
\hline Neophytou et al. (2011) & $\begin{array}{c}\text { Workflows para } \\
\text { luxo de dados } \\
\text { contínuos }\end{array}$ & $\begin{array}{c}\text { Aplicado (discute a } \\
\text { implementação do } \\
\text { modelo de workflows } \\
\text { CONFLuEnCE) }\end{array}$ & $\begin{array}{c}\text { Não suporta grandes } \\
\text { volumes de dados. Fica } \\
\text { restrito ao Kepler (SGWs) }\end{array}$ \\
\hline Filgueira et al. (2016) & $\begin{array}{c}\text { Workflows para } \\
\text { aplicações de dados } \\
\text { em sistemas } \\
\text { distribuídos }\end{array}$ & $\begin{array}{c}\text { Aplicado } \\
\text { (discorre a respeito } \\
\text { do Asterism) }\end{array}$ & $\begin{array}{c}\text { àtegra o SGW Pegasus } \\
\text { ferramenta dispel4py, } \\
\text { ficando restrito às } \\
\text { funcionalidades oferecidas } \\
\text { por eles }\end{array}$ \\
\hline Misale et al. (2018) & $\begin{array}{c}\text { Sistema construído } \\
\text { utilizando-se o } \\
\text { modelo de } \\
\text { dataflows }\end{array}$ & $\begin{array}{c}\text { Aplicado } \\
\text { (desenvolvido na } \\
\text { linguagem C++) }\end{array}$ & $\begin{array}{c}\text { Novo arcabouço, } \\
\text { restrito à execução no } \\
\text { Fast Flow, não } \\
\text { buscando abstrair } \\
\text { outros já existentes }\end{array}$ \\
\hline
\end{tabular}

Tabela 3.3: Comparação entre trabalhos relacionados a workflows orientados a dados

\subsection{Considerações sobre o capítulo}

A partir do estudo da literatura relacionada, é possível observar que este trabalho difere-se dos demais ao não se restringir a uma ferramenta específica ou a um determinado sistema gerenciador de workflows. Buscou-se integrar diferentes ferramentas, seja por suporte direto na abstração, que inclui a API e o mapeamento desenvolvidos, ou viabilizando uma extensão da mesma para cobrir novas ferramentas que possam surgir. 


\section{Capítulo 4}

\section{Ferramentas de Big Data e suas características}

Há várias ferramentas para processamento de Big Data disponíveis na atualidade. Embora essas ferramentas tenham o mesmo propósito geral, elas se diferem bastante entre si sob diferentes perspectivas, tais como as interfaces, o modelo de processamento que empregam e a maturidade de suas implementações. Ferramentas e arcabouços de Big Data são utilizados como sinônimos no presente trabalho, visto que arcabouços são estruturas que viabilizam a implementação de programas de processamento de Big Data sendo, portanto, ferramentas que permitem o tratamento de grandes volumes de dados.

Neste trabalho, realizou-se um estudo para identificar as principais características das ferramentas de Big Data de código aberto mais utilizadas no momento da análise. Esse estudo guiou a escolha de duas ferramentas para as quais foram implementados mapeamentos, utilizados como prova de conceito do funcionamento da interface e do sistema de abstração para dataflows desenvolvidos neste trabalho.

A Seção 4.1 descreve a comparação realizada e os critérios usados na seleção das ferramentas escolhidas: Apache Flink e Apache Apex. As seções subsequentes aprofundam a caracterização delas, considerando aspectos como arquitetura, operadores, forma de representação de dataflows, tolerância a falhas, entre outros.

\subsection{Comparação de ferramentas}

Foram realizadas análises nos âmbitos quantitativo e qualitativo dos arcabouços. Dentre os aspectos quantitativos estão: data de entrada para Apache Incubator, quando foi considerado pela Apache como projeto de alto nível, quantidade de versões, número de forks ${ }^{1}$, quantidade de issues $^{2}$ fechadas ou resolvidas, entre outros. Entre as características qualitativas analisadas, tem-se: linguagens de programação que suportam, o seu modelo de processamento de dados, a forma de acesso aos dados, o modo de especificação dos dataflows, entre outras. A Tabela 4.1 trata-se de uma comparação quantitativa, enquanto as tabelas 4.2 e 4.3 comparam aspectos do ponto de vista qualitativo.

As colunas 2 e 3 da Tabela 4.1 são a respeito da entrada de cada ferramenta para a Apache Incubator e quando foram consideradas projetos de alto nível pela Apache, aspectos relacionados à maturidade de cada ferramenta. Por exemplo, Spark e Samza são as primeiras ferramentas de processamento, dentre as analisadas, a fazerem parte da Apache. Assim, por serem mais antigas, já são bem estáveis e consolidadas. De uma forma geral, contudo, pode-se notar que, exceto pelo Apex, as demais ferramentas entraram para Apache nos anos 2013 e 2014 e foram consideradas como alto nível em 2014.

\footnotetext{
${ }^{1}$ Fork é uma cópia de um repositório e permite realizar modificações no mesmo, sem afetar o projeto original.

${ }^{2}$ Issue é uma tarefa, melhoria ou correção de bug a ser feita em um projeto.
} 


\begin{tabular}{|c|c|c|c|c|c|c|}
\hline $\begin{array}{c}\text { Ferramentas/ } \\
\text { Características }\end{array}$ & $\begin{array}{c}\text { Entrada para } \\
\text { Apache Incubator }\end{array}$ & $\begin{array}{c}\text { Projeto de alto } \\
\text { nivel na Apache }\end{array}$ & Versão atual & Contribuidores & $\begin{array}{c}\text { Número de } \\
\text { forks }\end{array}$ & $\begin{array}{c}\text { Número de } \\
\text { issues fechadas }\end{array}$ \\
\hline Apache Flink & Março de 2014 & Dezembro de 2014 & 1.8 & 546 & 5220 & 10902 \\
\hline Apache Storm & Setembro de 2013 & Setembro de 2014 & 2.0 .0 & 298 & 3919 & 2413 \\
\hline Apache Spark & Junho de 2013 & Fevereiro de 2014 & 2.4 .3 & 1403 & 19697 & 26270 \\
\hline Apache Samza & Julho de 2013 & Janeiro de 2014 & 1.2 .0 & 105 & 242 & 1604 \\
\hline Apache Apex & Agosto de 2015 & Abril de 2016 & $\begin{array}{c}3.7 \text { (Core), } \\
3.8 \text { (Malhar) }\end{array}$ & $\begin{array}{c}42 \text { (Core) } \\
54 \text { (Malhar) }\end{array}$ & $\begin{array}{c}179 \text { (Core) } \\
150 \text { (Malhar) }\end{array}$ & $\begin{array}{c}536 \text { (Core), } \\
449 \text { (Malhar) }\end{array}$ \\
\hline
\end{tabular}

Tabela 4.1: Comparação entre ferramentas - análise quantitativa (atualizada em agosto de 2019)

Todavia, mesmo tendo entrado depois, refletindo no número de forks e issues concluídas, Apex já apresenta várias versões, estando atualmente nas versões 3.7 e 3.8 para o Apex Core e Malhar, respectivamente. Embora seja uma única ferramenta, o desenvolvimento dessas duas partes do Apex ocorrem em repositórios diferentes, sendo o Core a parte central e Malhar a biblioteca de operadores.

A maturidade do Spark reflete no número de contribuidores, forks e issues, sendo a ferramenta com maior número nesses quesitos. O segundo a apresentar mais contribuidores e issues é o Flink. Embora seja o segundo no número de contribuidores, apresenta menos da metade da quantidade do Spark. Apesar disso, todas as ferramentas possuíam comunidades ativas no momento em que foi realizada a análise inicial para escolha das ferramentas, isto é, em 2017, ano do começo do presente trabalho. A atividade é evidenciada pelas atualizações realizadas nos respectivos repositórios das ferramentas, ilustrando que se tratam de projetos grandes, com várias issues encerradas. Assim, as características analisadas na Tabela 4.1 evidenciam que todas essas ferramentas poderiam se beneficiar com a abstração. Os dados da Tabela 4.1 foram atualizados com informações de agosto de 2019.

\begin{tabular}{|c|c|c|c|c|}
\cline { 3 - 4 } \multicolumn{2}{c|}{} & \multicolumn{2}{c|}{ Conectores } \\
\hline $\begin{array}{c}\text { Ferramentas/ } \\
\text { Características }\end{array}$ & Escrita em & APls & $\begin{array}{c}\text { Integra ao } \\
\text { Kafka e Hadoop }\end{array}$ & $\begin{array}{c}\text { Integra ao } \\
\text { RabbitMQ }\end{array}$ \\
\hline Apache Flink & Java, Scala & Declarativa & Sim & Sim \\
\hline Apache Storm & Java, Clojure & Composicional & Sim & Não \\
\hline Apache Spark & $\begin{array}{c}\text { Java, Scala, } \\
\text { Python, R }\end{array}$ & Declarativa & Sim & Sim \\
\hline Apache Samza & Java, Scala & Declarativa & Sim & Não \\
\hline Apache Apex & Java, Scala & $\begin{array}{c}\text { ApexStream - declarativa } \\
\text { DAG API - composicional }\end{array}$ & Sim & Sim \\
\hline
\end{tabular}

Tabela 4.2: Comparação entre ferramentas - linguagens de programação e conectores

Como mostra a Tabela 4.2, a maioria das ferramentas analisadas são escritas em Java ou Scala e todas têm suporte a Java. Portanto, é esperado que, embora exista suporte a outras linguagens, as atualizações e melhorias mais recentes das ferramentas sejam lançadas inicialmente em Java e Scala. Por essa razão, e também levando-se em consideração os conhecimentos prévios da autora, foi utilizado Java na implementação do projeto aqui proposto.

Exceto pelo Apache Storm, todas as ferramentas analisadas apresentam APIs de especificação de workflows declarativas, consideradas de mais alto nível. O Storm apresenta apenas a composicional, de mais baixo nível, enquanto Apex possui ambas as APIs, que podem ser misturadas. Essa combinação de APIs de níveis diferentes foi uma referência importante para este trabalho, pois evidenciou os aspectos passíveis de serem abstraídos e as interfaces mais simples de serem usadas pelo usuário final.

Todas as ferramentas analisadas podem ser integradas ao Kafka e ao HDFS. Como os principais brokers utilizados atualmente são o Kafka e o RabbitMQ, o suporte ao RabbitMQ também foi analisado como critério de escolha. Dentre as ferramentas avaliadas, as que possuem suporte ao 
RabbitMQ de acordo com a documentação são: Flink, Storm e Apex. Os recursos oferecidos por essas ferramentas para a definição e execução de fluxos são discutidos na sequência.

\begin{tabular}{|c|c|c|c|c|}
\hline $\begin{array}{c}\text { Ferramentas/ } \\
\text { Características }\end{array}$ & $\begin{array}{c}\text { Processamento } \\
\text { em tempo real }\end{array}$ & Latência & Vazão & $\begin{array}{c}\text { Garantias de } \\
\text { consistência }\end{array}$ \\
\hline Apache Flink & Nativo & Baixa & Alta & Exatamente uma vez \\
\hline Apache Storm & $\begin{array}{c}\text { Nativo } \\
\text { Micro-lotes com Storm Trident }\end{array}$ & $\begin{array}{c}\text { Muito } \\
\text { baixa }\end{array}$ & Alta & $\begin{array}{c}\text { Exatamente uma vez } \\
\text { (apenas para o Trident) }\end{array}$ \\
\hline Apache Spark & Micro-lotes & $\begin{array}{c}\text { Não é adequado } \\
\text { para baixas latências }\end{array}$ & Alta & Exatamente uma vez \\
\hline Apache Samza & Nativo & Baixa & Alta & Pelo menos uma vez \\
\hline Apache Apex & Nativo & Baixa & Alta & Exatamente uma vez \\
\hline
\end{tabular}

Tabela 4.3: Comparação entre ferramentas - modelo de processamento e consistência

Como o foco deste projeto é o processamento de dados em tempo real, um requisito importante para as ferramentas analisadas é o suporte a processamento de streams. Pode-se ver na Tabela 4.3 que Flink, Storm, Samza e Apex atendem a esse requisito. O Spark gera dados de saída somente em lotes, até mesmo no Spark Streaming, que pode receber como entrada fluxos de dados em tempo real. Essa característica reflete na latência e, assim, Spark não é adequado para aplicações que precisam de baixa latência, diferentemente das demais ferramentas analisadas. Com isso, Spark foi eliminado da escolha dos arcabouços que seriam utilizados como prova de conceito.

As garantias de consistência oferecidas pelas ferramentas são fundamentais para alcançar tolerância a falhas, como descrito na Seção 2.2.4. A garantia de "exatamente uma vez" é a mais forte e, portanto, embora mais difícil de se obter, é a mais almejada. Todas as ferramentas consideradas a oferecem, exceto Apache Samza, o que levou à eliminação dessa ferramenta na prova de conceito. O Storm consegue essa garantia por intermédio da API Trident, caso contrário a garantia é "pelo menos uma vez".

Como o Apache Samza e Spark foram eliminados da escolha, restaram o Flink, Storm e Apex. Outra característica analisada no estudo foi a forma de acesso às fontes de dados das ferramentas que contam com suporte a streams. O Storm pode ser integrado a sistemas de armazenamento de dados, como MongoDB (2020), Apache Kafka (2020), HDFS (2020), HBase (2020), Redis (2020), JDBC (2020), entre outros. O Flink pode receber dados de arquivos, soquetes e de sistemas como Kafka, HDFS, RabbitMQ, MongoDB. Além disso, pode executar código do Hadoop. O Apex pode se conectar a sistemas de armazenamento externo, como sistemas de arquivos, bancos de dados e sistemas de mensagens. É nativamente integrável ao Hadoop e se integra ao Kafka, HDFS, RabbitMQ, Hive (2020), HBase, entre outros.

O Flink é um sistema em camadas construídas umas sobre as outras para aumentar o nível de abstração dos modelos de dataflows que elas aceitam como entrada. O Flink possui diversas APIs que interagem com diferentes camadas do sistema. Como exemplos, é possível destacar a Data Stream, para especificação de dataflows de processamento de streams e, em um nível de abstração mais alto, a Table API, que é uma linguagem declarativa específica de domínio com operações relacionais sobre tabelas com dados em tempo real. O Storm apresenta uma API experimental chamada Storm SQL Integration, que permite executar consultas SQL sobre streams de dados. O Storm possui também uma extensão, o Trident, que oferece uma interface de programação mais abstrata que a do Storm e possui algumas operações de manipulação de dados embutidas, como junções, agregações, agrupamentos e filtros. O Trident utiliza micro-lotes como forma de melhorar o desempenho. O Apex tem uma plataforma, a Apex Core, para a construção de aplicações distribuídas sobre o Hadoop. Ele também vem com a Malhar, uma biblioteca de conectores e funções lógicas que facilita a criação de aplicações não triviais.

A análise realizada apontou Flink e Apex como as melhores opções para o desenvolvimento da prova de conceito neste projeto, pelos seguintes motivos: 
- O Flink e o Apex se integram ao HDFS, Kafka e RabbitMQ, bastante utilizados na atualidade.

- As APIs desses arcabouços possuem algumas características interessantes para a abstração: o Flink apresenta duas APIs declarativas, uma API para lotes e outra para lidar com tempo real, enquanto o Apex apresenta uma API declarativa e outra topológica que podem ser combinadas. O fato do Apex permitir a combinação das suas APIs possibilita a realização de análises durante o desenvolvimento do projeto e o mapeamento realizado para esse arcabouço funciona como modelo de mapeamento para outros arcabouços de baixo nível, facilitando a extensão da abstração para outras ferramentas.

- A arquitetura do Flink, baseada em camadas com diferentes níveis de abstração, bem como a biblioteca de operadores Malhar do Apex facilitam a implementação do mapeamento.

Abaixo há uma breve comparação das duas ferramentas, de modo a levantar algumas vantagens que uma tem em relação à outra.

\section{Vantagens do Flink:}

1. Os dataflows construídos no Flink são de mais alto nível em comparação àqueles construídos utilizando-se as APIs do Apex.

2. Enquanto o Apex possui suporte à versão 2 do Hadoop, o Flink possui integração à versão 3 também.

3. A biblioteca TableAPI permite lidar com SQL no Flink, realizando operações de agregação, projeções, junções, inserções, entre outras. Enquanto isso, o suporte a SQL no Apex é um trabalho em andamento, já que a integração com o Apache Calcite provê suporte a consultas básicas, sendo necessário expandir o suporte para agregações, por exemplo.

\section{Vantagens do Apex:}

1. A biblioteca Malhar de operadores permite a chamada e execução de código escrito em linguagens como JavaScript, Ruby e R, realizando um envólucro do código, por meio de operadores do próprio Malhar.

2. A personalização de operadores é evidenciada no Apex, inclusive na estrutura de sua arquitetura e na documentação da ferramenta. Isso não significa que não seja possível fazer o mesmo no Flink, mas pelo fato dos programas escritos para Apex serem de mais baixo nível, as personalizações da parte do programador tendem a ser mais frequentes.

\subsection{Operadores para processamento de Big Data}

Ferramentas de processamento de Big Data possibilitam transformações sobre os dados e, para isso, disponibilizam alguns operadores. Na sequência, os operadores mais comuns nessas ferramentas (e, portanto, considerados no desenvolvimento deste trabalho) são descritos.

Visto que as ferramentas utilizam o modelo de MapReduce (vide Seção 2.2.1) ou se baseiam nele, os operadores que realizam mapeamento e redução são fundamentais. Operadores de mapeamento recebem um elemento de entrada e produzem um elemento na saída (função map) ou podem produzir zero, um ou mais elementos (função flatMap). A fase de redução do dado combina um elemento atual com outro reduzido anteriormente, de modo a emitir um novo valor, como ilustrado na Figura 4.1.

Além disso, operações utilizadas em bancos de dados também estão presentes em arcabouços de Big Data. Um exemplo disso são as funções de agregação que transformam dados de entrada, de forma a sumarizá-los de acordo com algum critério para produzir como saída um resultado mais significativo, como somas, contagens, entre outros. Outras operações de bancos de dados tais como 


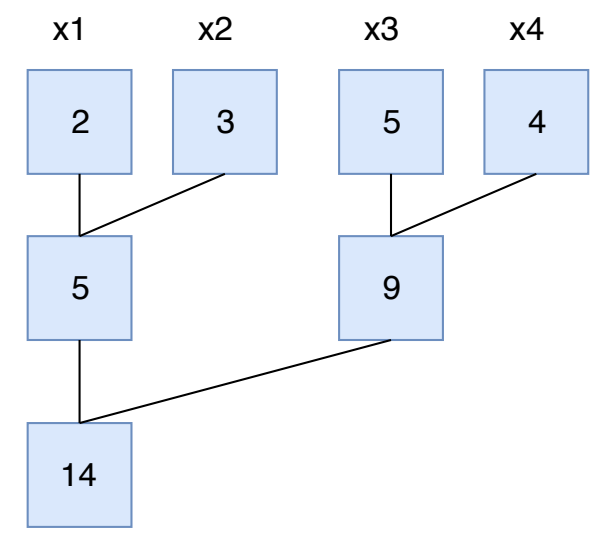

Figura 4.1: Exemplo de redução de dados, utilizando como lógica a adição dos elementos

seleção de atributos (select), junções (joins), agrupamento (group by) e filtros (where-clauses) estão presentes nos arcabouços.

Os arcabouços usam janelas, as quais possibilitam agrupar dados com base em alguma característica, como o tempo (exemplo, a cada dez segundos), contagem de elementos (a cada três, a cada cinco, etc.) ou por sessões, como descrito na Seção 2.2.5. Essas operações podem ser sobre dados já particionados por chaves ou não (existe uma operação que particiona um fluxo de dados por chave, deixando-o no formato de pares chave e valor).

\subsection{Estudo do Apache Flink}

Apache Flink (2020) é um arcabouço de processamento em tempo real e começou como um fork do projeto Stratosphere, este último iniciado em 2010, em Berlim. Flink virou um projeto da Apache Incubator em março de 2014 e, em 2015, houve a primeira edição da conferência anual Flink Forward. Possui uma comunidade aberta e ativa de desenvolvedores e usuários, com rápido crescimento e de âmbito internacional.

Essa ferramenta lida com verdadeira análise em tempo real (isto é, sem o uso de micro-lotes) e processamento de dados históricos, usando uma única tecnologia (processador de stream) sem apresentar uma camada dedicada para lote. O processamento em lote é tratado como um caso especial de processamento de dados em tempo real, em que a janela definida é global e todos os registros pertencem à mesma janela. Com a otimização correta, um processador de tempo real como o Flink pode desempenhar bem tarefas que seriam típicas de processadores em lote.

Pode ser utilizado em diversas aplicações, como health care - monitoramento em tempo real de queda de pacientes (Ajerla et al.), implementação de algoritmos de aprendizado de máquina (Kamburugamuve et al., 2018), entre outras.

Atualmente é utilizado por diversas empresas (Flink, 2020) como King, que possui jogos em diferentes países e consegue lidar com o massivo volume de dados de stream e possui um painel de análise de dados de tempo real utilizando o Flink; a Uber que construiu sua plataforma de análise de streams sobre o arcabouço Flink; e Ericsson, que utiliza para o monitoramento de uma infraestrutura de nuvem, classificando anomalias.

\subsubsection{Arquitetura}

O núcleo computacional do Flink, chamado Flink runtime, trata-se de um sistema distribuído que aceita dataflows de tempo real, os executando com tolerância a falhas. Pode ser rodado em um aglomerado, como em uma aplicação do YARN, ou em apenas uma máquina (algo útil para depuração). Os programas aceitos por esse núcleo, embora sejam poderosos, são verbosos e difíceis de se programar diretamente. 
Devido a isso, Flink oferece APIs (interfaces) no topo do runtime, que geram esses programas de dataflow de tempo real. São duas interfaces acima do runtime, como pode ser visto na Figura 4.2: uma para processamento em tempo real, chamada de DataStream API, e outra que lida com processamento em lote, a DataSet API.

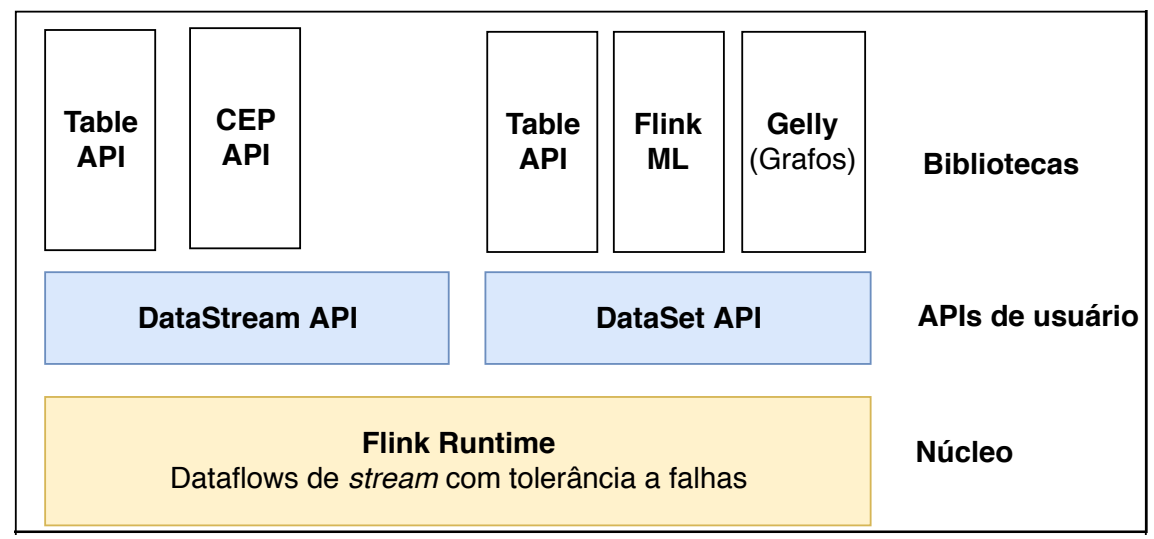

Figura 4.2: Arquitetura $^{3}$ do Apache Flink

Um programa desenvolvido usando as interfaces do Flink pode conter uma combinação de várias transformações, formando um encadeamento de operações e topologias sofisticadas. Acima delas há bibliotecas de mais alto nível para diversas aplicações, como para processamento de eventos complexos, aprendizado de máquina, processamento de grafos e consultas SQL (Friedman e Tzoumas, 2016).

\subsubsection{Streams, operadores e janelas}

Catacterísticas importantes de se conhecer sobre uma ferramenta que processa grandes volumes de dados são: se ela lida com streams fora de ordem e com janelas, se provê agregações acuradas, se consegue reproduzir dados passados e como são a latência, a vazão e as garantias em caso de falhas.

Operadores do Flink podem ser paralelizados em uma ou mais subtarefas, bem como os streams podem ser divididos em uma ou mais partições. As transformações realizadas pelo Flink, isto é, operações que recebem um ou mais streams de entrada e produzem um ou mais como saída, não são executadas até que haja uma operação de destino conectada a elas. As transformações atuam em um registro por vez, o qual não segue uma ordem determinada. Contudo, ao aplicar operações que atuam por registro, a ordem acaba sendo preservada, mas o Flink consegue lidar com streams que cheguem fora de ordem (Friedman e Tzoumas, 2016). A troca de dados entre os operadores utiliza a abstração de streams intermediários, os quais são produzidos por um operador e podem ser consumidos por um ou mais.

O estado do operador pode ser persistido em disco ou memória e não é acessível globalmente. Cada subtarefa de um operador somente tem acesso ao próprio estado, não podendo ler ou escrever no estado de outra subtarefa do mesmo operador.

Um dos operadores é a janela, que permite discretizar os streams. Flink possui janelas de tempo e de contagem (Friedman e Tzoumas, 2016). Com relação às janelas de tempo, Flink possui tempo de evento, ingestão e processamento e elas podem ser escolhidas de acordo com a semântica e acurácia necessária para a aplicação. O tempo de evento é quando este é criado, como quando um sensor gera um dado; o tempo de ingestão é o momento em que o dado chega ao Flink e o de processamento quando é processado pela ferramenta. O tempo de evento é o mais poderoso em termos de corretude de cálculos. Com relação às janelas de sessão, elas são compostas por períodos de atividade que precedem e são seguidos por períodos de inatividade. São especificadas com tempos de expiração (timeout).

\footnotetext{
${ }^{3}$ Baseada na figura de https://flink.apache.org/introduction.html. Acesso em fevereiro de 2020
} 


\subsubsection{Representação dos dataflows}

Apache Flink apresenta duas APIs declarativas, uma para processamento em lote, chamada Dataset e outra para processamento em tempo real, chamada DataStream.

Os dataflows expressos por meio dessas APIs apresentam uma ou mais fontes de entrada e terminam em uma ou mais saídas. A estrutura básica dos dataflows é composta por operadores, responsáveis por realizar transformações sobre os dados, e streams. Mesmo na API para dados em lote a representação interna é dada por streams. Nas listas 4.1 e 4.2 estão exemplificadas partes do código de um programa contador de palavras, retirados do site de documentação da ferramenta ${ }^{4}$.

Ao iniciar um programa no Flink, cria-se um ambiente de execução. Então, os dados são lidos de uma fonte, como arquivos, filas de mensagens, entre outros. Em ambas as interfaces é possível realizar funções de mapeamento dos dados e agrupá-los por chave. Cada vez que uma palavra aparece novamente no texto, é somado o número 1 à sua frequência. Depois disso, o resultado (palavras e suas frequências) é impresso na saída padrão. Na Lista 4.2 conta-se palavras vindas de um soquete, utilizando-se janelas de tempo de cinco segundos. Janelas são detalhadas na próxima seção. O dataflow das Listas 4.1 e 4.2 está representado pela Figura 4.3.

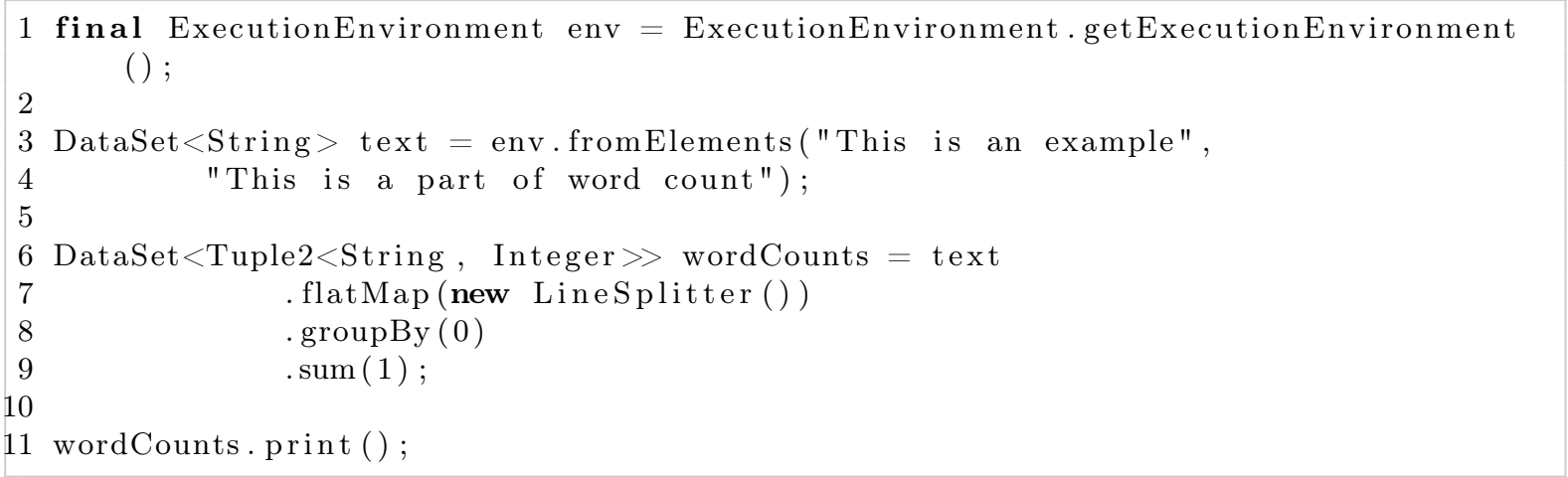

Lista 4.1: Contagem de palavras com a API para lotes do Apache Flink

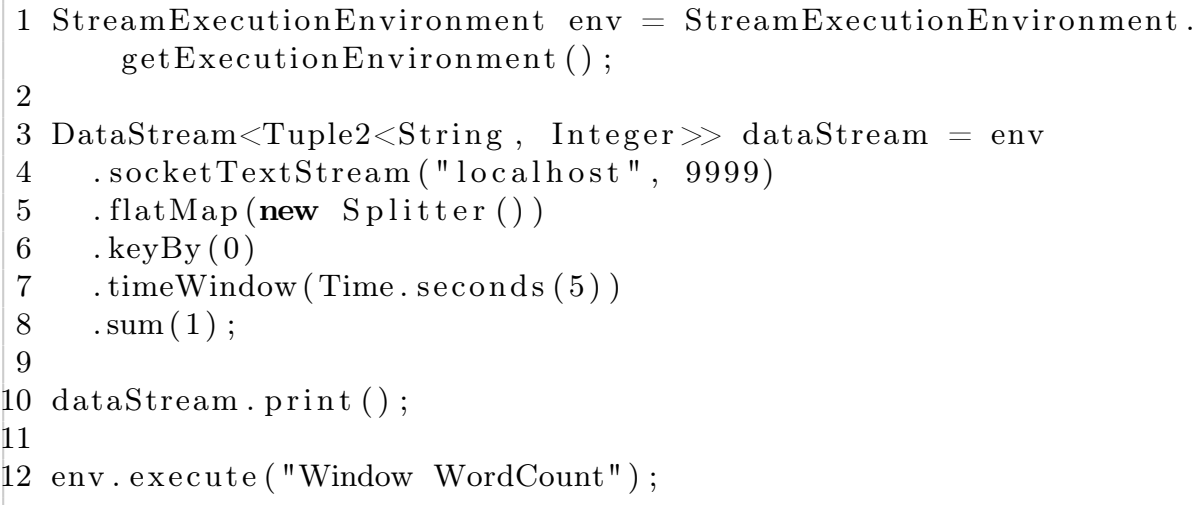

Lista 4.2: Contagem de palavras com a API para dados de tempo real do Apache Flink

\subsection{Estudo do Apache Apex}

Apache Apex (2020) é uma plataforma de processamento de Big Data que unifica dados de tempo real e de lote. É nativa do YARN, também da Apache, e começou a ser desenvolvida desde 2012 pela empresa DataTorrent, localizada nos Estados Unidos. Inicialmente, era um projeto fechado, mas depois o código foi aberto e entrou em incubação para a Fundação da Apache em agosto de 2015. Após oito meses, já era um projeto de alto nível da Apache.

\footnotetext{
${ }^{4}$ https://ci.apache.org/projects/flink/flink-docs-release-1.5/ Acesso em fevereiro de 2020
} 


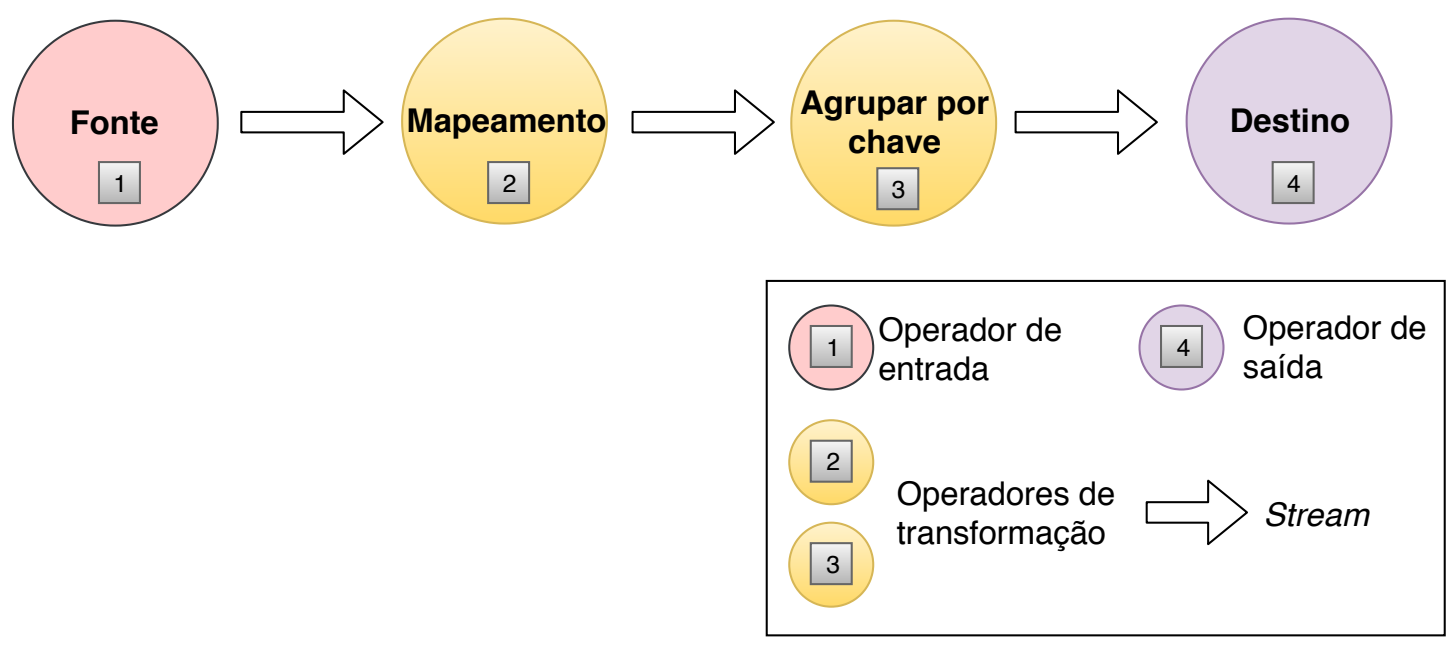

Figura 4.3: Dataflow do Apache Flink para um contador de palavras

O Apex pode ser utilizado em diversas áreas, como em serviços de finanças, para monitorar risco e fraude; em telecomunicações, para entender o comportamento do cliente; na manufatura, para manutenção preventiva, monitorando máquinas; em Internet das Coisas; para análise preditiva; entre outras aplicações (Weise et al., 2017).

Pode-se citar algumas empresas ${ }^{5}$ que utilizaram o Apex em suas aplicações: General Electric - cuida de segmentos como aviação, energia, petróleo, gás, entre outros - para dados industriais e análises em sua plataforma na nuvem; Capital One - oitavo maior banco dos Estados Unidos - para detecção de fraudes; PubMatic - empresa de software de automação de propaganda para editores - para realizar análises em tempo real para melhores tomadas de decisão.

\subsubsection{Arquitetura}

Apache Apex é uma plataforma que aproveita os recursos do YARN e usa HDFS para armazenar estado de forma persistente. Acima do YARN e HDFS, Apex apresenta o núcleo (Apex Core) que unifica processamento de tempo real com lote e, acima deste último, tem o Apex Malhar ${ }^{6}$ que trata-se de uma biblioteca de operadores.

Há operadores de entrada e saída para sistemas de arquivos, bancos de dados e barramento de mensagens. Malhar também provê operadores computacionais como filtros, ordenação, mapeamento, geradores de dados, contagem de frequência, entre outros. Os operadores do Malhar foram pensados como parte do Apex, não como simples anexos, de modo a melhorar o desempenho e não haver perdas de dados em caso de falhas. Isso encontra-se ilustrado na Figura 4.4.

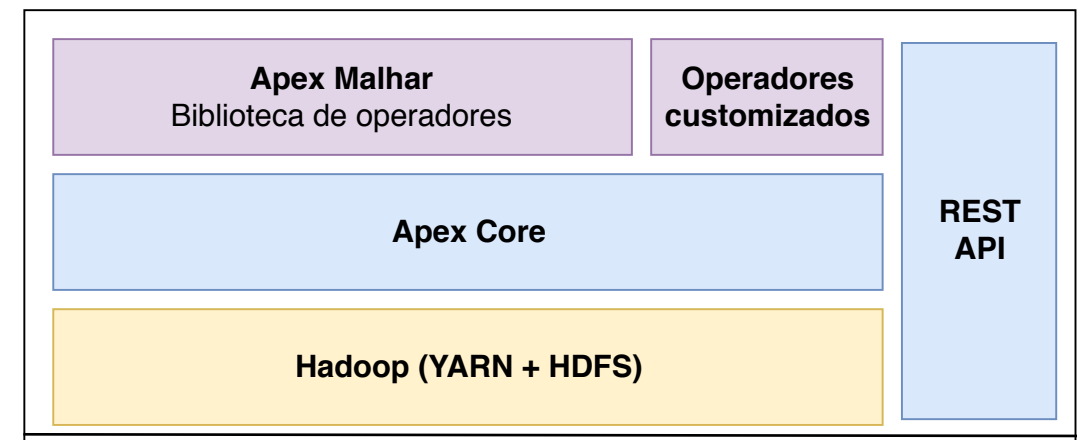

Figura 4.4: Arquitetura ${ }^{7}$ do Apache Apex

\footnotetext{
${ }^{5}$ https://apex.apache.org/powered-by-apex.html Acesso em fevereiro de 2020

${ }^{6}$ https://apex.apache.org/docs/malhar/ Acesso em fevereiro de 2020

${ }^{7}$ Baseada na figura de http://dt-docs.readthedocs.io/en/latest/rts/ Acesso em fevereiro de 2020
} 
Apex apresenta duas interfaces, uma de baixo nível (DAG API) e outra de alto-nível (ApexStream). A primeira é composicional, o que significa que os DAGs são explícitos, sendo indicados os operadores e portas de conexão de streams. A segunda é declarativa e abstrai a interface de baixo nível. Embora a composicional seja mais difícil de usar, é mais flexível que a declarativa por permitir criar e modificar os próprios operadores. Além disso, a ApexStream é mais recente e está em fase de expansão e melhorias.

A plataforma do Apex integra bem com tecnologias Hadoop (YARN, por exemplo) e as utiliza para gerenciamento de recursos, tolerância a falhas, sistema distribuído de arquivos, logs, entre outras funcionalidades. Além disso, o arcabouço lida automaticamente com gerenciamento de estado, escalabilidade e segurança, isentando o usuário da responsabilidade por essa parte operacional.

\subsubsection{Streams, operadores e janelas}

Assim como no Flink, as aplicações que rodam no Apache Apex seguem o modelo de DAG formado por operadores (nós do grafo) e streams (os arcos). Os dados de entrada realizam computações na memória, podendo salvar a saída em disco de forma não bloqueante.

Os dados que fluem entre operadores são chamados de tuplas e tratam-se de elementos atômicos, unidos à definição de tipo e são gerenciados em uma fila de mensagens. Operadores são unidades básicas de computação que processam tuplas de entrada de forma assíncrona e emitem zero ou mais tuplas de saída. Para desenvolver uma aplicação, é preciso conectar operadores de forma a implementar a lógica desejada.

Um operador recebe e emite tuplas por meio das portas, as quais devem ser efêmeras, uma vez que não possuem estado. Dessa forma, cada operador deve ter pelo menos uma porta. Com as APIs do Apache Apex é possível agrupar vários operadores em um único nó, contêiner ou em uma mesma thread, mas no geral operadores são leves, separando tarefas independentes entre si que possam ser executadas em paralelo e aproveitem a arquitetura distribuída do Apex.

Para o Apex, um stream é uma abstração fundamental e consiste de tuplas entregues sempre na mesma ordem em que foram emitidas. Assim, um stream é composto por uma sequência de janelas, as quais são formadas por uma coleção de tuplas ordenadas. Os streams podem ser persistidos e isso é feito normalmente no HDFS. As tuplas estão associada às janelas, não podendo existir fora delas e, dessa maneira, para reprocessar streams é necessário reprocessar um conjunto de janelas. A ordem das tuplas em um stream é garantida em um reprocessamento, mas se as tuplas pertencerem a streams diferentes, a ordem pode ser diferente.

As janelas são um dos operadores do Apex e ajudam a obter maior vazão de dados, maior escalabilidade, menor tempo de recuperação, uma vez que funcionam como um micro-lote de tuplas, processadas juntas como uma operação atômica. Assim, mesmo que as computações sejam feitas a nível das tuplas, a contagem é feita para aquelas que estão na janela. O Apache Apex apresenta suporte a janelas de tempo fixas, deslizantes, de sessão e globais (que abrangem a aplicação inteira).

\subsubsection{Representação dos dataflows}

Os dataflows são expressos pelos usuários do arcabouço Apache Apex de formas diferentes, dependendo da API utilizada. Na de baixo-nível, para a qual toda aplicação é mapeada, a representação é mais explícita. Os operadores são adicionados e conectados aos streams e recebem e emitem os dados por meio de portas. Na de alto-nível o usuário não precisa trabalhar diretamente com os operadores, mas com métodos que realizam transformações sobre os streams. Essa interface pode ser estendida de modo a prover novas transformações.

Com as listas 4.3 e 4.4 pode-se comparar a notação usada por programas que rodam no arcabouço, utilizando as duas APIs. Ambos os exemplos foram retirados de (Weise et al., 2017) e se tratam de trechos de código para um programa contador de palavras.

1 LineReader lineReader = dag.addOperator("input", new LineReader ());

2 Parser parser $=$ dag.addOperator ("parser", new Parser()); 


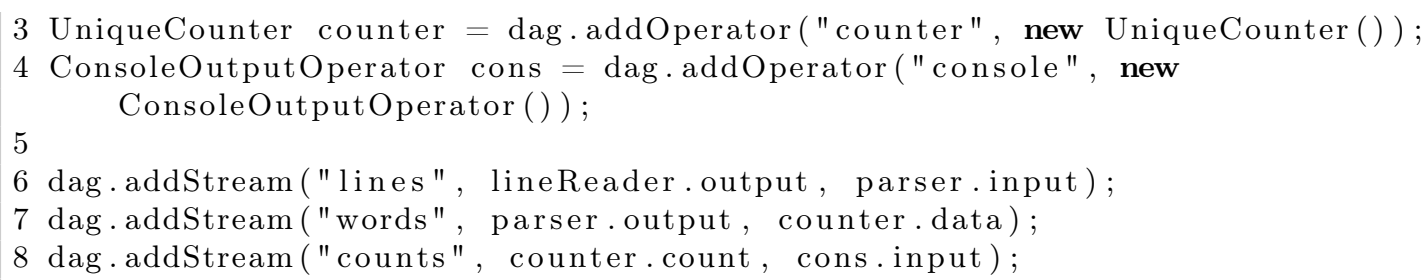

Lista 4.3: Programa contador de palavras especificado na DAG API do Apache Apex

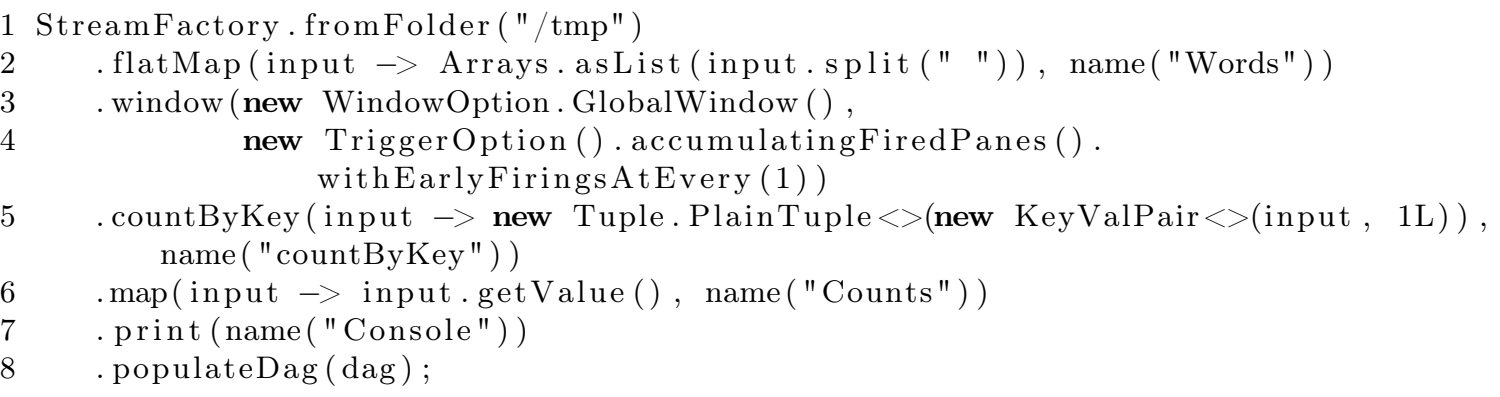

Lista 4.4: Programa contador de palavras especificado na ApexStream API do Apache Apex

No primeiro exemplo há dois métodos importantes: addOperator e addStream, os quais são responsáveis por adicionar operadores e streams no DAG, respectivamente. Ao adicionar operadores ao grafo, é necessário ter classes associadas que os implementem. Esse é o caso da classe LineReader, que é responsável por fazer leitura de linhas de um arquivo de entrada e retorná-las. Para adicionar streams, que são as arestas do grafo, o método addStream possui como parâmetros um identificador e as portas de saída e de entrada.

No segundo exemplo, os operadores são implementados por métodos como o de mapeamento, o de contagem por chave, entre outros. Eles são implementados no mesmo arquivo, não precisando de classes adicionais de operadores. Para as funções foi utilizada a notação de lambdas presentes no Java 8.

A estrutura de dataflow expressa pelas listas 4.3 e 4.4 está representada na Figura 4.5.

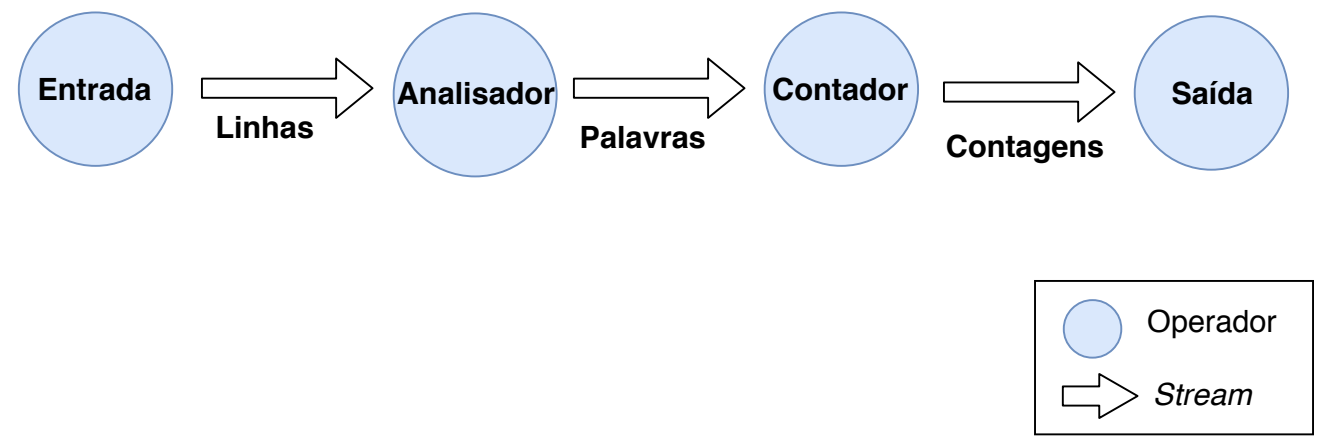

Figura 4.5: Dataflow do Apache Apex para um contador de palavras

\subsection{Estrutura geral dos projetos no Flink e Apex}

Os arcabouços Apache Flink e Apex são escritos em Java e suas bibliotecas permitem que os usuários dessas ferramentas produzam seus programas nessa linguagem. O Maven (Maven, 2020) pode ser utilizado como gerenciador dos projetos de software, sendo vantajoso por possuir algumas convenções e organizar os projetos em uma estrutura padrão. Ele é inclusive indicado nos sites desses arcabouços para fazer a compilação (build) dos projetos, gerando o respectivo JAR (Java Archive) que trata-se de um arquivo compactado composto por classes Java. Além disso, a padronização 
advinda do uso do Maven permite que o desenvolvedor acostumado a programar em Java já saiba onde encontrar os componentes do projeto, mesmo sendo de ferramentas diferentes.

Todos os projetos apresentam um arquivo chamado pom.xml que contém as configurações e dependências necessárias. POM (Modelo de Objeto do Projeto) é a unidade de trabalho no Maven e trata-se de um arquivo com formato XML que possui informações do projeto e configurações que permitem construí-lo. Algumas das informações especificadas são: versão do projeto, descrição, lista de e-mail, entre outras. Dentre as configurações, pode-se citar as dependências e plugins a serem executados.

Há dois diretórios principais na estrutura do Maven: src/ e target/. Os demais são subdiretórios dos anteriores ou metadados (como .git, .svc). O diretório src/ contém todo o código-fonte do projeto, enquanto target / é usado como destino para todas as saídas resultantes da compilação do projeto.

Dentre os subdiretórios padrão em projetos Maven estão:

- src/main/java/: contém o artefato de compilação principal;

- src/main/resources/: contém arquivos de propriedades;

- src/test/java/: contém os fontes de teste;

Os arquivos de propriedades do Apache Apex costumam ficar no subdiretório META-INF/ sob src/main/resources/. Uma das diferenças entre os projetos Flink e Apex é que no Flink a função principal main, ilustrada na Figura 4.6, fica, de fato, sob a estrutura src/main/ java/, enquanto se localiza no src/test/ java/ para programas do Apex. Na estrutura src/main/ java/ do Apex ficam fontes que criam operadores, bem como a classe que cria o DAG (nós e suas conexões), indicada na Figura 4.7, mas que é instanciado apenas pela chamada dentro da função main.

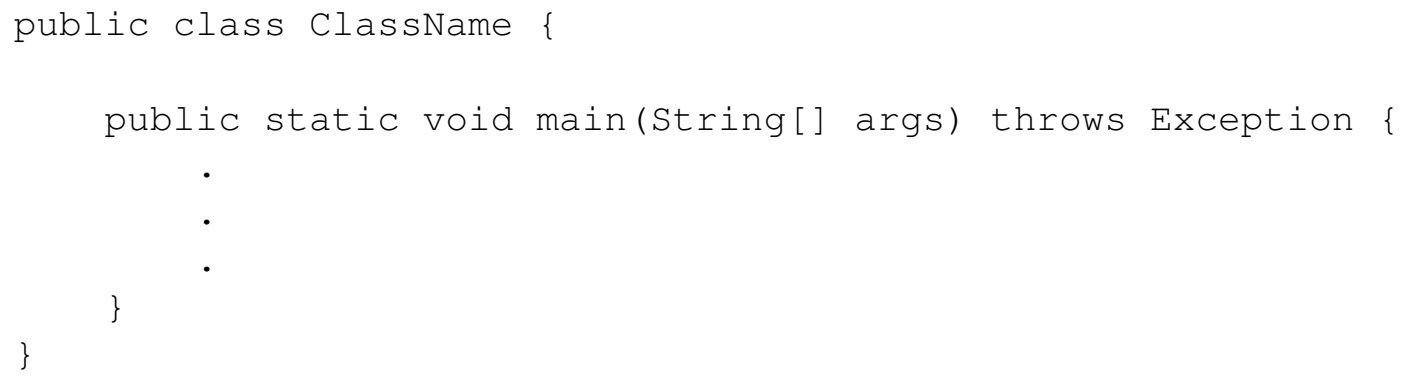

Figura 4.6: Método main - Apache Flink

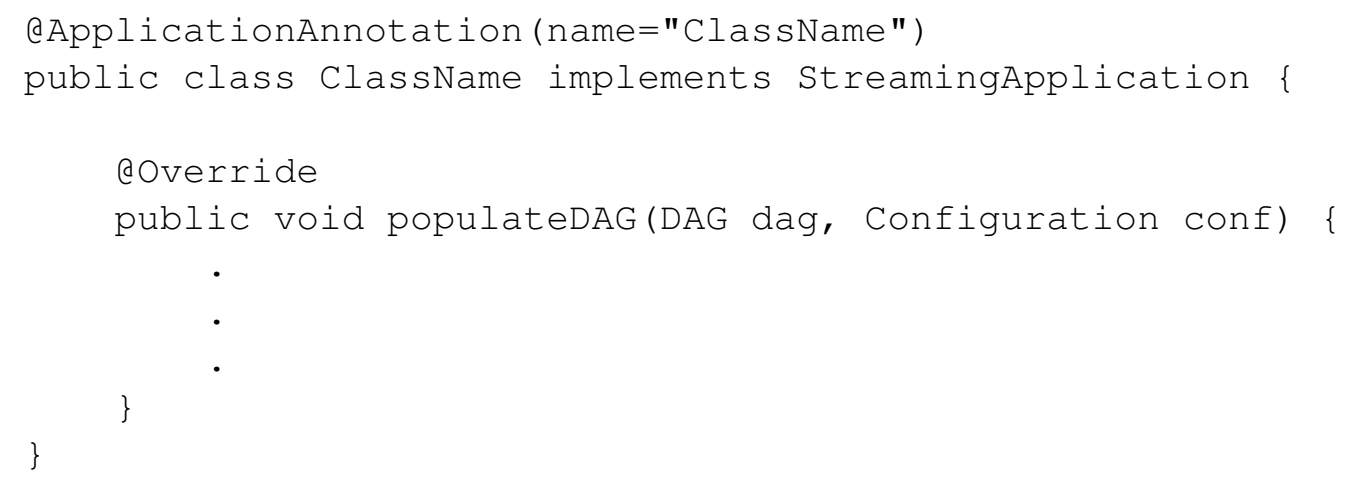

Figura 4.7: Método populateDAG - Apache Apex 
A compilação e execução dos projetos podem ser realizadas utilizando o Maven pelo terminal ou dentro de alguma IDE (como o IntelliJ, por exemplo). A execução pode ser realizada também por meio da interface de linha de comando (CLI) disponibilizada por cada arcabouço. A interface do Flink fica sob o diretório <flink-dir>/bin/flink/ e a do Apex <apex-core-dir>/engine/ src/main/scripts/apex. Essas interfaces permitem lançar e encerrar aplicações, assim como gerenciá-las e monitorá-las.

\subsection{Considerações sobre o estudo das ferramentas}

Este capítulo apresentou os resultados de um estudo de caracterização e comparação de ferramentas de Big Data para processamento de dados em tempo real. A partir dos resultados iniciais do estudo, foram selecionadas duas ferramentas - Apache Flink e Apache Apex - consideradas as mais adequadas para apoiar o planejamento e validação da API de abstração e do sistema desenvolvidos neste projeto (que serão apresentados nos próximos capítulos). As duas ferramentas foram analisadas de forma mais aprofundada, a fim de se compreender suas especificidades e semelhanças. 


\section{Capítulo 5}

\section{Interface para representação de dataflows}

A abstração desenvolvida no presente trabalho ${ }^{1}$ é composta por uma API (interface) - detalhada no presente capítulo - para a construção de dataflows de processamento de dados em lotes e em tempo real e um sistema de software para mapeamento desses dataflows em modelos empregados em ferramentas de Big Data.

Foi realizado o levantamento das ferramentas de processamento de dados existentes na atualidade, de modo a caracterizá-las quanto a formatos de dados suportados, interfaces fornecidas para a especificação dos fluxos, linguagens de programação suportadas, entre outros. Com base nesse estudo (apresentado no Capítulo 4), foram identificadas as características comuns a elas, as quais foram consideradas na construção da interface desenvolvida para o usuário da abstração.

Os blocos de construção básicos da abstração são os operadores, os streams de dados, os lotes de dados e os canais para as transferências de dados (entre os operadores, das fontes de dados para operadores ou destes para os sorvedouros de dados). O operador é uma unidade de processamento que recebe dados de entrada e gera dados de saída. As dataflow process networks (Lee e Parks, 1995), explicadas na Seção 2.3.2, foram usadas como modelo teórico subjacente para a abstração desenvolvida neste projeto.

\subsection{Arquitetura desenvolvida}

A arquitetura da abstração, representada na Figura 5.1, possui serviços (numerados de 1 a 4) que interpretam modelos de dataflows e que os mapeiam para as ferramentas de Big Data. As setas representam os dataflows provenientes de etapas prévias na arquitetura.

O serviço Dataflow Parser (indicado por 1 na Figura 5.1) é responsável por receber o modelo de dataflow provido pelo usuário, que o define por intermédio da API desenvolvida. Esse serviço realiza uma análise sobre os componentes utilizados da interface, direcionando para os serviços de mapeamento (2 e 3) as partes que precisam ser mapeadas para ferramentas de Big Data, de modo a converter os dataflows para formatos de entrada inteligíveis a elas. O serviço 4 ilustra que é possível expandir a abstração para novas ferramentas, isto é, o sistema foi planejado de modo a ser flexível, permitindo a adição de novos mapeamentos para ferramentas do interesse do usuário. Os mapeadores indicados por 2, 3 e 4 na Figura 5.1 geram arquivos com código que pode ser executado diretamente nos arcabouços de Big Data.

\subsection{Estrutura de classes da API}

Com o intuito de permitir que um usuário realize um processamento usando diversas ferramentas de Big Data, sem precisar aprender a sintaxe de cada uma delas, escolheu-se fornecer uma API, de

\footnotetext{
${ }^{1} \mathrm{O}$ código é aberto e está disponível no GitLab, em https://gitlab.com/interscity/dataflow-mapper
} 


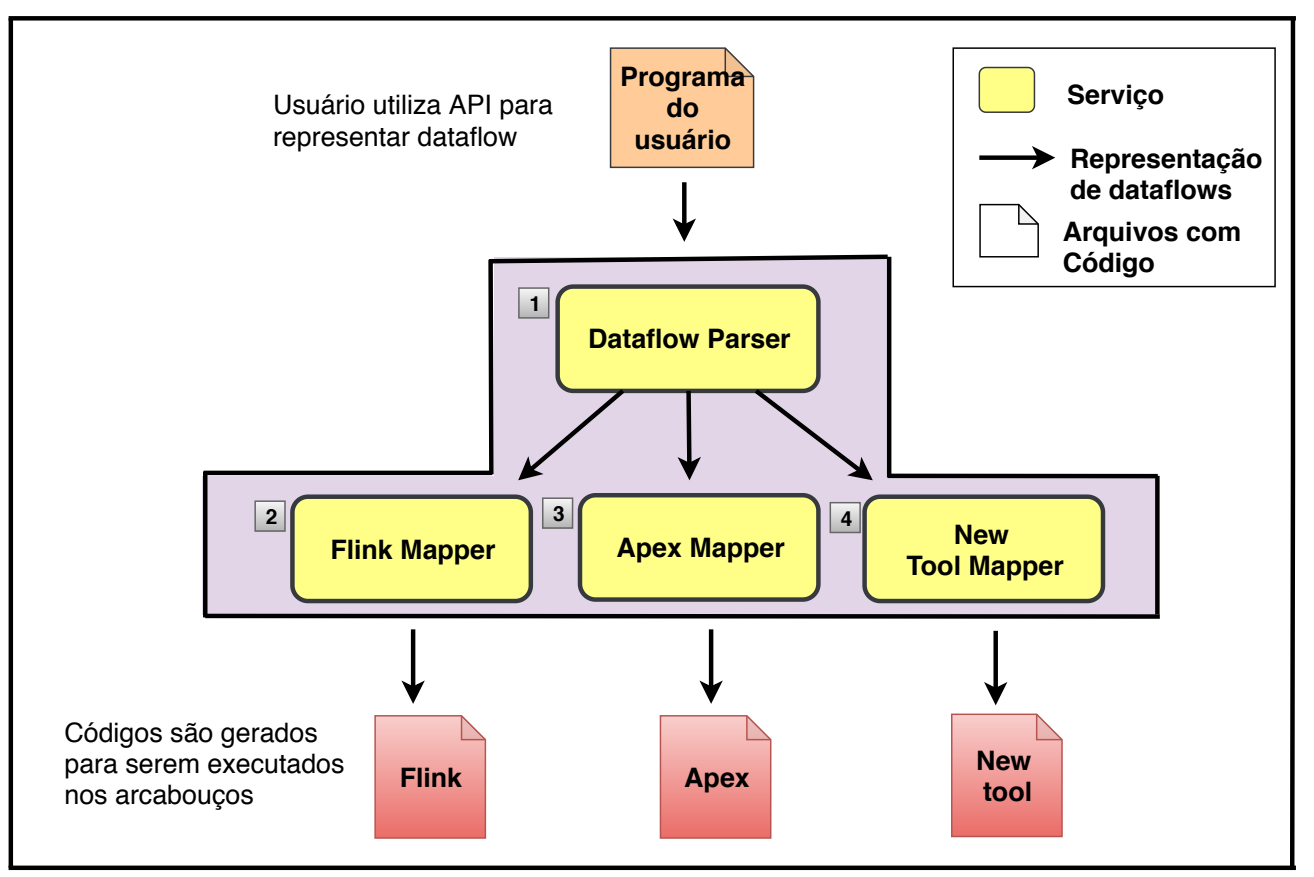

Figura 5.1: Arquitetura do sistema de abstração de ferramentas de Big Data

forma que o usuário precisaria aprender somente a sintaxe da interface desenvolvida. Assim, visto que a API abstrai a complexidade, a escolha de sua estrutura impacta diretamente na facilidade de uso das ferramentas de Big Data.

O diagrama de classes UML da Figura 5.2 apresenta as classes e atributos que estão presentes na interface desenvolvida neste trabalho e como elas interagem entre si. As classes Project Settings, Data e pelo menos uma das classes filhas de IO estão sempre presentes no programa do usuário, pois são necessárias para a construção de um dataflow. Classes relacionadas às operações de transformação de dados não aparecem no diagrama UML da interface, pois são utilizadas indiretamente pelo usuário, por intermédio da classe Data. Todas as classes estão detalhadas na Seção 5.3.

Para o desenvolvimento da interface foram considerados alguns conceitos da programação orientada a objetos, como herança, composição, agregação e polimorfismo. Diferentes linguagens de programação abordam e implementam esses conceitos de maneiras distintas. Neste trabalho, estes conceitos são empregados de acordo como são implementados na linguagem de programação Java, utilizada no desenvolvimento do sistema. Para a definição da API, além da base de programação orientada a objetos, foram relevantes os conceitos relativos a arcabouços de Big Data e as similaridades presentes nos operadores dessas ferramentas.

Para especificar um dataflow, um usuário deve criar uma classe em Java - nomeada Dataflow no diagrama, mas que pode receber qualquer nome desejado pelo usuário - e, dentro dela, utilizar os componentes da interface: conectores de entrada e saída de dados, os próprios dados e suas transformações, como também algumas configurações definidas instanciando-se a classe Projectsettings. Esta última permite definir algumas propriedades, tais como: para qual ferramenta será realizado o mapeamento (Flink, Apex ou ambas), qual o tipo de processamento a ser considerado (em lotes, em tempo real), entre outras.

As classes da API utilizam tipos genéricos do Java² para evitar a criação de várias classes com códigos muito similares para tipos diferentes, ou seja, eliminar redundâncias desnecessárias. Adicionalmente, isso permite que erros relativos à tipagem possam ser capturados em tempo de compilação.

As classes foram projetadas de modo a possibilitar a expansão das funcionalidades de forma

\footnotetext{
${ }^{2}$ Generics são um recurso de programação genérica, existente em algumas linguagens como Java, que permite abstrair tipos. Os nomes de parâmetros dos tipos genéricos costumam ser uma única letra maiúscula, como a letra $\mathrm{T}$ para representar tipos, $\mathrm{K}$ para chaves, $\mathrm{V}$ para valores.
} 


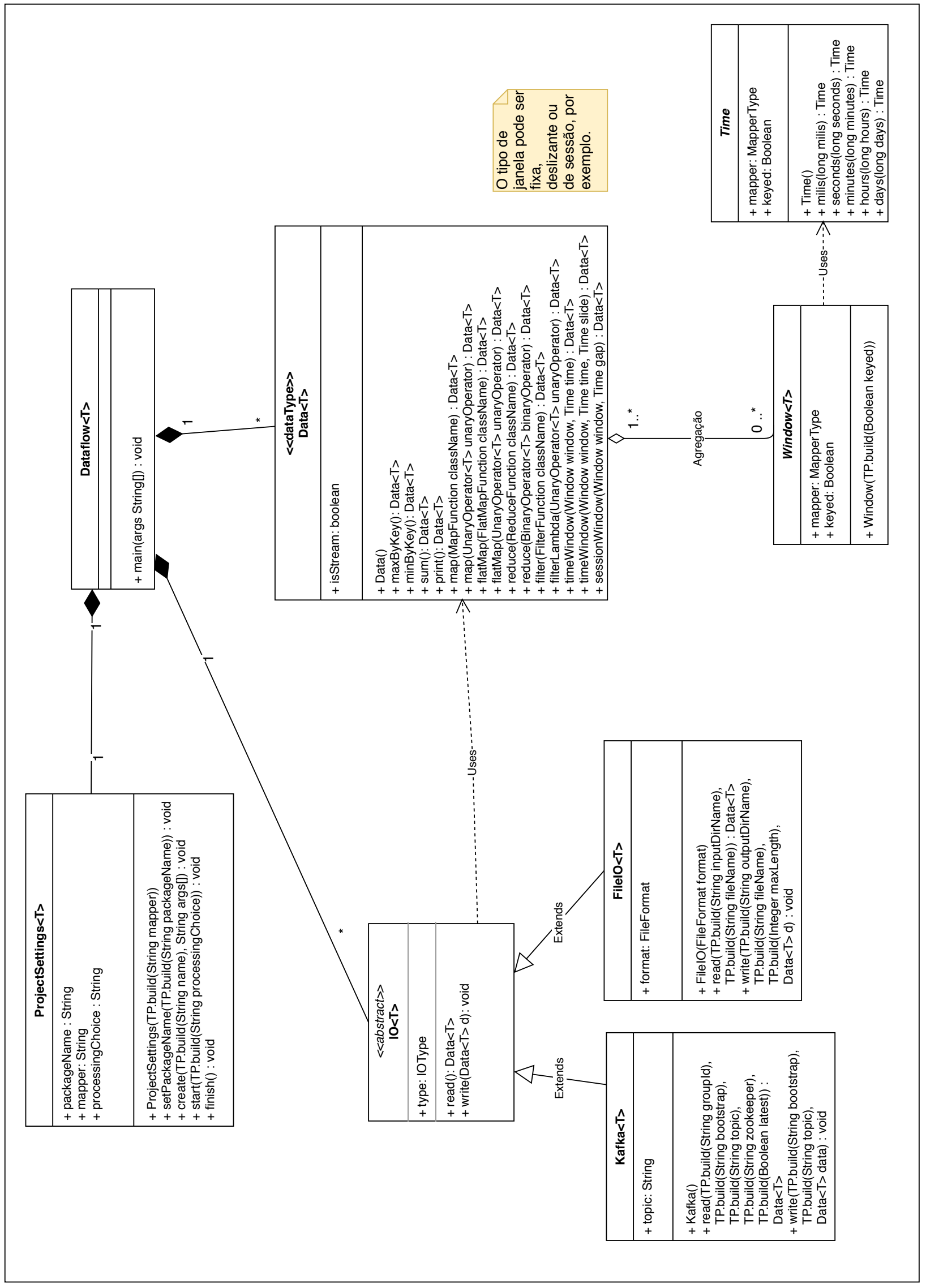

Figura 5.2: Diagrama UML com as classes presentes na interface desenvolvida 
transparente ao usuário. Por exemplo, para incluir uma nova fonte de dados, pode-se continuar usando a classe abstrata $\mathrm{IO}<\mathrm{T}>$ e criar uma classe concreta para o novo operador desejado. $\mathrm{O}$ mesmo vale para a saída de dados. Foram implementados conectores para o Kafka e arquivos (texto, sistemas de arquivos como HDFS), visto que são conectores normalmente presentes em ferramentas de Big Data.

Os dados que circulam pelo dataflow podem ser limitados ou ilimitados e são criados pela instanciação de Data $<\mathrm{T}>$, conectada tanto à classe de conectores de entrada e saída (IO), quanto à de transformação sobre os dados (DataTransformation). Isso permite que um usuário possa aplicar transformações encadeadas no dataflow.

As operações de transformações, descritas na Seção 4.2, estão associadas à DataTransformation $<\mathrm{T}>$ e à $\mathrm{UDF}<\mathrm{T}>$, as quais não fazem parte da API, mas são utilizadas indiretamente pelo usuário da interface, por intermédio da classe Data $<\mathrm{T}>$. Considerando-se que as transformações precisam ser aplicadas sobre algum dado, a classe Data $<\mathrm{T}>$ expõe ao usuário da interface os métodos das outras duas classes, sem que elas precisem ser instanciadas. Além de apresentar métodos para agregação de dados, como cálculo do valor máximo e mínimo, o DataTransformation $<\mathrm{T}>$ é a classe mãe das UDFs - funções definidas pelo usuário. As UDFs são métodos flexíveis e implementados com a lógica desejada pelo usuário. Entre elas estão as funções de mapeamento e redução, fundamentais no modelo de processamento das ferramentas de Big Data. Mais detalhes sobre classes que realizam mapeamento serão apresentados no Capítulo 6.

Janelas também atuam sobre os dados, apresentando papel fundamental no processamento deles, principalmente para lidar com streams. Desse modo, foi desenvolvida a classe $\mathrm{W}$ indow $<\mathrm{T}>$ para criar janelas e definir suas propriedades, mas os métodos associados a elas também são expostos através da classe Data $\langle\mathrm{T}>$. As janelas podem ser de vários tipos, apresentando tamanho fixo ou variável, podendo apresentar sobreposição e atuar sobre streams que estão ou não divididos por chaves. A classe Time permite indicar o intervalo de tempo associado às janelas (milissegundos, segundos, minutos, horas, dias).

\subsection{Interface para construção de dataflows: componentes abstraí- dos}

A interface permite que o usuário da abstração possa expressar seus dataflows. Desse modo, ela precisa abranger fontes de entrada e saída de dados, ter uma forma de representar o dado em si e seus fluxos, bem como transformações aplicadas a ele. A Lista 5.1 contém um exemplo de programa para especificação de um dataflow que poderia ser escrito pelo usuário da abstração. O dataflow exemplificado lê streams do Kafka e realiza um filtro sobre os valores lidos, de modo que apenas valores maiores que trinta sejam impressos na saída padrão. Poderia ser utilizado em algum cenário de mobilidade urbana para filtrar valores de espera aceitáveis em determinada parada de ônibus, por exemplo.

As próximas seções explicam as classes que compõem a interface de forma mais detalhada. 


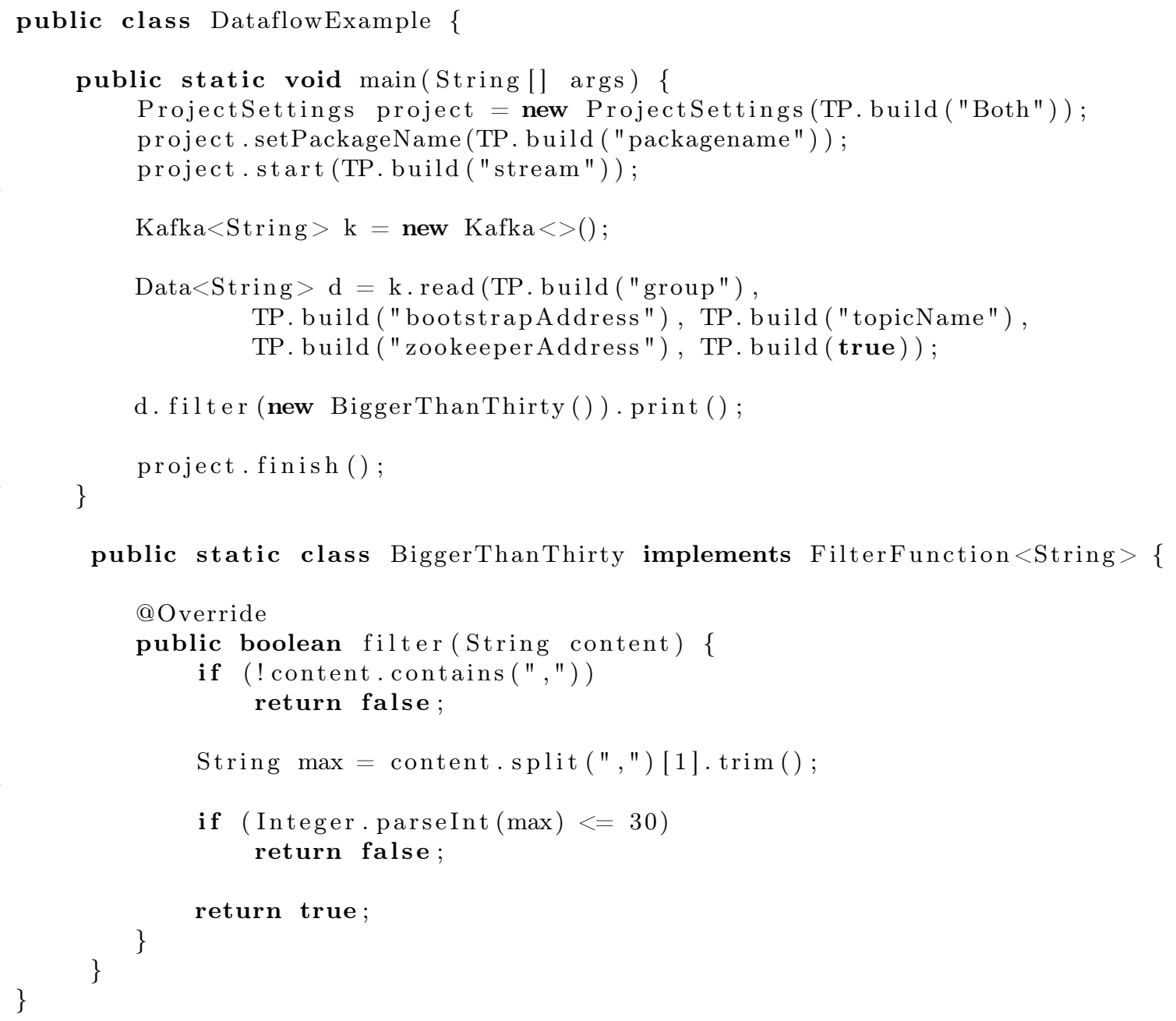

Lista 5.1: Exemplo de dataflow definido com o uso da interface

\subsubsection{Tipo de parâmetro}

Os conectores de entrada e saída de dados, assim como o próprio dado e suas transformações são instanciados e realizam chamadas a métodos. Os parâmetros dos construtores e dos demais métodos precisam ser de alguma das classes da interface (como Data, Window, Time) ou do tipo TP, criado na interface para funcionar como um invólucro, com o intuito de padronizar os possíveis parâmetros a serem recebidos, garantindo além de consistência na interface, maior robustez ao mapeamento.

Um exemplo de uso do TP é mostrado na Lista 5.1, nos parâmetros de métodos das classes ProjectSettings e Data. O método de TP responsável por realizar o invólucro dos diferentes tipos utilizados pelo usuário da interface é o build, que pode receber como parâmetro uma String, Integer, Boolean, entre outros.

\subsubsection{ProjectSettings}

A classe ProjectSettings permite definir para qual arcabouço o código deve ser gerado, bem como o nome do pacote (package) em que ela ficará, utilizado para agrupar classes com funcionalidades relacionadas ou similares. Pode-se escolher também como será o processamento: em lotes ou em tempo real. A Tabela 5.1 mostra os métodos públicos dessa classe e a Lista 5.2 mostra um exemplo do uso do Projectsettings. 


\begin{tabular}{|l|l|}
\hline \multicolumn{2}{|c|}{ ProjectSettings<T> } \\
\hline Retorno & Métodos \\
\hline--- & <<construtor $>>$ ProjectSettings(TP.build(String mapper)) \\
\hline void & setPackageName(TP.build(String packageName)) \\
\hline void & create(TP.build(String name), String[ ] args) \\
\hline void & start(TP.build(String processingChoice)) \\
\hline void & finish() \\
\hline
\end{tabular}

Tabela 5.1: Métodos públicos da API para a classe ProjectSettings

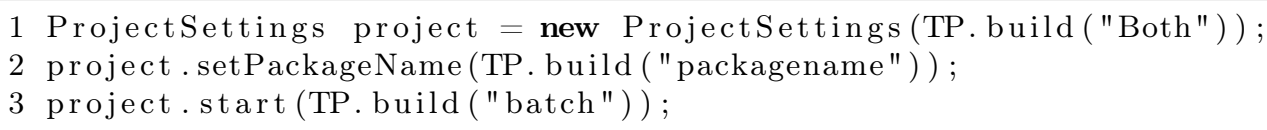

Lista 5.2: Criação do projeto para pacote já existente, escolha do mapeamento para ambas as ferramentas e do tipo de processamento (em lote)

O primeiro método da Tabela 5.1 é o construtor. Em seguida estão os métodos set e create e a diferença entre eles é que o primeiro considera que o pacote já existe, enquanto o segundo cria um novo pacote com o nome fornecido. O método start permite indicar qual é o tipo de processamento realizado no dataflow. O ProjectSettings provê também o finish, responsável por sinalizar o fim do código do usuário e produzir o código no destino final para executar nos arcabouços. $\mathrm{O}$ construtor e chamadas aos métodos setPackageName e start estão exemplificados na Lista 5.2.

\subsubsection{Operadores de entrada e saída de dados}

Considerando-se que os dados são disponibilizados em diferentes formatos, o usuário da abstração pode optar por diversos conectores para entrada e saída de dados: Kafka para dados em tempo real e arquivos de texto, HDFS e CSV para dados em lote ou históricos.

\section{Kafka}

O Kafka é um broker de dados e seus conectores de entrada e de saída permitem realizar leituras e escritas em tempo real. Os métodos associados a esse operador estão representados na Tabela 5.2. O primeiro método é o construtor, enquanto read e write fazem a leitura e escrita, respectivamente.

\begin{tabular}{|l|l|}
\hline \multicolumn{2}{|c|}{ Kafka<T> } \\
\hline Retorno & Métodos \\
\hline--- & $<<$ construtor>> Kafka() \\
\hline & $\begin{array}{l}\text { read(TP.build(String groupld), TP.build(String bootstrap), } \\
\text { TP.build(String topic), TP.build(String zookeeper), } \\
\text { TP.build(Boolean latest)) }\end{array}$ \\
\hline void & $\begin{array}{l}\text { Trite(TP.build(String bootstrap), TP.build(String topic), } \\
\text { Data }<\text { T > data) }\end{array}$ \\
\hline
\end{tabular}

Tabela 5.2: Métodos públicos da API para a classe Kafka

Alguns parâmetros precisam ser passados pelo usuário da abstração para utilizar o Kafka. No contexto de leitura, os argumentos são: groupid, bootstrap, topicName, zookeeper, initialoffset. Para a escrita são: bootstrap, topicName e dado do tipo Data. Essas propriedades estão descritas na Tabela 5.3, enquanto um exemplo de leitura e escrita no Kafka usando a interface pode ser visto na Lista 5.3. 


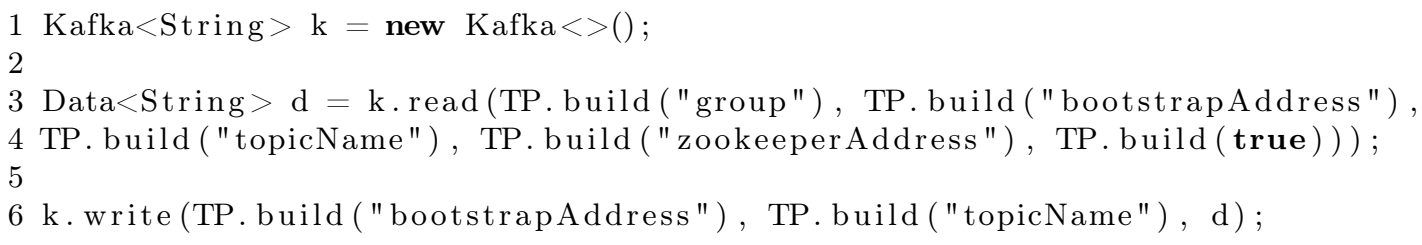

Lista 5.3: Leitura e escrita no Kafka com a interface desenvolvida

\begin{tabular}{|c|c|c|}
\hline Propriedades & Etapa & Descrição \\
\hline groupid & Leitura & O identificador do grupo que consome as mensagens do Kafka \\
\hline bootstrap & $\begin{array}{l}\text { Leitura e } \\
\text { escrita }\end{array}$ & $\begin{array}{l}\text { Provê máquinas para a conexão inicial com o cliente Kafka, } \\
\text { identificando os servidores ativos no cluster. Trata-se de uma lista } \\
\text { de strings separadas por vírgulas no formato nomeDaMáquina:porta }\end{array}$ \\
\hline topicName & $\begin{array}{c}\text { Leitura e } \\
\text { escrita }\end{array}$ & Nome do tópico do Kafka para o consumo ou envio de mensagens. \\
\hline zookeeper & Leitura & $\begin{array}{l}\text { Especifica o Zookeeper (gerenciador de clusters) dos clusters } \\
\text { do Kafka, dos quais deseja-se consumir ou enviar mensagens. } \\
\text { Precisa estar no formato nomeDaMáquina:porta, } \\
\text { nomeDaMáquina2:porta2 e assim por diante, sendo portas do servidor } \\
\text { do Zookeeper. }\end{array}$ \\
\hline initialOffset & Leitura & $\begin{array}{c}\text { Se for escolhida a opção latest, o operador irá consumir mensagens } \\
\text { do ponto em que parou na fila do Kafka, enquanto na opção earliest } \\
\text { irá consumir desde o começo. }\end{array}$ \\
\hline
\end{tabular}

Tabela 5.3: Propriedades utilizadas para a leitura e escrita no Kafka

File

A classe File foi criada de modo que possa ser estendida para contemplar diferentes tipos de arquivo. Dois formatos merecem destaque e são detalhados a seguir: arquivo de texto do sistema de arquivos da máquina local e do HDFS, como indicado nas Listas 5.4 e 5.5, respectivamente.

A Tabela 5.4 ilustra os métodos públicos dessa classe. O formato do arquivo é especificado no construtor de FileIO, por meio do parâmetro Fi leFormat. Para realizar a leitura, os argumentos necessários são: o diretório em que se encontra o arquivo e seu respectivo nome. Para a escrita, além desses dois argumentos, são passados os seguintes:

- Uma propriedade relativa ao tamanho máximo (maxLength) em Bytes que o arquivo pode ter. Ao atingi-lo, o arquivo é rotacionado, isto é, um novo arquivo começa a ser escrito.

- Um objeto do tipo Data que contém os dados a serem escritos no conector de saída.

\begin{tabular}{|c|c|}
\hline \multicolumn{2}{|r|}{ FilelO<T> } \\
\hline Retorno & Métodos \\
\hline--- & <<construtor $\gg$ FilelO(FileFormat format) \\
\hline Data $<\mathrm{T}>$ & $\begin{array}{l}\text { read(TP.build(String inputDirName), } \\
\text { TP.build(String fileName)) }\end{array}$ \\
\hline void & $\begin{array}{l}\text { write(TP.build(String outputDirName), } \\
\text { TP.build(String fileName), } \\
\text { TP.build(Integer maxLength), Data }<T>\text { d) }\end{array}$ \\
\hline
\end{tabular}

Tabela 5.4: Métodos públicos da API para a classe FileIo 


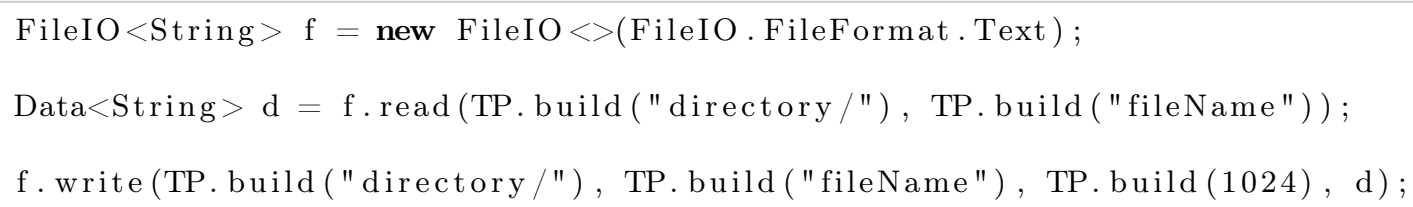

Lista 5.4: Leitura e escrita com arquivos de texto do sistema de arquivos local usando a interface

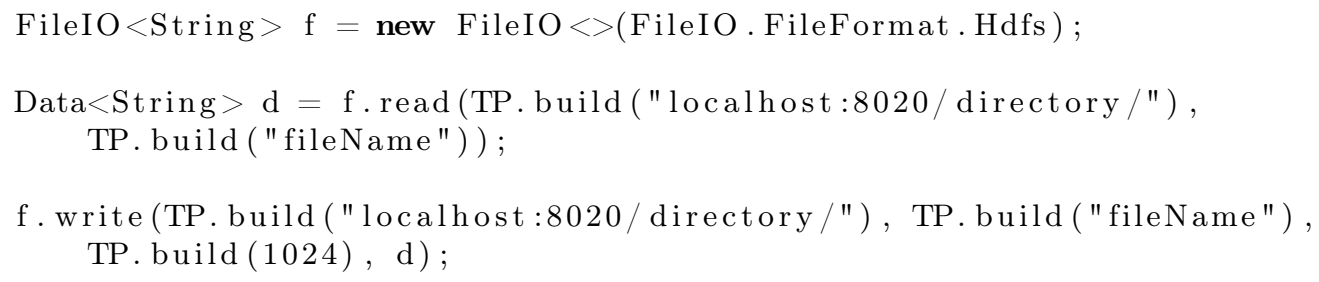

Lista 5.5: Leitura e escrita com arquivos do HDFS usando a interface

\subsubsection{Data}

A peça fundamental e motivação por trás de arcabouços de Big Data é o dado. Desta forma, foi dedicada uma classe da abstração - a Data - para representar dados, os quais podem ser lidos, transformados e escritos. A classe possui um conjunto de métodos para aplicar transformações sobre dados, conforme indicado na Tabela 5.5.

\begin{tabular}{|l|l|}
\hline \multicolumn{2}{|c|}{ Data $<\mathrm{T}>$} \\
\hline Retorno & Métodos \\
\hline--- & $<<$ construtor $>>$ Data() \\
\hline Data $<\mathrm{T}>$ & maxByKey() \\
\hline Data $<\mathrm{T}>$ & minByKey() \\
\hline Data $<\mathrm{T}>$ & sum() \\
\hline Data $<\mathrm{T}>$ & print() \\
\hline Data $<\mathrm{T}>$ & map(MapFunction className) \\
\hline Data $<\mathrm{T}>$ & map(UnaryOperator $<\mathrm{T}>$ unaryOperator) \\
\hline Data $<\mathrm{T}>$ & flatMap(FlatMapFunction className) \\
\hline Data $<\mathrm{T}>$ & flatMap(UnaryOperator $<\mathrm{T}>$ unaryOperator) \\
\hline Data $<\mathrm{T}>$ & reduce(ReduceFunction className) \\
\hline Data $<\mathrm{T}>$ & reduce(BinaryOperator $<\mathrm{T}>$ binaryOperator) \\
\hline Data $<\mathrm{T}>$ & filter(FilterFunction className) \\
\hline Data $<\mathrm{T}>$ & filterLambda(UnaryOperator $<\mathrm{T}>$ unaryOperator) \\
\hline Data $<\mathrm{T}>$ & timeWindow(Window window, Time time) \\
\hline Data $<\mathrm{T}>$ & timeWindow(Window window, \\
\hline Data $<\mathrm{T}>$ & sessionWindow(Window window, Time gap) \\
\hline
\end{tabular}

Tabela 5.5: Métodos públicos da API para a classe Data

Dentre as transformações de dados, encontram-se as funções de agregação como maxByKey (), minByKey () e sum(), para realizar o cálculo do máximo, mínimo e a soma dos valores lidos, respectivamente. A Lista 5.6 mostra um exemplo de dataflow definido por meio da interface que obtém o valor mínimo em um stream de dados provenientes da leitura de um arquivo do HDFS. 


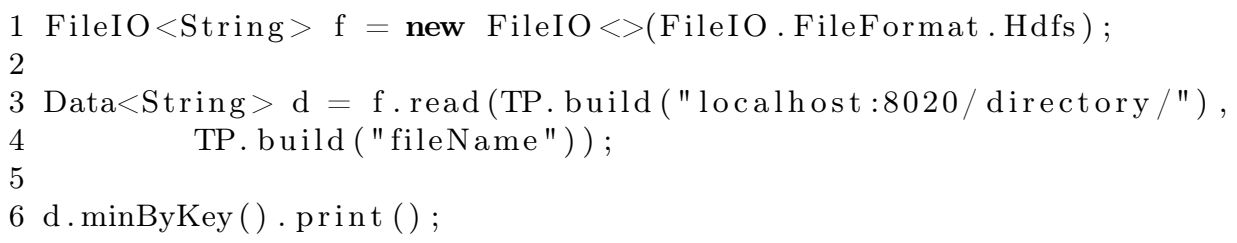

Lista 5.6: Cálculo do mínimo sobre um conjunto de dados

Outro tipo de transformação possível são as funções definidas pelo usuário (UDF, de user defined functions). Como indicado pelo nome, são métodos nos quais o usuário da interface fornece sua própria lógica. Não há como prever o conteúdo dessas funções e, assim, o papel desempenhado pela abstração nesses casos é receber a função definida pelo usuário, realizar alguns mapeamentos e juntála ao restante do código gerado. É o caso das funções map, fl latMap, reduce e filter da Tabela 5.5, que realizam mapeamento, redução e filtros sobre os dados. Para cada uma dessas funções há duas possíveis assinaturas na interface: aquela que recebe como parâmetro uma Function como MapFunction, por exemplo, e outra que recebe um operador unário ou binário (Unary ou Binary Operator, respectivamente). No primeiro caso, o usuário passa o nome da classe implementada com a lógica desejada, enquanto no segundo é passada uma função lambda ${ }^{3}$.

Como cada arcabouço tem sua própria sintaxe, sem o uso da interface um usuário que desejasse executar um MapReduce no Flink e no Apex precisaria escrever dois pares de funções de Map e Reduce, um para para cada arcabouço. Com o uso da API desenvolvida neste trabalho, o usuário precisa escrever apenas um par de funções e o sistema de software da abstração se encarrega de gerar os códigos para os arcabouços escolhidos.

Para reduzir a complexidade e evitar possíveis erros, foram criadas interfaces Java para UDFs mais comuns, como Map, FlatMap, Reduce, Filter. A interface Java criada para a função Filter é mostrada na Lista 5.7, para ilustrar a abordagem empregada.

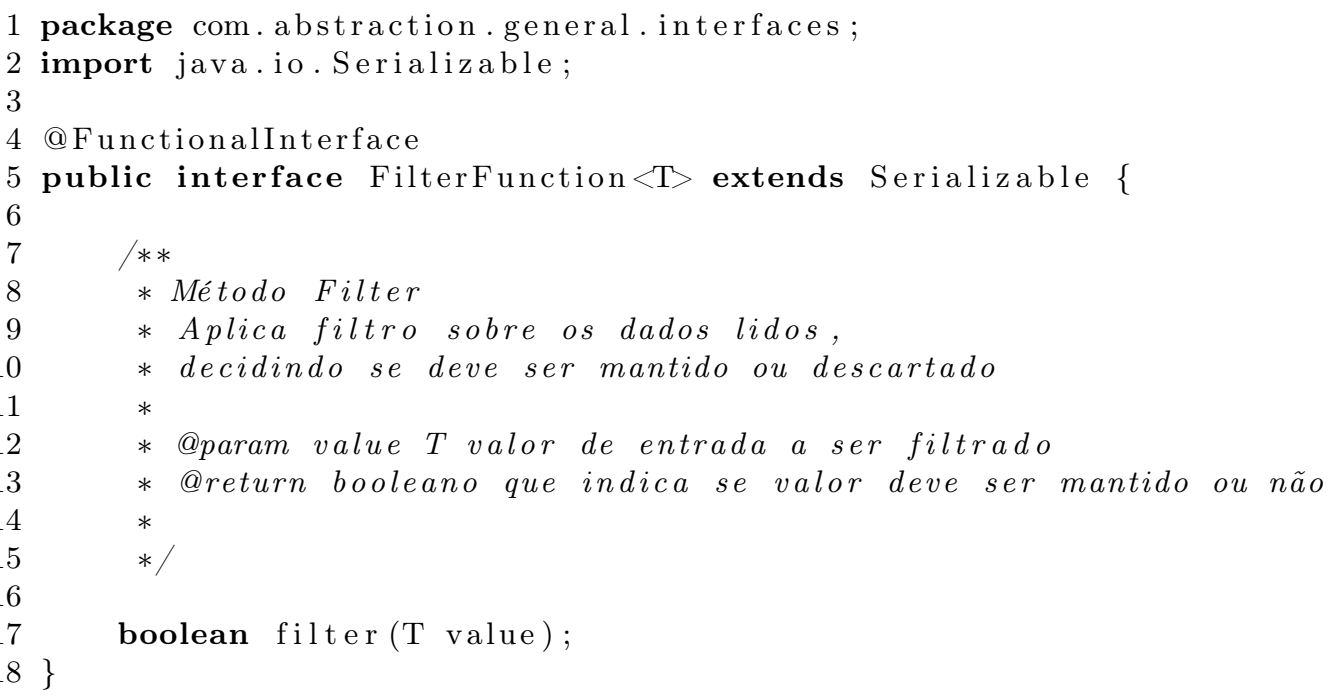

Lista 5.7: Interface Java para UDF do tipo Filter

Assim, o usuário da API precisa criar um método que implemente a UDF desejada e realize a chamada dessa função, conforme exemplificado na Lista 5.8 que ilustra a implementação de uma FilterFunction responsável por filtrar valores maiores que trinta.

\footnotetext{
${ }^{3}$ Uma expressão lambda do Java é uma função que pode ser criada sem pertencer à nenhuma classe, sendo declarada no local em que será utilizada. Possui o formato (argumento) -> (corpo).
} 


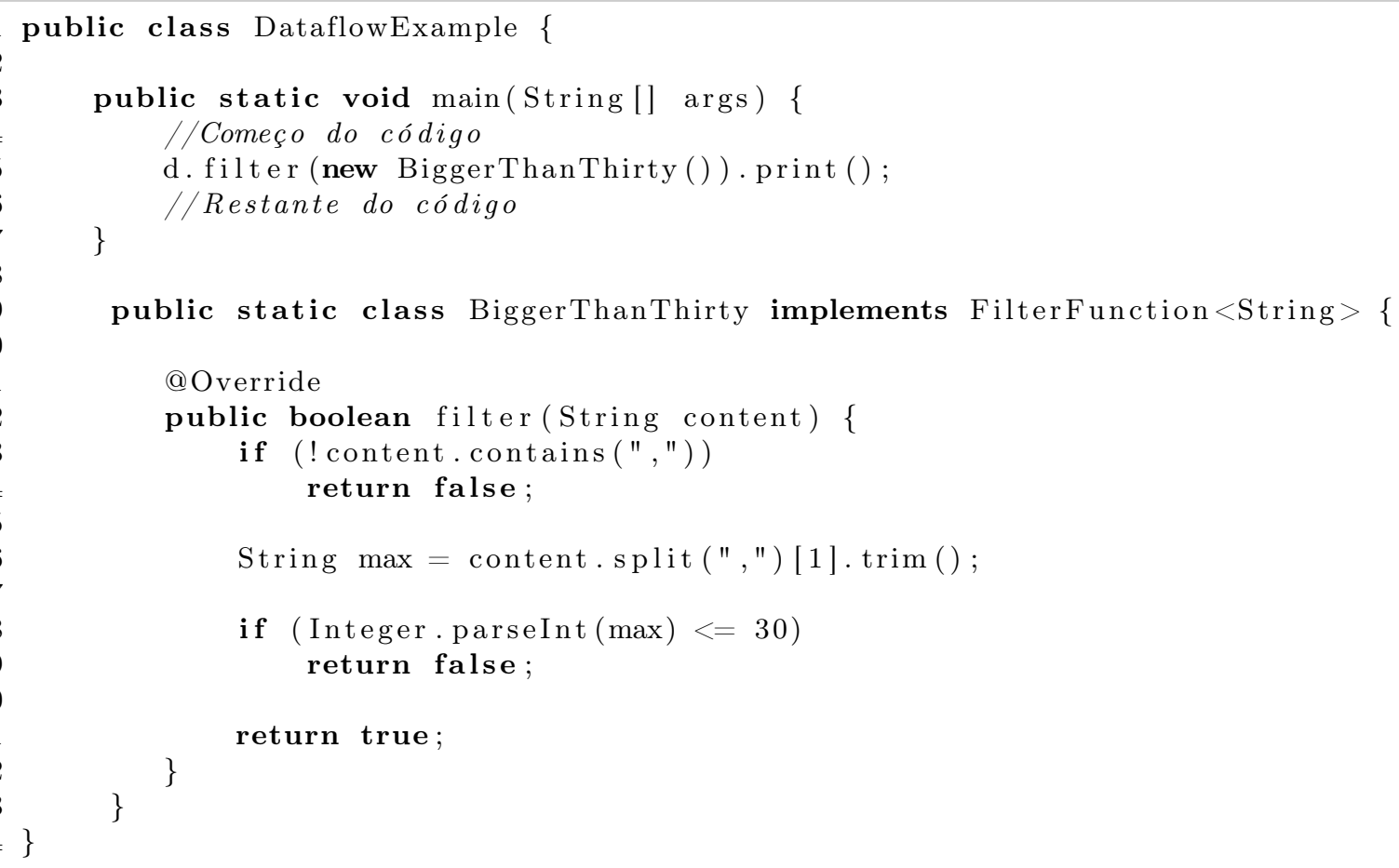

Lista 5.8: Exemplo de definição e uso de uma UDF do tipo Filter

Os métodos timeWindow e sessionWindow presentes na Tabela 5.5 são métodos relativos a janelas e serão detalhados na Seção 5.3.5. Optou-se por criar os métodos como parte da classe Data porque as janelas atuam sobre os dados.

\subsubsection{Window}

Janelas são formas de discretizar volumes ilimitados de dados e um dos critérios de definição dos tamanhos de janela é o tempo (como descrito na Seção 2.4). Uma vez que atuam sobre o dado, há uma relação de agregação entre Data e Window, visto que os dados podem ou não possuir janelas. Essa relação é representada no diagrama de classes da Figura 5.2.

Para utilizar janelas em seu dataflow, o usuário precisa instanciar a classe Window. O valor booleano keyed passado como argumento no construtor da janela está relacionado ao chaveamento ou não dos streams. Quando verdadeiro, os streams são divididos por chaves e isso permite o paralelismo, pois cada stream pode ser processado independentemente. No caso de ser falso, não há essa divisão e a lógica da janela será aplicada para uma única tarefa, isto é, sem paralelismo.

O objeto de Window criado é passado como argumento nos métodos timeWindow e sessionWindow presentes na classe Data, listados na Tabela 5.5. A assinatura de timeWindow varia para janelas fixas e deslizantes: para esta última é necessário colocar a quantidade de tempo do deslizamento. Exemplos de chamadas a esses métodos estão na Lista 5.9. 


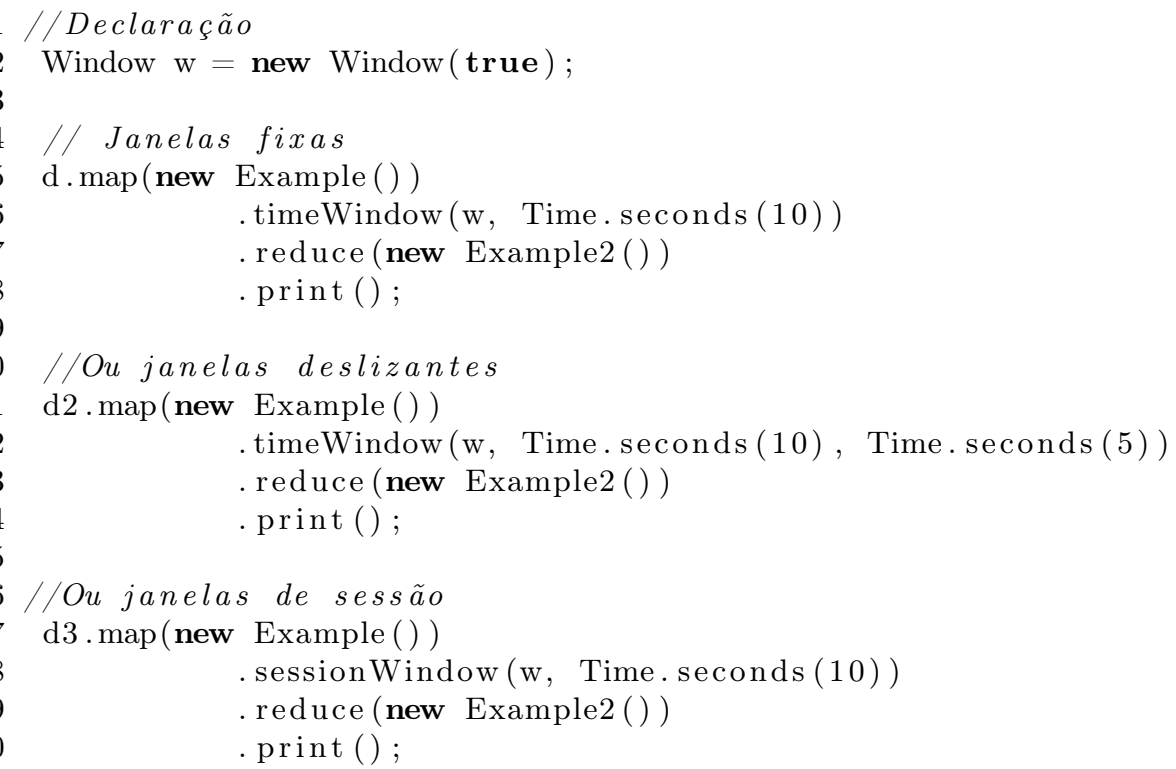

Lista 5.9: Exemplo de janelas fixas, deslizantes e de sessão, usando as classes Window e Data da interface

\subsubsection{Sequência das classes da interface}

O diagrama de sequência da Figura 5.3 ilustra a sequência de passos envolvidos na criação de um dataflow, mostrando a interação entre as classes explicadas nas seções anteriores e ilustradas no diagrama de classes da Figura 5.2.

No caso de uso ilustrado pelo diagrama, o usuário da abstração cria uma classe contendo o dataflow com a lógica desejada, utilizando a interface. Como pode ser visto na Figura 5.3, é solicitado o início do projeto, chamando-se o ProjectSettings. A classe Data é instanciada e, posteriormente, é feita uma solicitação de leitura de dados usando-se um conector de entrada. Transformações são aplicadas sobre os dados lidos, como pode ser visto na Ação 2. O usuário utiliza janelas de tempo, ocorrendo chamadas às classes Window e Time. Ao realizar transformações, o resultado é escrito em um conector de saída de dados. Por fim, depois de concluir a leitura, as transformações e a escrita de dados, o projeto é finalizado, encerrando o dataflow.

Um caso de uso do sistema é representado pelo diagrama, mas é importante ressaltar que há outros casos possíveis e, assim, pode haver mais de uma leitura e escrita de dados, bem como nem todas as aplicações desenvolvidas precisam utilizar janelas. Neste diagrama buscou-se explorar todas as classes criadas na interface.

\subsection{Considerações sobre a interface desenvolvida}

Para a criação da interface, foram levantados quais são os principais componentes utilizados em arcabouços de Big Data e buscou-se centralizar as operações necessárias em torno do dado. Por exemplo, é possível utilizar uma função que calcula o mínimo fazendo-se data.minByKey ( ), sendo data um dado no formato chave e valor.

Para evitar que o usuário da interface tenha que criar arquivos de propriedades e configurações (necessários às ferramentas de Big Data), no projeto da interface optou-se por representar essas informações nos parâmetros de alguns métodos. Dessa forma, o aparente aumento de complexidade no número de parâmetros é compensado pela redução de código que o usuário precisa escrever.

As classes foram projetadas de modo a facilitar que a abstração seja estendida com novos recursos de manipulação de dados ou para outros arcabouços de Big Data. Para citar um exemplo, a classe abstrata $\mathrm{IO}<\mathrm{T}>$ reúne as classes relativas a conectores de entrada e saída de dados e, assim sendo, caso deseje-se incluir um novo conector, basta criar uma nova classe que herde de $\mathrm{IO}<\mathrm{T}>$. 


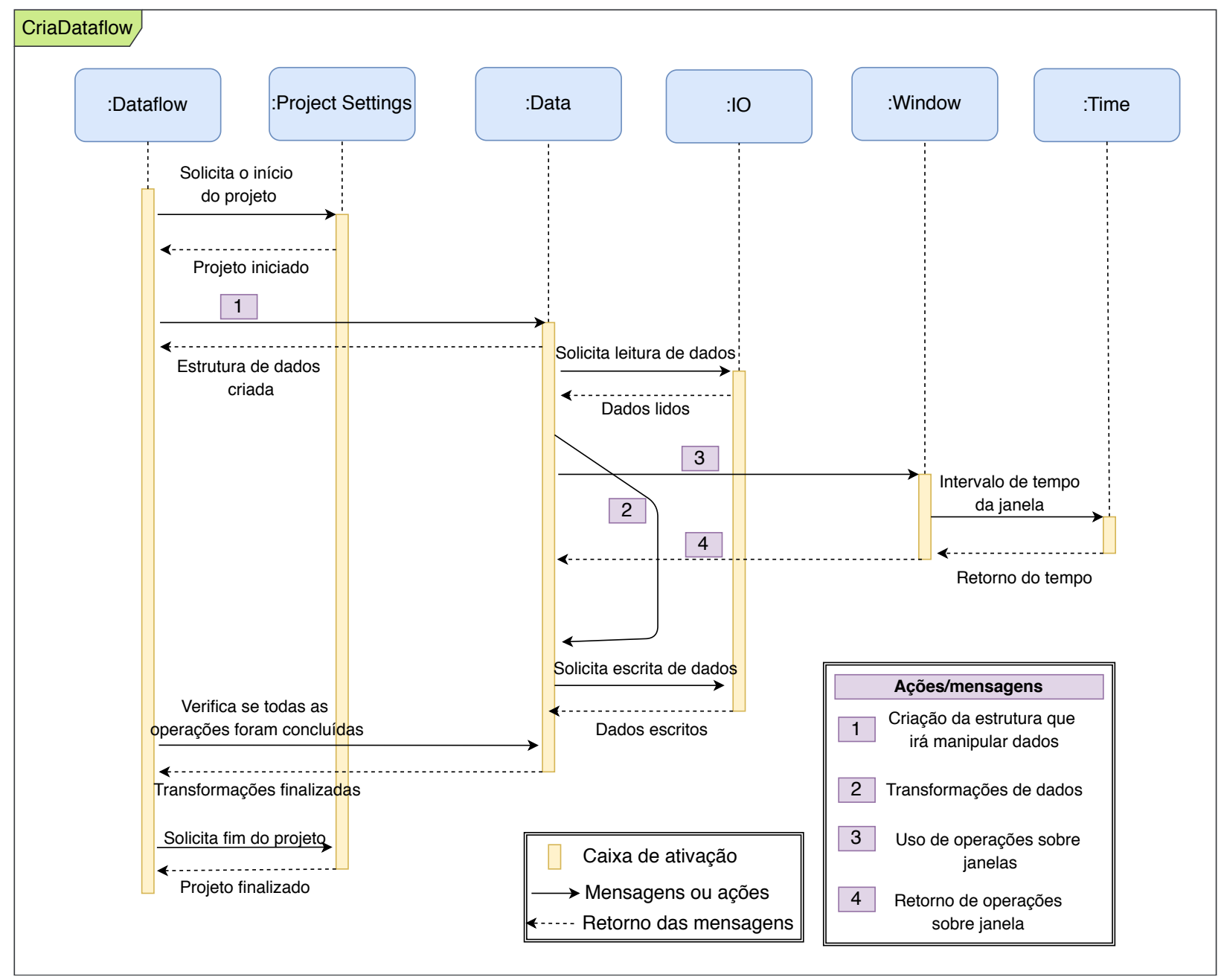

Figura 5.3: Diagrama de sequência ilustrando os passos na criação de um dataflow com a interface desenvolvida

Como uma abstração precisa ser o mais flexível possível e seu usuário pode declarar métodos dos mais variados tipos, um recurso útil presente nas linguagens de programação, cada qual com sua própria sintaxe, é o uso de métodos, variáveis e classes genéricas (generics em Java). Isso permite, por exemplo, que um mesmo método possa ser invocado usando-se parâmetros com tipos diferentes. Uma vez que linguagens de programação como Java possuem vários tipos, sem o uso de generics seria necessário definir métodos diferentes para cada variação de tipo dos parâmetros.

A interface criada permite definir dataflows em mais alto nível, enquanto as especificidades de cada arcabouço ficam a cargo do sistema de software detalhado no Capítulo 6. O usuário da interface escreve seus dataflows em termos de fontes de dados, suas transformações e destino final, sem precisar detalhá-los no nível topológico do grafo. 


\section{Capítulo 6}

\section{Análise e mapeamento de dataflows}

Este capítulo tem por objetivo detalhar a análise feita sobre o dataflow construído pelo usuário por meio da interface, bem como o mapeamento realizado para as ferramentas de Big Data. Inicialmente, o usuário do sistema de abstração precisa expressar a lógica da aplicação que deseja construir usando a interface de dataflows (explicada no Capítulo 5), provendo um arquivo de entrada. Esse arquivo é composto por código que usa a API, mas pode conter também código escrito com estruturas usuais da linguagem de programação Java.

Um exemplo encontra-se no código do dataflow na Lista 6.1, o qual compara valores gerados pseudo-aleatoriamente com valores lidos de um arquivo. Esse código contém trechos com o uso da interface nas linhas de 8 a 10, 24 a 27 e 31. Esses trechos são os que precisam ser mapeados. As demais linhas contêm construções da própria linguagem Java, como condicionais. O uso de outras estruturas do Java, além daquelas providas pela interface, permite enriquecer a aplicação do usuário, uma vez que possibilita o uso de recursos e bibliotecas da linguagem.

Dessa forma, é necessário separar os trechos de código Java que usam a interface daqueles que não a utilizam e isso é realizado através de um analisador, detalhado na Seção 6.1 e implementado pelo serviço Dataflow Parser da arquitetura mostrada na Figura 5.1. A partir da especificação do dataflow feita por meio da API, é preciso gerar código que seja decifrável aos arcabouços de Big Data e, assim, os trechos de código que usam a interface passam por uma etapa de mapeamento, detalhada na Seção 6.2 e representada pelos serviços Mapper (Flink Mapper, Apex Mapper e New Tool Mapper) na arquitetura. O código que não utiliza a interface não precisa passar pelo mapeamento, pois já é inteligível aos arcabouços de Big Data.

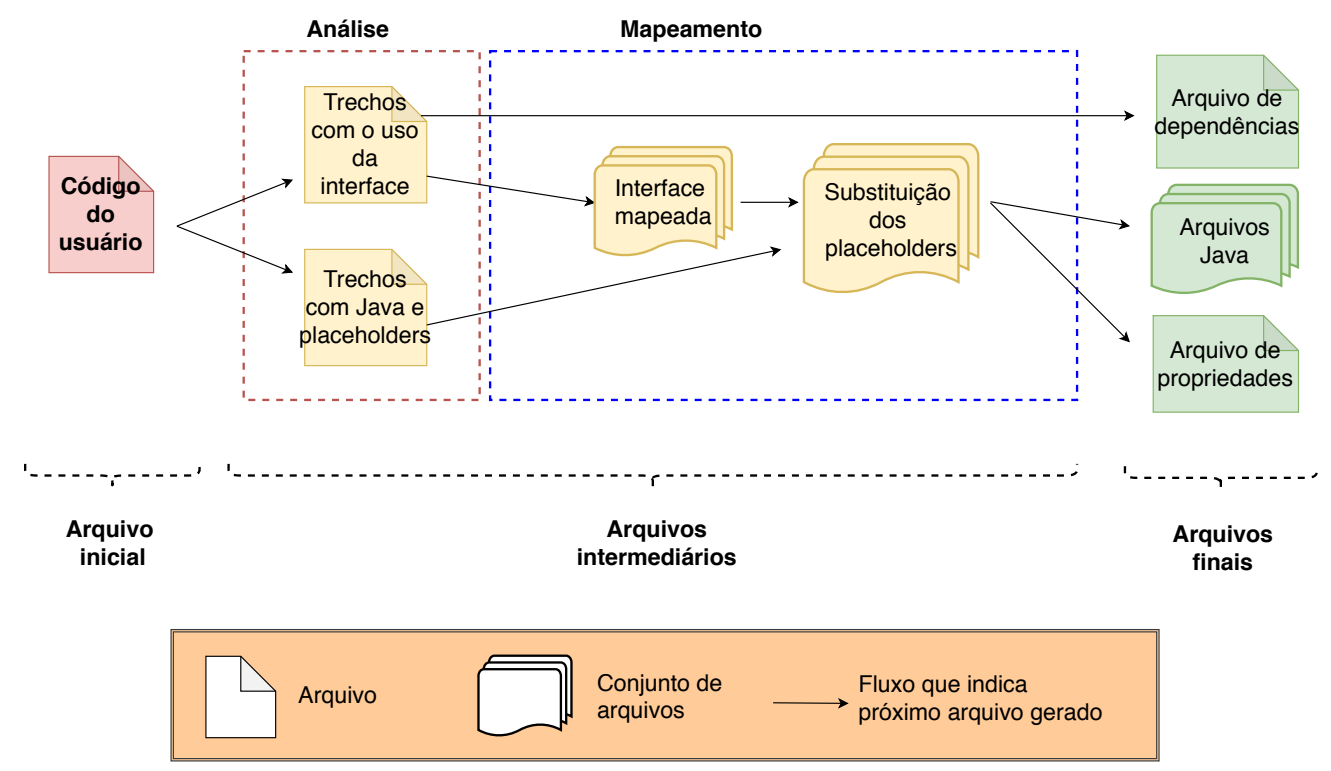

Figura 6.1: Fluxo de conversão do arquivo inicial do usuário aos arquivos finais 
Uma parte dos arquivos gerados nas etapas de análise e mapeamento são intermediários, visto que eles não serão executados nos arcabouços, mas são fundamentais para produzir os arquivos finais que executam nessas ferramentas. Como pode ser visto na Figura 6.1, há dois tipos de arquivos intermediários: um que possui apenas código da interface que precisa ser mapeado e outro com código Java que não é parte da interface e placeholders (identificadores que ficam no lugar onde estariam as chamadas à interface). Esse segundo tipo de arquivo é utilizado para a geração dos arquivos finais, sendo que os placeholders são substituídos pelo código mapeado correspondente. Os arquivos finais são compostos pelas dependências necessárias para a execução do programa no arcabouço, pelo código Java que contém a lógica do dataflow e pelo arquivo com as propriedades dos conectores utilizados. O fluxo de geração dos arquivos intermediários e finais a partir do inicial por meio das etapas de análise e mapeamento está ilustrado na Figura 6.1.

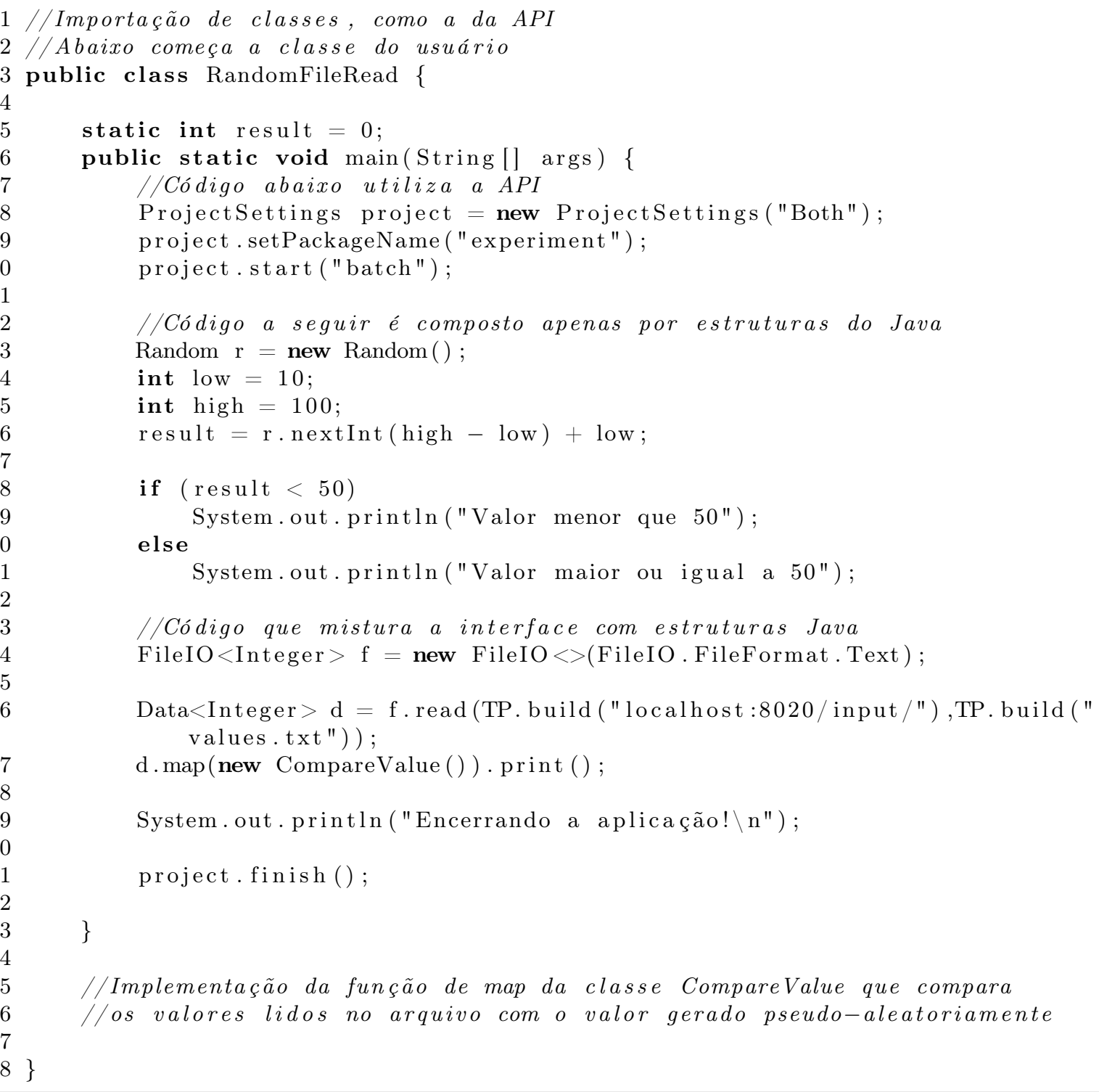

Lista 6.1: Exemplo de código que mistura o uso da interface e código Java puro

\subsection{Analisador de código}

O analisador é um programa que realiza a tarefa de analisar o código de especificação de um dataflow e separar os trechos que utilizam a API daqueles que não a utilizam. Na geração dos arquivos intermediários, o analisador precisa lidar com as seguintes situações: 
- As dependências precisam ficar nos arquivos intermediário e final, uma vez que sem as bibliotecas necessárias, ambos os programas apresentariam erros de dependências faltantes.

- A estrutura "public class NomeDaClasse" também precisa estar presente, visto que arquivos escritos em Java precisam ter o mesmo nome da classe contida neles.

- Além da classe, o arquivo Java possui métodos como o main (essencial para executar o código da classe), entre outras funções definidas pelo usuário.

- Linhas com comentários devem aparecer no arquivo final de saída que executará no arcabouço, assim como funções que imprimem na saída padrão ou de erro.

- Existe a possibilidade de haver dois métodos que possuam o mesmo nome, mas um pertence à interface e outro vem de uma biblioteca do Java. A diferenciação ocorre por meio do objeto que está chamando o método, uma vez que ele pertence a uma classe, a qual pode fazer parte ou não da interface.

- Dentro de laços e estruturas de controle, pode haver chamadas de métodos que pertencem à interface e que, portanto, precisam ser mapeados, enquanto o laço ou o fluxo de controle fazem parte da linguagem Java e precisam aparecer no código final que será gerado para rodar diretamente no arcabouço. Como uma estrutura pode aninhar outras, o analisador precisa percorrer a árvore sintática que representa o código fornecido pelo usuário da abstração.

Assim, uma implementação simples do analisador, apenas com estruturas de dados, bibliotecas para manipulação de arquivos e uso de expressões regulares para identificar os padrões de interesse no código, não se mostrou suficiente e nem adequada. Foi necessário construir um analisador mais robusto, que facilitasse o tratamento dos vários casos que precisam ser considerados na separação do código. Isso levou à busca de alguma biblioteca de análises léxica e sintática, para auxiliar a implementação. Optou-se pelo JavaParser, descrito na Seção 6.1.1.

\subsubsection{JavaParser: analisador léxico e sintático}

JavaParser (Java Parser, 2020) é uma biblioteca que permite analisar e processar código Java, utilizando representação de árvore sintática abstrata. Esta é composta pela raiz, que trata-se do ponto de origem, a partir do qual saem ramificações, de modo que instruções (statements) mais complexas se subdividem em instruções mais simples até chegar aos nós terminais (folhas), conforme o analisador progride de acordo com a gramática da linguagem. Uma ramificação não tem conexão com as outras sem ser pelo nó de origem. A árvore é composta por nós: um deles é a raiz que apresenta grau de entrada zero, enquanto os demais apresentam cada um deles grau de entrada um. Com relação ao grau de saída, não há restrições. Caso apresente grau de saída igual a zero, é chamado de folha.

Como a unidade principal do JavaParser é o nó, conceitos como declarações de métodos, parâmetros, instruções são considerados filhos dessa classe. Boa parte dos nomes utilizados pelo JavaParser mantêm consistência com aqueles definidos na especificação oficial da linguagem Java (Especificação - Linguagem Java, 2020), um dos motivos que levou à escolha dessa biblioteca. Outros pontos foram: a quantidade de contribuidores do repositório oficial (125 em dezembro de 2019) e o fato de ter código aberto.

JavaParser é o nome da biblioteca para análise de código Java, mas também o nome de seu principal componente, o analisador. Além da classe JavaParser que gera a árvore sintática a partir do código, há duas outras principais dessa biblioteca: CompilationUnit, que representa toda a informação que o compilador tem sobre o arquivo que irá compilar, e Visitors, que permite encontrar partes específicas da árvore.

Nem sempre a informação fornecida pela árvore sintática abstrata é suficiente e, nesses casos, pode ser necessária a criação de novas conexões entre os nós, transformando a árvore em um grafo, por meio da resolução de símbolos e referências. Símbolos são elementos representados por um 
nome como variáveis, parâmetros, entre outros. Visto que um mesmo símbolo pode apresentar tipos diferentes dependendo do contexto, ao ser utilizado precisa ser mapeado para a sua respectiva declaração, isto é, para a referência correta. Um exemplo disso, está na Lista 6.3 em que a variável f é do tipo Integer dentro do método printBytes (), mas é String na função principal.

A biblioteca JavaSymbolSolver foi utilizada para resolver referências dos elementos da árvore sintática e vem integrado à biblioteca JavaParser. O JavaSymbolsolver conecta elementos relacionados, por exemplo, a chamada de método à sua declaração. As listas 6.2 e 6.3 evidenciam a necessidade de utilizar essa biblioteca. Na primeira lista, a variável $f$ é declarada como sendo do tipo FileIO<String >. A constante FileFormat. Hdfs e o método read() - ambos da classe FileIo - são utilizados. Na Lista 6.3, a quantidade de bytes da variável f é obtida no trecho f.BYTES. Se a variável $f$ da Lista 6.3 fosse do tipo String na função printBytes (), no lugar do incremento da variável teria-se uma concatenação. O contexto, portanto, que irá definir se está ocorrendo o acesso ao campo de uma variável ou a atributos e métodos de uma classe e como o dado deve ser tratado e analisado. Por isso é necessário analisar os símbolos juntamente às suas referências.

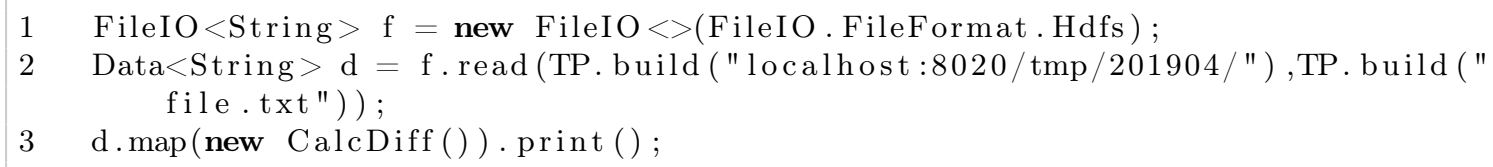

Lista 6.2: Declaração e uso das variáveis $f$ e d

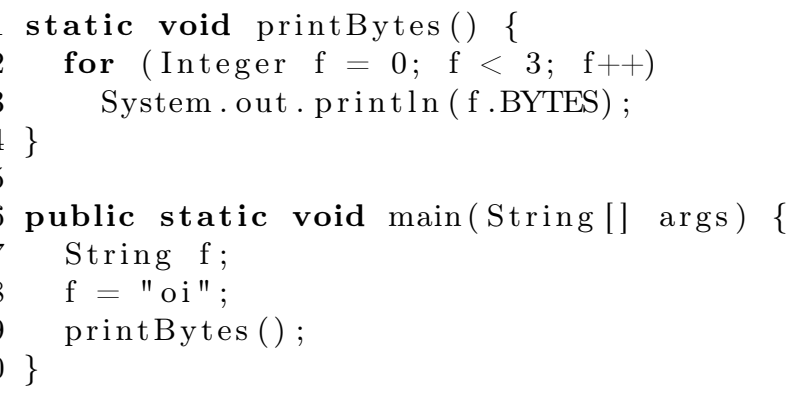

Lista 6.3: Declaração e uso da variável $f$

Existem estruturas principais que precisam ser observadas e tratadas no código Java do usuário da abstração e, assim, foram construídas classes que estendem Visitors para analisar estruturas específicas da árvore sintática, de forma a modularizar o analisador desenvolvido neste trabalho. As classes criadas para esse fim lidam com os seguintes tipos de expressão: MethodDeclaration, MethodCallExpr, VariableDeclarationExpression e ClassorInterfaceDeclaration, cujos nomes são autoexplicativos e referem-se a declarações de métodos, suas chamadas, declaração de variáveis, criação de classes e interfaces. Cada tipo de expressão possui um conjunto de propriedades associadas. No caso da declaração de método, por exemplo, há propriedades como o próprio nome do método, o tipo de retorno, os argumentos e o corpo da função.

Desse modo, o JavaParser auxilia na navegação do código Java, facilitando na busca de determinadas estruturas.

\subsubsection{Estrutura do analisador desenvolvido}

O funcionamento geral do analisador desenvolvido está descrito em pseudocódigo no Algoritmo 1. 


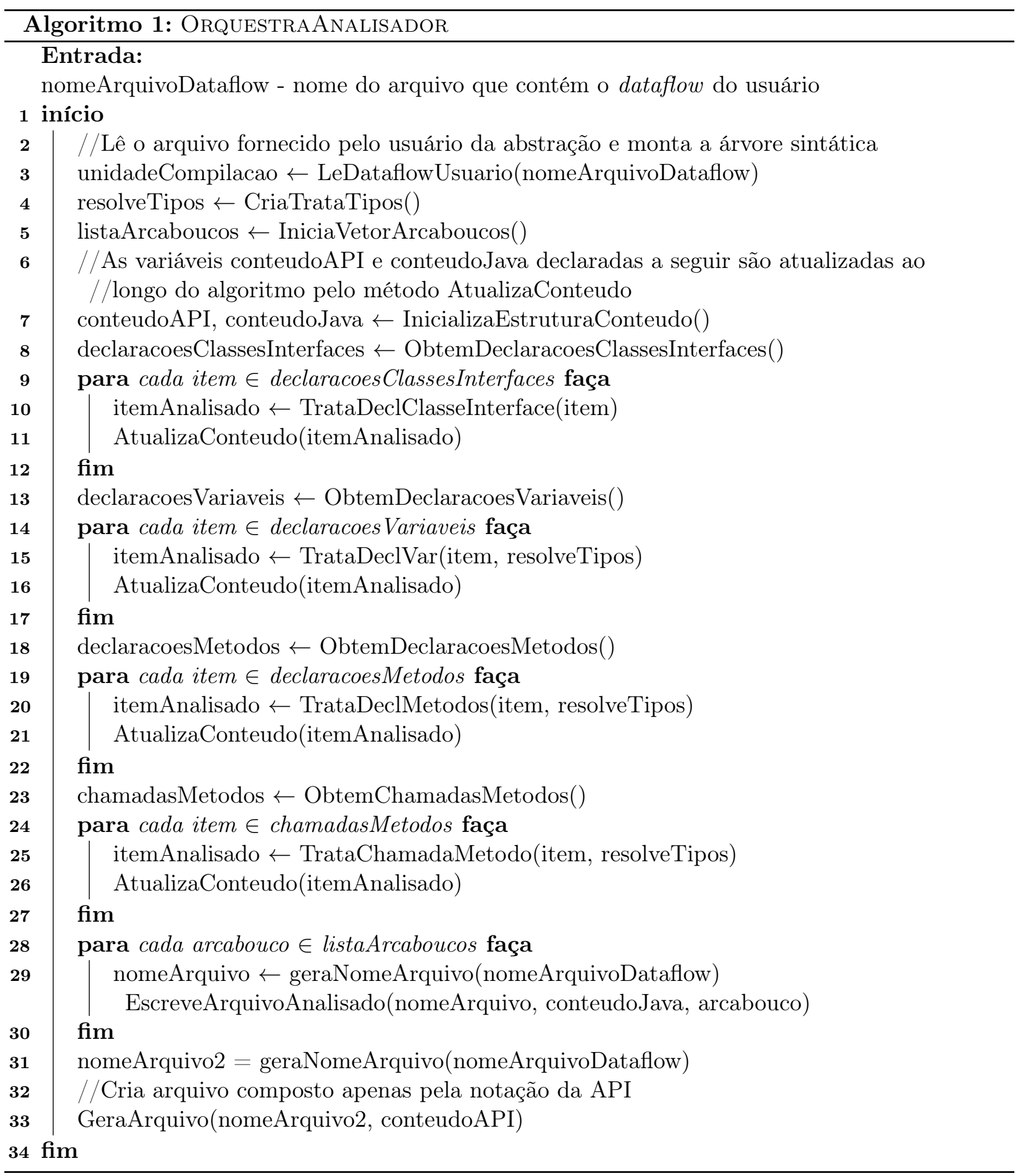

O arquivo contendo o dataflow do usuário é lido e a árvore sintática abstrata é armazenada na unidade de compilação, estrutura que pode ser navegada. As estruturas de dados conteudoAPI e conteudoJava têm escopo visível ao analisador inteiro, de modo que podem ser atualizadas pelo método AtualizaConteudo ao longo da aplicação. O conteudoJava contém código Java que não faz parte da interface e placeholders, enquanto conteudoAP I possui código da interface a ser mapeado na próxima fase para os arcabouços desejados, presentes na estrutura listaArcaboucos.

Estruturas que o código do usuário pode conter nas partes em que a interface é utilizada são: declaração de classes e interfaces, declaração de variáveis (o que inclui instanciação de objetos) e de métodos, bem como chamadas a métodos. Cada uma dessas estruturas precisa ser tratada e foram criados métodos com essa finalidade: TrataDeclclasseInterface, TrataDeclVar, TrataDeclMetodos e TrataChamadaMetodo. Estruturas como laços e fluxos de controle são 
mantidas no código final sem a necessidade de realizar mapeamento sobre elas. As funções que realizam tratamento retornam o nó atualizado para cada tipo de estrutura e esse nó é parâmetro do método AtualizaConteudo, responsável por atualizar as estruturas de dados conteudoAPI e conteudoJava, as quais são escritas em arquivos depois do processo de análise ser concluído pelo analisador. Esses arquivos são escritos pelas funções GeraArquivo e EscreveArqui voAnalisado.

O pseudocódigo do método EscreveArquivoAnalisado encontra-se no Algoritmo 2. Esse método insere-se na etapa de geração de arquivos intermediários pelo analisador, etapa que precede o mapeamento, mas algumas das dependências que estarão no arquivo final já são inseridas nos intermediários. O restante do conteúdo do arquivo resultante da execução de EscreveArquivoAnalisado é composto por código Java e placeholders nos lugares apropriados, onde se encontravam chamadas à interface no programa do usuário.

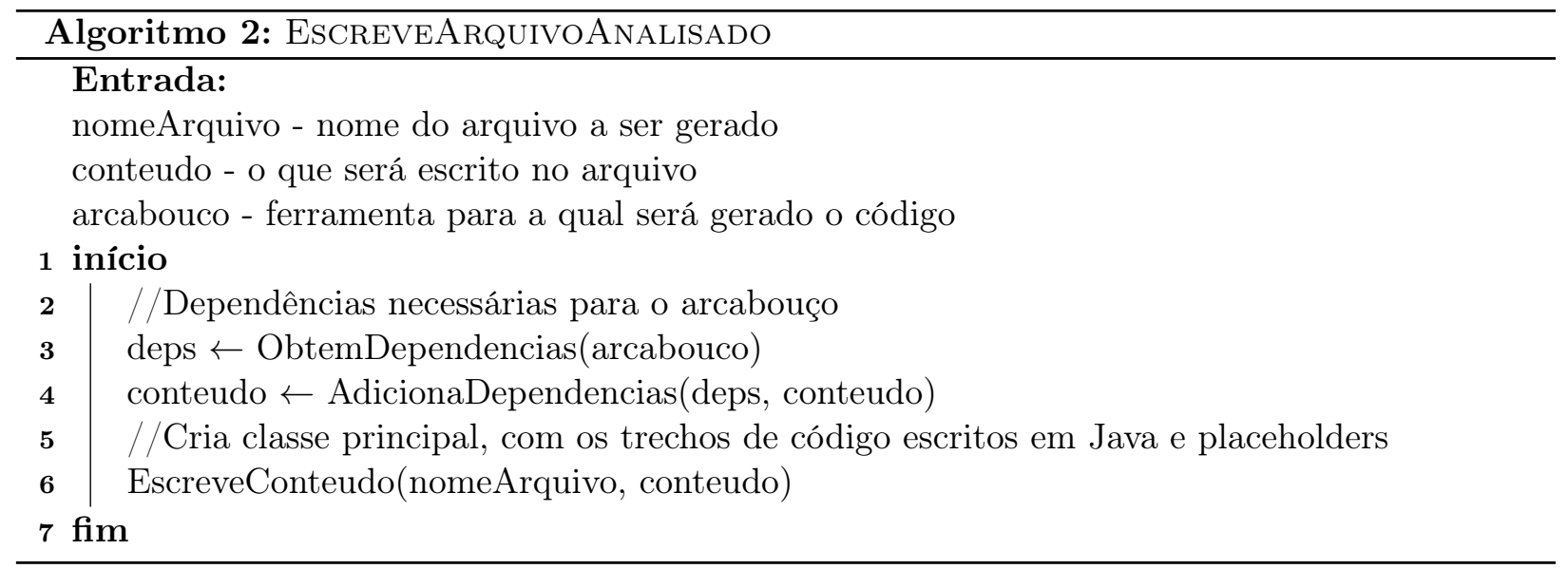

\subsection{Serviços de mapeamento}

Após analisar e separar o código que usa a interface daquele que não usa, é necessário realizar a etapa de mapeamento dos comandos da interface para uma linguagem inteligível aos arcabouços de Big Data. Para facilitar o mapeamento, os métodos da API de dataflows desenvolvida neste trabalho geram código-fonte: eles realizam chamadas a outros métodos escritos em Java e Python responsáveis por produzir código para os arcabouços desejados pelo usuário. O código resultante do mapeamento é composto por arquivos com extensão . java, os quais podem ser compilados e executados diretamente nos arcabouços, e arquivos.xml de configuração e propriedades, como ilustrado na Figura 6.1.

Há três tipos de componentes principais na interface que precisam ser mapeados: os dados, suas transformações e os conectores de entrada e saída que permitem realizar leituras e escritas de dados. Foram criadas algumas classes para realizar o mapeamento desses componentes e as principais estão ilustradas na Figura 6.2.

De uma forma geral, para cada estrutura mapeada existe por trás uma classe principal mais genérica e classes específicas por arcabouço. Então, para realizar o mapeamento de um conector de arquivos, por exemplo, existe a classe FileIo da interface que direciona o mapeamento para as classes FileF e FileA que geram código para o Flink e o Apex, respectivamente. Isso pode ser visto na Figura 6.2, que mostra a relação de classes da interface com classes criadas para o mapeamento. O pacote ToolPackage indica que é possível estender para outras ferramentas a lógica do mapeamento. Por exemplo, caso pretenda-se expandir a abstração para realizar o mapeamento de arquivos para novos arcabouços é necessário criar uma nova classe responsável por mapear o conector para o novo arcabouço.

Como citado anteriormente, há estruturas centrais da interface que precisam ser mapeadas (conectores, dados e transformações) e os algoritmos que seguem visam a elucidá-las, sendo os algoritmos 3 e 4 voltados aos conectores de entrada e saída, enquanto os algoritmos 5, 6 e 7 estão associados a transformações aplicadas sobre os dados. 


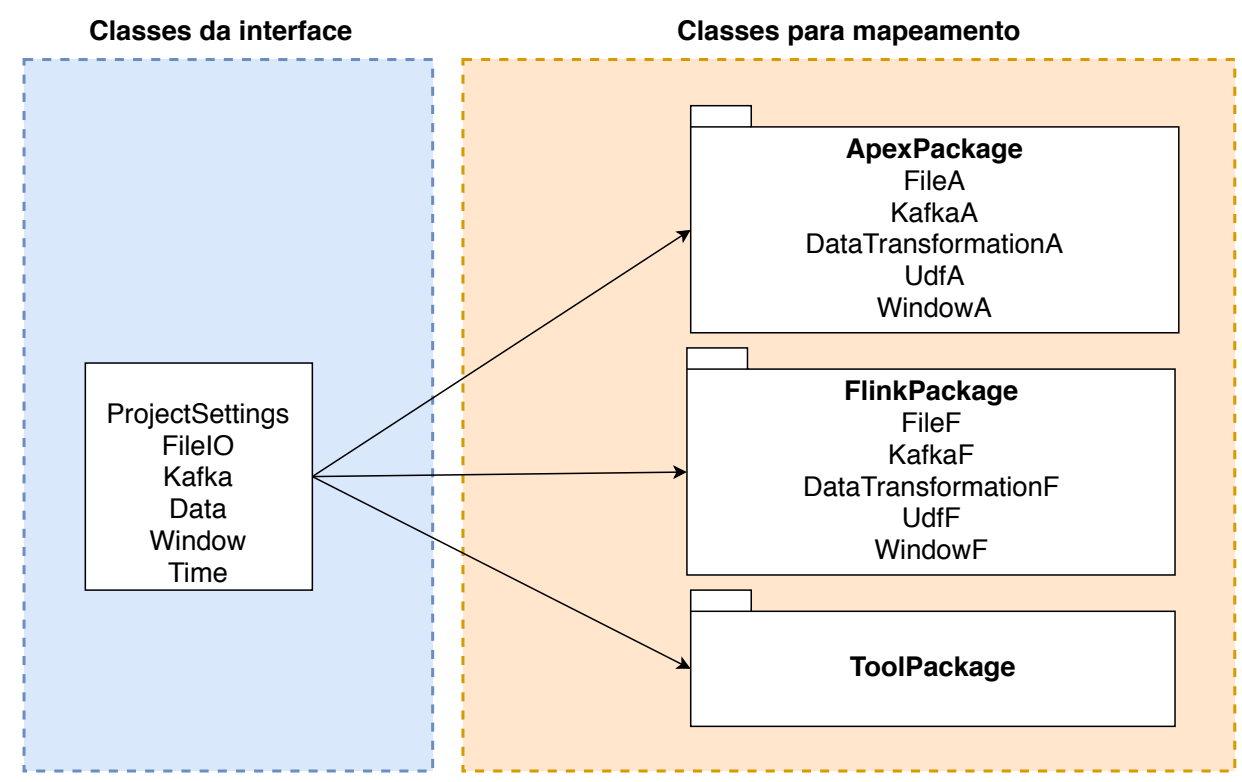

Figura 6.2: Visão das classes da interface e daquelas criadas para realizar o mapeamento de código

Com o intuito de facilitar o entendimento do sistema de software desenvolvido e compactar os pseudocódigos aqui descritos, os algoritmos foram padronizados, de modo que em todos há um laço em que se percorre uma lista com todos os arcabouços desejados e dentro dele são chamados os métodos necessários de acordo com o objetivo do algoritmo. Exemplo disso encontra-se no Algoritmo 3, cujo laço está entre as linhas 2 e 8 . Os métodos nele contidos (AdicionaDependenciaLeituraHdfs, AdicionaPropriedadeLeituraHdfs, entre outros) estão associados ao conector HDFS. Se a variável arcabouço está definida com o valor "Flink", serão utilizados os métodos AdicionaDependenciaLeituraHdfs e AdicionaPropriedadeLeituraHdfs que geram código para o Flink. Então, em cada iteração do laço, são aplicados os métodos descritos para o arcabouço corrente da iteração.

Há diferentes tipos de conectores de entrada e saída, como arquivo de texto, HDFS e Kafka. Para exemplificar o mapeamento realizado para esses conectores, escolheu-se arbitrariamente a construção do pseudocódigo para o caso do HDFS, sendo o Algoritmo 3 a função de leitura e o Algoritmo 4 o de escrita. Tanto para a leitura quanto para a escrita de arquivos no HDFS é necessário adicionar as dependências a serem utilizadas pelo código. Além disso, ambos possuem propriedades que precisam ser incluídas no arquivo final de propriedades utilizado pelos arcabouços. Os tipos presentes no dataflow que fazem parte da interface, isto é, que não são tipos nativos do Java, são mapeados pela função MapeiaTipo. O código a ser gerado para ser executado diretamente em cada arcabouço é produzido pelos métodos MapeiaLeituraHdfs e MapeiaEscritaHdfs e a escrita do código é realizada por EscreveResultadoMapeado. 

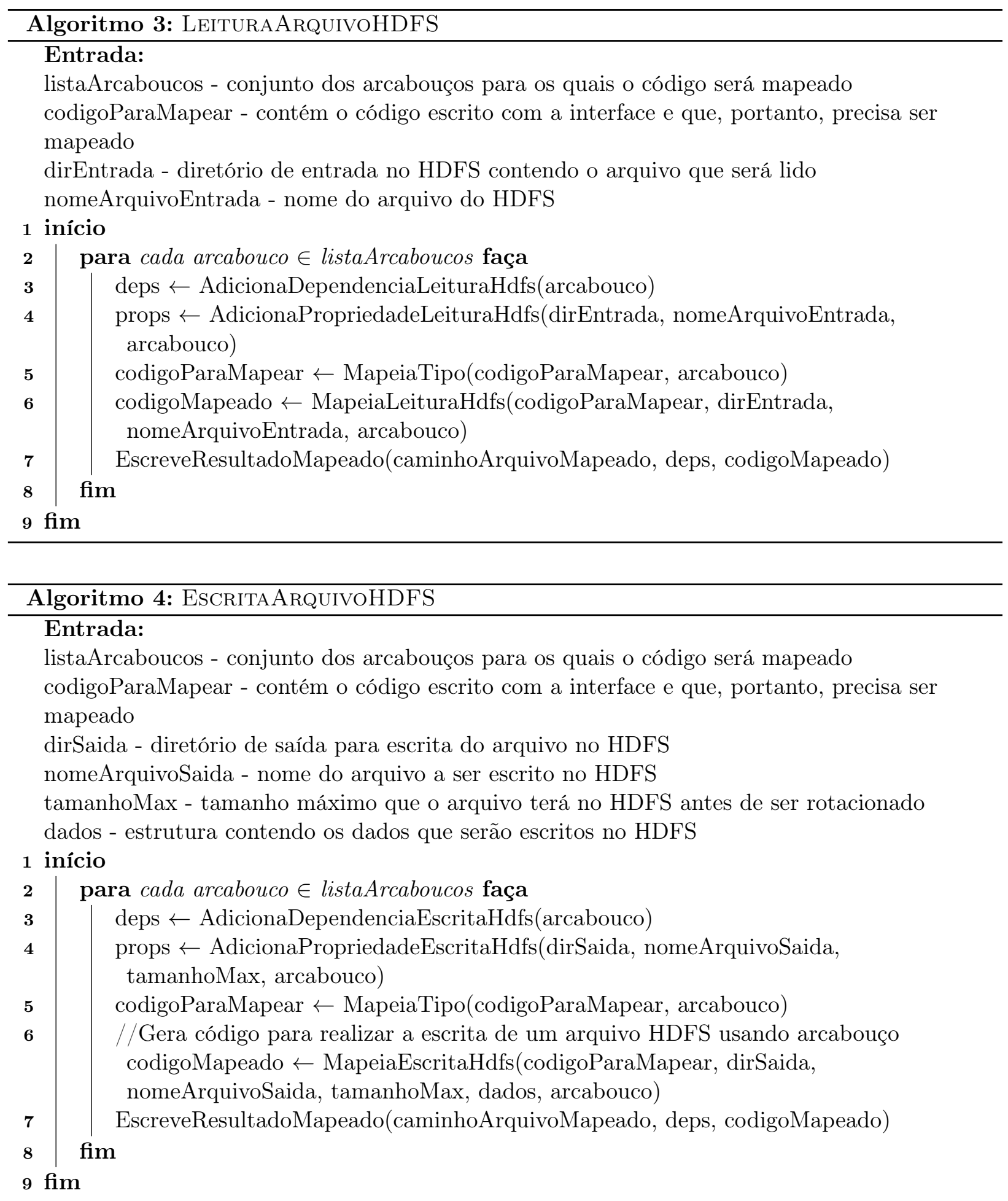

Ao utilizar a interface, o usuário aplica transformações (como soma, UDFs, etc.) sobre o dado, chamando métodos da classe Data $<\mathrm{T}>$ da interface. Essas transformações, contudo, são implementadas e mapeadas em DataTransformation $\langle\mathrm{T}>$ e UDF $\langle\mathrm{T}>$, de forma transparente ao usuário. Optou-se por expor esses métodos de transformação de dados na interface por meio da classe Data $<\mathrm{T}>$ para que ficasse mais intuitiva ao usuário final, uma vez que seriam classes a menos para instanciar e, além disso, como as transformações são aplicadas diretamente sobre os dados, faz sentido que sejam métodos de Data $<\mathrm{T}>$.

Uma dessas transformações pode ser vista no Algoritmo 5 que mostra a lógica aplicada para mapear a função que calcula o valor mínimo sobre um conjunto de dados. Como a lógica de mapeamento é similar para outras funções de agregação, como máximo e soma, optou-se por utilizar 
apenas uma delas para explicar esse tipo de mapeamento. De forma similar, foram escolhidas a função de Map no Algoritmo 6 para elucidar a lógica aplicada para as funções definidas pelo usuário e as janelas de tempo fixas no Algoritmo 7 para ilustrar o tratamento das janelas.

Para mapear funções de agregação, como é o caso do mínimo ilustrado no Algoritmo 5, é passado como argumento o tipo de processamento escolhido, ou seja, em lote ou tempo real. Com base nisso, aplica-se mapeamentos diferentes utilizando-se as funções MapeiaMinLote ou MapeiaMinStream, respectivamente.

Tanto para funções de agregação (Algoritmo 5), quanto UDFs (Algoritmo 6) e janelas (Algoritmo 7) é necessário adicionar novas dependências que são demandadas pelo código que está sendo gerado no mapeamento. Assim, para todos esses mapeamentos há uma função responsável por adicionar as dependências (como AdicionaDependenciaMap, por exemplo). Além disso, o código gerado precisa ser escrito em algum arquivo que condensa o resultado do mapeamento do dataflow do usuário e isso é realizado pelo método EscreveResultadomapeado. Um exemplo real de código gerado para o Apex e Flink, a partir de um dataflow especificado pelo usuário utilizando a interface, pode ser visto no Apêndice A.
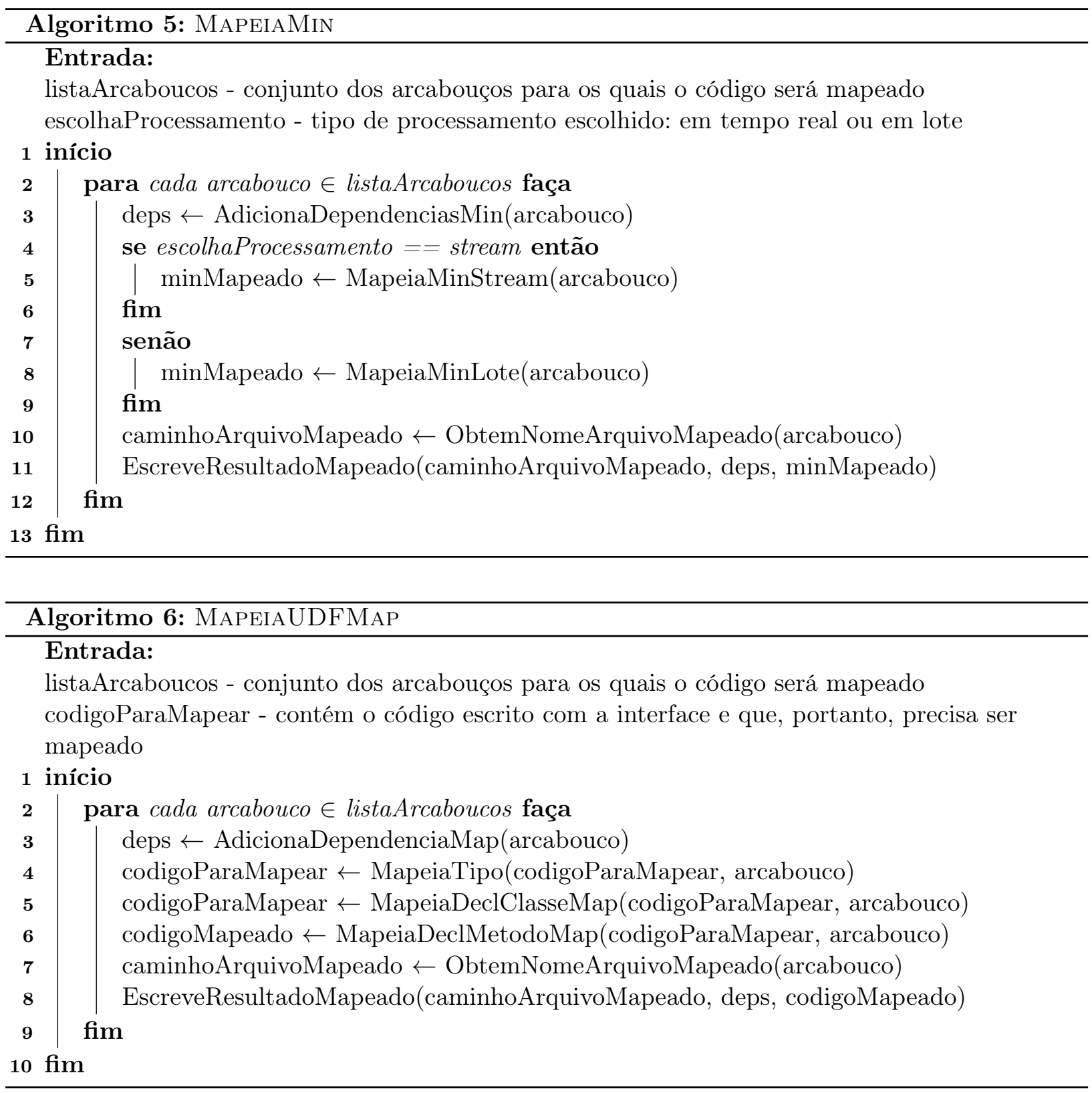


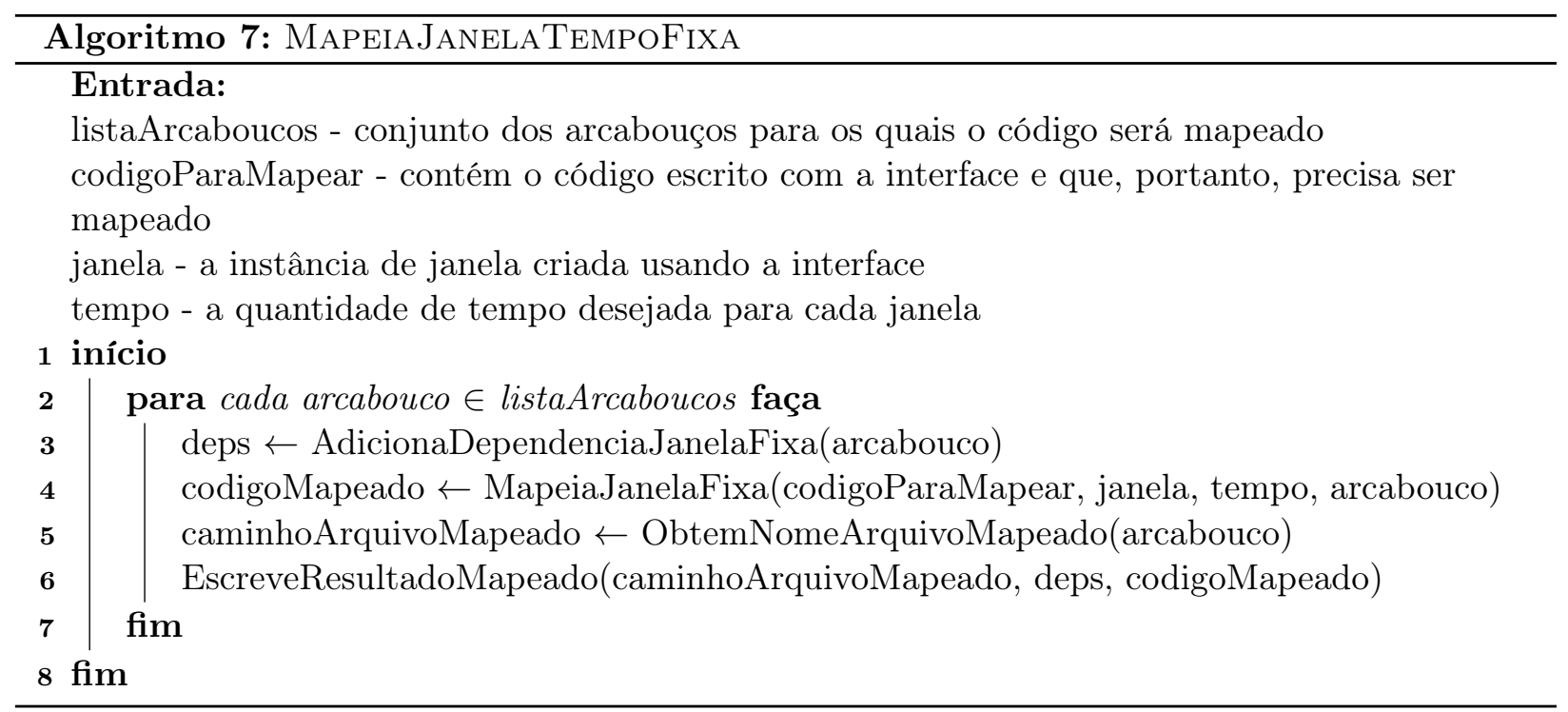

\subsubsection{Tratamento dos tipos de dados}

O conhecimento dos tipos dos parâmetros dos métodos da API é essencial para a realização do mapeamento do código do usuário para sintaxe inteligível aos arcabouços. De modo a flexibilizar os tipos que podem ser utilizados pelos usuários da interface, optou-se pelo uso de tipos genéricos (chamados de generics no Java) na criação das classes da interface. Contudo, na implementação deles o compilador Java aplica o TypeErasure (descarte do tipo), isto é, os tipos são apenas forçados em tempo de compilação, mas a sua informação é eliminada em tempo de execução. A remoção do tipo se aplica para classes, métodos, entre outros. Assim, quando tipos genéricos são usados, ocorrem checagens em tempo de compilação e conversões explícitas (casts) em tempo de execução. Embora o compilador retenha informação sobre o tipo, não é possível identificar qual é o tipo genérico utilizado na execução do programa.

Visando a obter o tipo em tempo de execução, por ser necessário para realizar o mapeamento, foi utilizada reflexão (Java reflection), já que trata-se de uma forma de inspecionar o estado do próprio código fonte. Assim, o tipo genérico é obtido pela referência de um objeto, visto que ele próprio não tem a informação a respeito do tipo em que foi parametrizado. Como foi construído um analisador de código, optou-se por realizar o tratamento dos tipos no próprio analisador, utilizandose reflexão por intermédio da biblioteca JavaParser (Java Parser, 2020), de modo a facilitar a etapa de mapeamento.

\subsection{Considerações sobre o capítulo}

O presente capítulo detalha como foram implementados os programas para análise e mapeamento dos códigos escritos por meio da interface, que transformam dataflows especificados por usuários da abstração em códigos que possam ser executados diretamente pelas ferramentas de Big Data.

Foi explicado que, antes de gerar os códigos finais para os arcabouços (arquivos Java, de dependências e de propriedades), são produzidos arquivos intermediários que possuem a separação do código que utiliza a interface desenvolvida daquele composto por Java puro e placeholders a serem substituídos pelo código mapeado em etapa posterior.

Algumas estruturas principais foram analisadas, como declaração de variáveis, métodos, classes e interfaces, bem como chamadas a métodos. Para descrever o mapeamento, foram considerados exemplos para cada um dos principais tipos de componentes da API: dados, transformações que podem ser aplicadas a eles, além de conectores de entrada e saída de dados.

Visando à flexibilização da abstração construída, esses componentes são expansíveis, isto é, pode-se adicionar novas classes de mapeamento a eles, aproveitando-se a interface já construída. 
Desse modo, a extensão do sistema de abstração com serviços de mapeamento para novos arcabouços de Big Data é majoritariamente transparente aos seus usuários, que sempre usarão a mesma interface para especificar seus dataflows. Não é completamente transparente, pois pode haver alguma propriedade inerente ao novo arcabouço que precise ser incluída como parâmetro adicional a métodos já existentes na interface.

De acordo com sua documentação, o Apex tem vários tipos de conectores (ex.: HDFS, JDBC, Cassandra (2020), Kafka e RabbitMQ). Contudo, parte desses conectores não estão mais funcionando corretamente na ferramenta. Esse é o caso, por exemplo, do conector para o RabbitMQ: embora haja implementação desse componente no Apex, as dependências e métodos utilizados estão depreciados. Problemas com esse e outros componentes ocorreram pois a ferramenta foi perdendo o suporte até ser descontinuada em setembro de 2019 e migrada para o Apache Attic (2020), o qual centraliza justamente os projetos da Apache que não recebem mais contribuições. Isso reitera a necessidade de haver uma abstração que permita que um usuário especifique seus dataflows de forma independente e que depois possa executá-los em diferentes ferramentas, sem precisar escrever programas específicos para elas.

De qualquer forma, o fato do Apache Apex ter sido descontinuado não invalidou o seu uso neste trabalho, visto que trata-se de uma ferramenta de mais baixo nível e que atendeu à necessidade de ilustrar como incorporar um novo arcabouço com API topológica à abstração. Ademais, esse cenário reitera, na verdade, a importância de existir uma abstração para arcabouços, visto que ferramentas novas vão continuar surgindo ao mesmo tempo que as existentes podem ser descontinuadas. A abstração permite que essas mudanças impactem menos os projetistas e usuários de dataflows. 


\section{Capítulo 7}

\section{Experimentos e estudo de caso}

Conforme detalhado nos Capítulos 5 e 6, o sistema de abstração desenvolvido neste trabalho é composto por uma API para a especificação de dataflows e serviços que os mapeiam em códigos específicos para arcabouços de Big Data. Este capítulo apresenta os experimentos e o estudo de caso desenvolvidos para verificar o funcionamento do sistema de abstração.

Dos três experimentos realizados, dois envolveram processamento de dados em lote enquanto um tratou de dados em tempo real. Os dataflows dos experimentos possuem uma estrutura mais simples que a do estudo de caso, pois o objetivo deles foi testar o mapeamento dos principais componentes presentes na abstração de forma unitária.

Já o estudo de caso é mais abrangente, visto que além de misturar processamento em lotes com tempo real, explora diferentes conectores de entrada e saída de dados, bem como diversas transformações sobre os dados lidos. Esse dataflow mais complexo permitiu também que a integração dos componentes do sistema fosse melhor testada.

Tanto os experimentos quanto o estudo de caso desenvolvidos analisaram dados reais do sistema de transporte público por ônibus da cidade de São Paulo. As seções a seguir descrevem os dataflows especificados e os resultados de suas execuções nos arcabouços de Big Data (depois do seu mapeamento pelo sistema).

\subsection{Dados coletados da SPTrans}

Os dados usados nos experimentos e no estudo de caso foram coletados da São Paulo Transporte - SPTrans (SPTrans - Olho Vivo, 2020). Os ônibus do sistema público de transporte de São Paulo possuem o sistema de Localização Automática do Veículo (AVL, do termo em inglês Automatic Vehicle Location) que rastreia as coordenadas de GPS dos ônibus a cada 45 segundos (Olho Vivo, 2018). O site da SPTrans tem uma área para desenvolvedores de software e provê uma API que permite coletar dados públicos (em formato JSON) de linhas, paradas e localizações de ônibus.

Para este trabalho, coletou-se por meio da API da SPTrans duas categorias de dados: a posição dos ônibus por linha e a previsão de chegada dos ônibus por linha e parada. Os dados foram coletados de 14 de abril até 29 de setembro de 2019. Os dados dos meses de abril, maio e junho foram utilizados como histórico, com o intuito de obter-se o tempo médio que os ônibus levam para ir de uma parada à sua parada consecutiva. Foram utilizados tanto para os experimentos quanto para o estudo de caso. Já os dados de julho, agosto e setembro foram usados para simular o envio de dados em tempo real na execução do estudo de caso. A versão da API da SPTrans utilizada foi a 2.1. As chamadas foram feitas ao endereço http://api.olhovivo.sptrans.com.br/v2.1.

Foram escolhidas seis linhas de ônibus para as análises e, para a escolha delas, foram consideradas algumas linhas com interseç̧ão de paradas e outras sem, de forma a incluir trajetos afetados por fatores de trânsito diferentes, como trechos de maior engarrafamento, presença de faixas exclusivas para ônibus, etc. Os códigos e nomes das seis linhas escolhidas são listados a seguir:

- 198: Metrô Santa Cruz - Terminal Jardim Ângela 
- 1450: Terminal Bandeira - Terminal Guarapiranga

- 1465: Terminal Bandeira - Terminal Varginha

- 1651: Terminal Mercado - Terminal Sacomã

- 32772: Terminal Princesa Isabel - Terminal Santo Amaro

- 34694: Paraíso - Terminal Campo Limpo

Uma requisição à API da SPTrans solicitando a posição de ônibus de uma linha devolve as localizações geográficas (latitude e longitude) de todos os seus veículos em um determinado momento de tempo. Um exemplo dos campos devolvidos no JSON estão na Lista 7.1, sendo hr o horário de referência em que as informações foram geradas e vs uma lista dos veículos da linha que estão circulando na cidade. Para cada veículo encontrado, temos a indicação se ele é acessível ou não para deficientes (campo a), o seu prefixo p, a latitude (py), a longitude (px) e o horário (ta) da captura da localização (no horário universal - UTC).

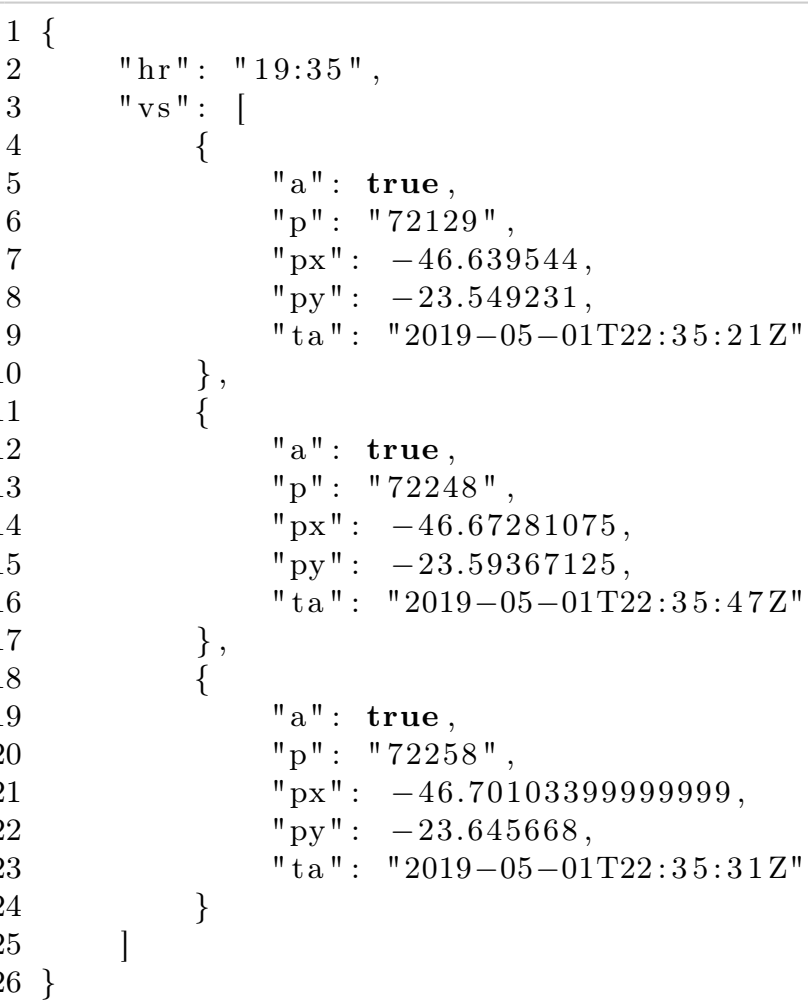

Lista 7.1: Amostra do JSON retornado na requisição de posição dos veículos de uma linha

A requisição contendo a previsão de chegada dos veículos de uma linha à determinada parada de ônibus foi realizada para todas as paradas das linhas escolhidas. A estrutura do JSON retornado para cada uma das paradas está ilustrado na Lista 7.2, sendo hr o horário de referência da geração das informações e $\mathrm{p}$ os dados referentes ao ponto de parada solicitado.

Para a parada escolhida temos o seu código identificador $(\mathrm{cp})$, o nome (np), a localização do veículo, isto é, latitude (py) e longitude(px) e informações (l) associadas à linha escolhida: letreiro completo (c), código da linha ( $c l$ ), sentido da operação ( $s$ l), letreiro de destino (lto) e de origem (lt1), a quantidade (qv) de veículos localizados para aquela linha, assim como a lista (vs) dos mesmos. 


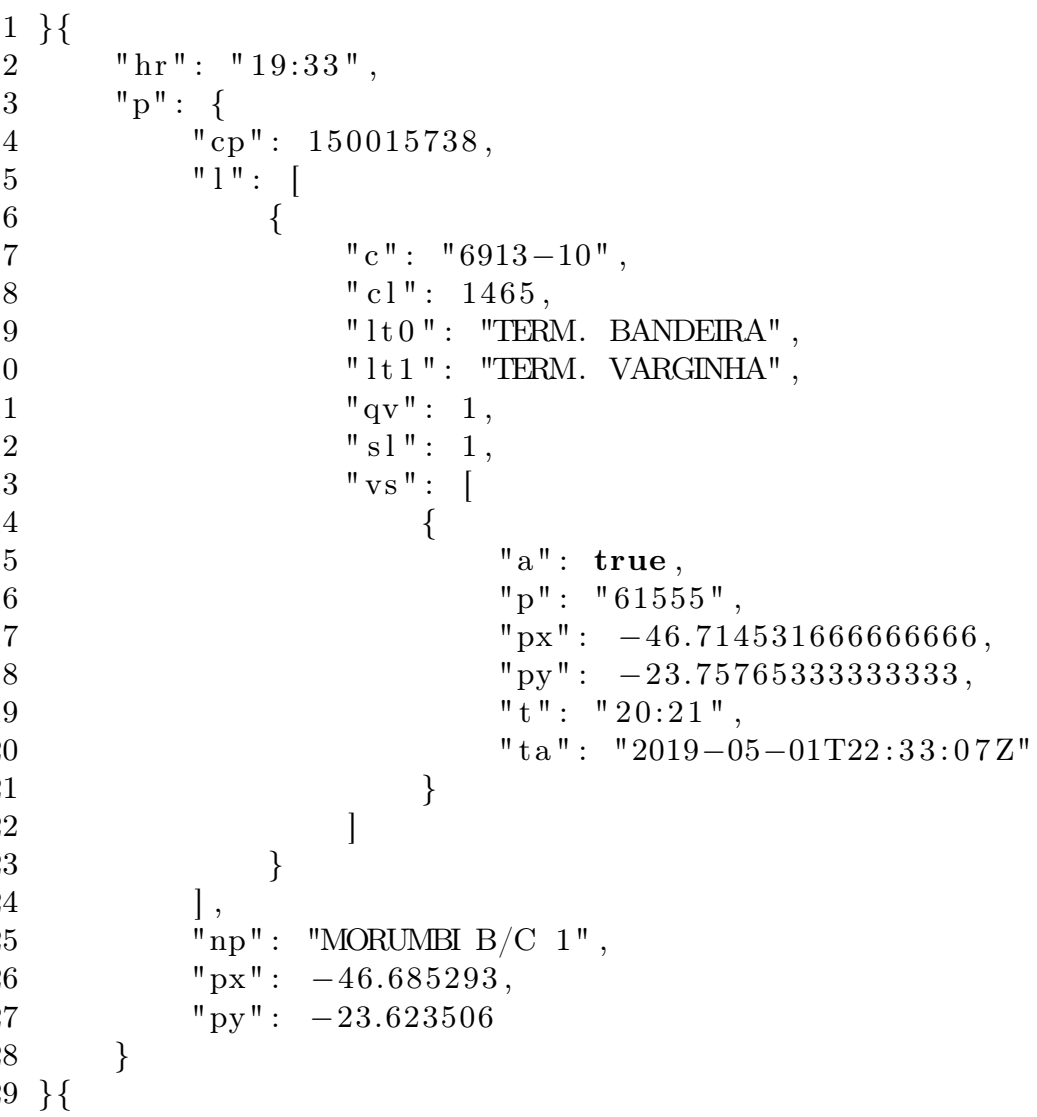

Lista 7.2: Amostra do JSON retornado na requisição de previsão de chegada para linha Terminal Bandeira - Terminal Varginha (1465) à parada Morumbi (150015738)

\subsection{Preparação dos dados}

A API da SPTrans não faz streamming das localizações dos ônibus, ela apenas traz respostas às requisições realizadas. Além disso, dependendo do horário do dia, os ônibus que estão circulando são reduzidos ou até mesmo não há veículos circulando, como de madrugada, por exemplo. Nesses casos, o vetor vs do JSON da resposta à requisição (que contém a localização dos veículos) vem vazio. Por essa razão, foram criados programas em Python para pré-processar os dados coletados da SPTrans a fim de limpá-los e simular, a partir deles, uma taxa de entrada de tempo real. Python foi utilizado como linguagem por possuir recursos que facilitam manipulação de arquivos de dados semiestruturados.

Os dados coletados referentes às posições dos ônibus foram transformados em tuplas do tipo

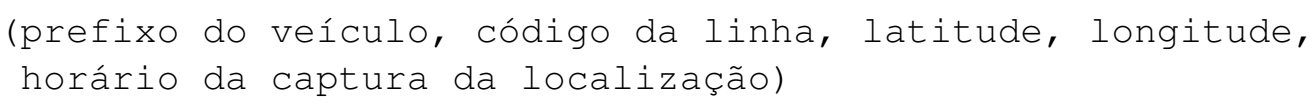

chamado no restante do texto de formato de localização. Para os dados de previsão de chegada, foram agrupadas paradas consecutivas de cada linha, criando tuplas do tipo

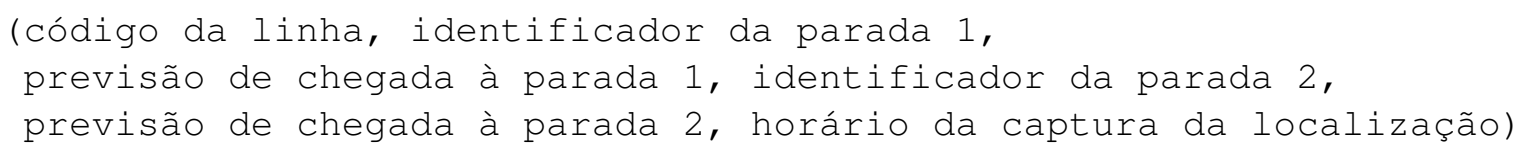

formato esse chamado aqui de previsão de chegada. Manteve-se apenas as tuplas que possuíam informação coletada para ambas as paradas, utilizando-se o mesmo horário de referência da geração da informação, indicado pelo último elemento da tupla. 
O programa Python que realiza a simulação da entrada de dados em tempo real envia ao Kafka - broker de mensagens escolhido para o estudo de caso - cerca de 1 registro a cada 50 milissegundos. Ou seja, o programa simula uma taxa de entrada de cerca de 20000 registros por segundo. Essa quantidade de registros por segundo foi escolhida porque, para ser considerado de tempo real, um sistema precisa ser capaz de processar de dezenas a centenas de milhares de eventos por segundo com latência de resposta de microssegundos a milissegundos (Stonebraker et al., 2005).

\subsection{Experimentos realizados}

Os experimentos descritos nesta seção utilizaram como entrada os dados coletados via API da SPTrans nos meses de abril, maio e junho de 2019. Ambos os experimentos realizaram processamento de dados em lote. Cada experimento consiste em um programa (dataflow) de análise de dados, especificado por meio da interface desenvolvida, mapeado de forma automática pelo sistema e depois executado diretamente nas ferramentas Flink e Apex.

Em cada experimento, para verificar a correção dos mapeamentos, primeiro executou-se os códigos mapeados em suas respectivas ferramentas. Depois, comparou-se os resultados obtidos nessas execuções com os resultados esperados, produzidos por um programa em Python que realiza as mesmas análises de dados feitas no dataflow do experimento. Além disso, para cada experimento, há gráficos que mostram os resultados obtidos a partir das execuções dos códigos mapeados e que permitem analisar sua coerência.

Para a execução dos experimentos foi utilizado um computador com:

- Processador i5-5200U, dois núcleos e quatro threads

- Memória RAM de 8GB, DDR3 Synchronous com frequência de $1600 \mathrm{MHz}$

- HDD com 5400RPM e taxa de transferência de até 600MB por segundo

- Sistema operacional Ubuntu 14.04.6 LTS

Os softwares utilizados foram:

- Apex Core: 3.7 e Apex Malhar: 3.8

- Flink: 1.5.4

- Hadoop: 2.8.4 (a versão precisou ser < 3.x para ser compatível com o Apex)

- Kafka: 0.8.2 para o Apex e 1.0.0 para o Flink

\subsubsection{Experimento 1: diferenças de previsão de chegada entre paradas conse- cutivas}

O dataflow construído para o Experimento 1 realiza processamento da dados em lote, utilizando conectores para o HDFS, saída padrão e uma transformação de dados. Mais detalhes sobre os passos que ele realiza estão a seguir:

- Leitura dos arquivos de um conjunto de diretórios do HDFS no formato / tmp / [AAAAMM] / (sendo AAAA o ano e MM o mês em que os dados foram coletados). Cada diretório possui 83 arquivos, pré-processados e não vazios, com registros no formato de previsão de chegada.

- Aplicação de uma transformação sobre cada registro dos dados de entrada, para obtenção da diferença de tempo das previsões de chegada no par de paradas consecutivas. Essa diferença é uma estimativa do tempo que se leva para ir de uma parada à parada seguinte.

- Escrita na saída padrão. 
- Escrita do resultado em arquivos no HDFS.

Os códigos para o Flink e Apex foram gerados automaticamente pelo sistema de mapeamento. Os arquivos resultantes foram executados e geraram o resultado na saída padrão. Ao executar o código no arcabouço Flink e no Apex com dados dos diretórios /tmp/[AAAAMM]/ do HDFS (meses de abril, maio e junho de 2019), salvou-se os conteúdos da saída padrão referentes às diferenças de previsões de chegada e comparou-se com os resultados escritos no HDFS.

A Tabela 7.1 mostra os conjuntos de dados de entrada utilizados no Experimento 1, enquanto a Tabela 7.2 sumariza os cenários experimentais executados. O dataflow do experimento, especificado por meio da interface, encontra-se na Lista 7.3.

\begin{tabular}{|l|l|l|}
\hline $\begin{array}{l}\text { Conjunto de } \\
\text { dados (dataset) }\end{array}$ & $\begin{array}{l}\text { Mês da coleta } \\
\text { dos dados }\end{array}$ & $\begin{array}{l}\text { Quantidade } \\
\text { de registros }\end{array}$ \\
\hline 1 & Abril de 2019 & 1.041 .324 \\
\hline 2 & Maio de 2019 & 2.377 .326 \\
\hline 3 & Junho de 2019 & 1.947 .510 \\
\hline
\end{tabular}

Tabela 7.1: Número de registros dos três datasets utilizados no Experimento 1

\begin{tabular}{|c|c|c|c|}
\hline Arcabouço & $\begin{array}{c}\text { Dataset } \\
\text { utilizado }\end{array}$ & Operação & $\begin{array}{c}\text { Conector(es) } \\
\text { de } \\
\text { saída }\end{array}$ \\
\hline Apex & 1 & \multirow{6}{*}{$\begin{array}{l}\text { Diferença } \\
\text { das } \\
\text { previsões }\end{array}$} & \multirow{6}{*}{$\begin{array}{l}\text { Saída } \\
\text { padrão }\end{array}$} \\
\hline Flink & 1 & & \\
\hline Apex & 2 & & \\
\hline Flink & 2 & & \\
\hline Apex & 3 & & \\
\hline Flink & 3 & & \\
\hline Apex & 1 & \multirow{6}{*}{$\begin{array}{c}\text { Diferença } \\
\text { das } \\
\text { previsões }\end{array}$} & \multirow{6}{*}{$\begin{array}{c}\text { Saída } \\
\text { padrão }+ \\
\text { escrita } \\
\text { em arquivos } \\
\text { do HDFS }\end{array}$} \\
\hline Flink & 1 & & \\
\hline Apex & 2 & & \\
\hline Flink & 2 & & \\
\hline Apex & 3 & & \\
\hline Flink & 3 & & \\
\hline
\end{tabular}

Tabela 7.2: Cenários de execução do Experimento 1 


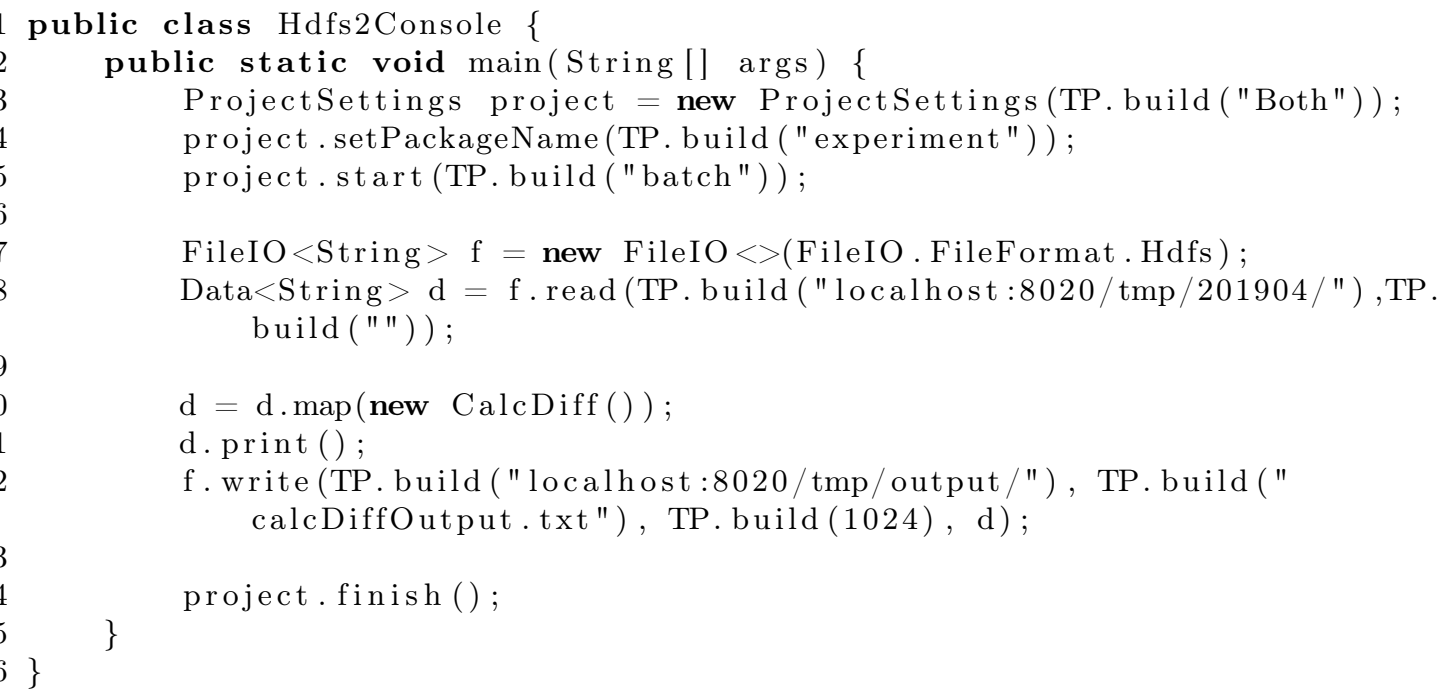

Lista 7.3: Dataflow do Experimento 1 especificado por meio da interface

Realizando-se análises sobre os dados gerados como resultado desse experimento, isto é, análises sobre as diferenças das previsões de chegada dos pares de paradas consecutivas, foi possível notar que havia alguns outliers nos dados de entrada, dados que diferiam significativamente dos demais observados. Por exemplo: analisando-se os tempos previstos entre as paradas de ônibus com identificadores 260016860 e 340015333 da linha identificada por 32772, boa parte dos tempos não passava de sessenta minutos. Contudo, alguns resultados apresentavam previsões com valores de 1415 minutos, ou seja, quase um dia inteiro. Claramente tratavam-se de dados com erros, visto que um ônibus não levaria um dia completo para ir de uma parada à seguinte. Foi realizada uma limpeza para remoção dos outliers e depois calculou-se a média e o erro padrão para os dados limpos.

Os gráficos presentes nas figuras 7.1 e 7.2 mostram o tempo médio em minutos (com intervalo de confiança de 99\%) que um ônibus leva entre duas paradas consecutivas para cada uma das seis linhas nos meses de abril, maio e junho de 2019. Como os erros padrão são pequenos para as seis linhas analisadas, os intervalos de confiança também são reduzidos e, consequentemente, difíceis de se ver nos gráficos. A fim de melhorar a legibilidade, os números que representam os limites inferior e superior também foram exibidos nos gráficos. Pode-se observar nos gráficos que os tempos médios variam pouco em função do mês (menos de meio segundo de variação). Estão entre 1,5 e 2,5 segundos para os três meses das seis linhas analisadas. Esse tempo pequeno pode ser explicado pelo fato das paradas analisadas serem consecutivas.

O Apêndice B realiza uma comparação entre os tempos de execução do experimento atual para ambos os arcabouços, com intervalo de confiança de $99 \%$. Para isso, o experimento foi executado trinta vezes para cada arcabouço, usando os conjuntos de dados da Tabela 7.1. 

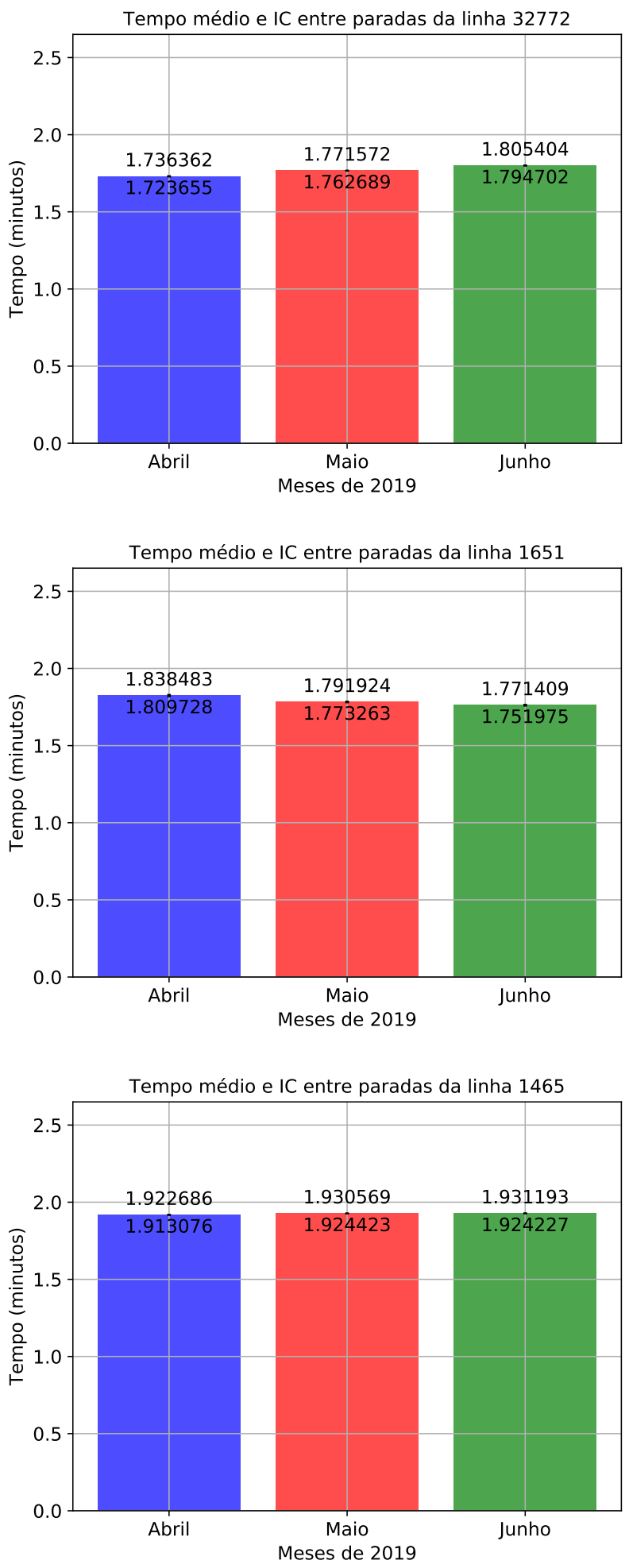

Figura 7.1: Tempo médio (com intervalo de confiança de 99\%) que os ônibus das linhas 32772, 1651 e 1465 levam entre duas paradas consecutivas nos meses de abril, maio e junho de 2019 

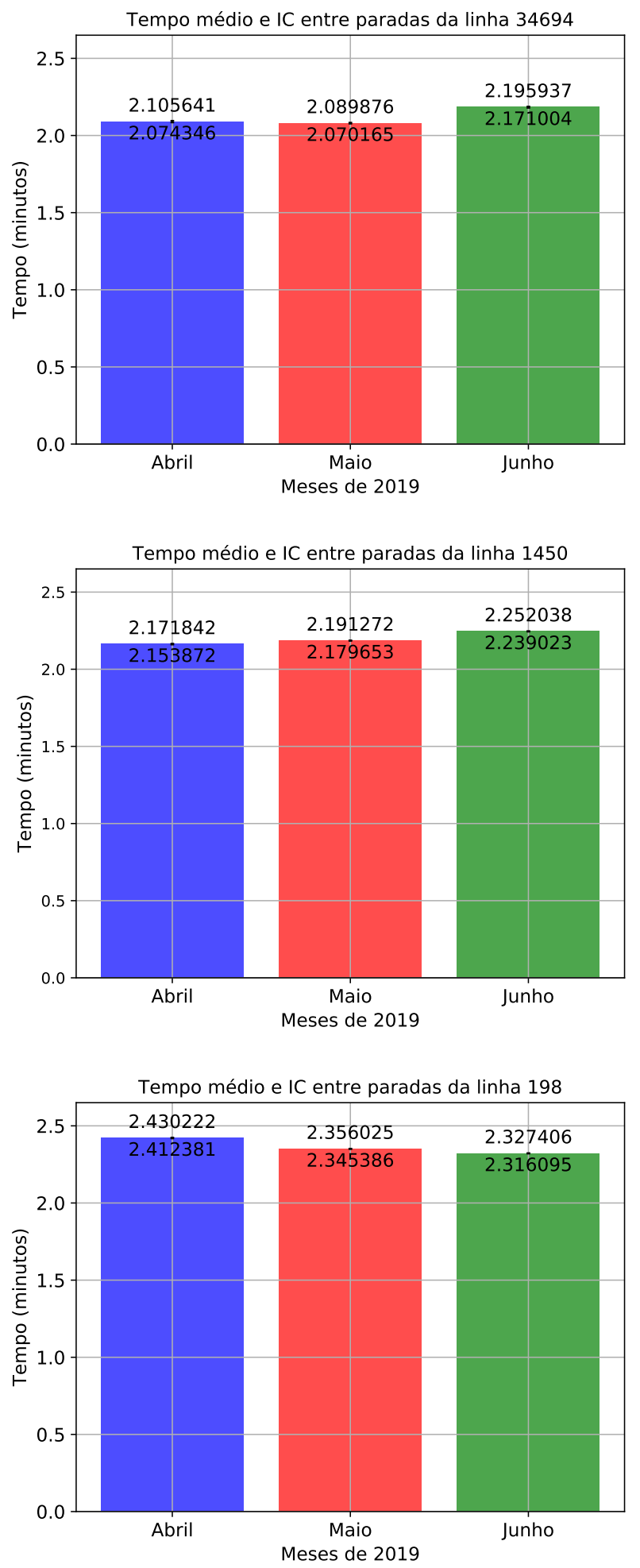

Figura 7.2: Tempo médio (com intervalo de confiança de 99\%) que os ônibus das linhas 34694, 1450 e 198 levam entre duas paradas consecutivas nos meses de abril, maio e junho de 2019 


\subsubsection{Experimento 2: menores e maiores tempos previstos entre paradas con- secutivas}

O dataflow desse experimento tem como objetivo obter, para cada linha de ônibus, os tempos máximo e mínimo previstos entre pares de paradas consecutivas $x_{i}$ e $x_{i+1}$ da linha e utiliza dados obtidos no experimento anterior.

O arquivo gerado como saída do Experimento 1 é composto por três colunas descritas a seguir:

1. Chave de um par de paradas consecutivas de uma linha, que é uma cadeia de caracteres no formato linha - parada $x_{i}-$ parada $x_{i+1}$

2. A diferença entre os tempos de previsão de chegada nas paradas $x_{i+1}$ e $x_{i}$

3. Data e horário de quando as previsões de chegada foram coletadas

As diferenças dos tempos das previsões de chegada nesse arquivo possuem alguns valores atípicos (outliers), muito divergentes dos demais, que apontam para erros nos dados coletados da SPTrans, como constatado no Experimento 1. Esses valores discrepantes foram eliminados do arquivo e, por isso, as quantidades de registros nos datasets usados no Experimento 2, listadas na Tabela 7.3, são menores que as quantidades do Experimento 1, representadas na Tabela 7.1.

Os dataflows para os cálculos de mínimo e máximo são bem parecidos, mudando apenas na etapa do cálculo realizado sobre os dados. As etapas do processamento são as seguintes:

- Leitura de arquivo do HDFS;

- Tratamento dos registros por uma função map, que mantém a primeira coluna como cadeia de caracteres e converte a segunda para um tipo numérico;

- Cálculo do mínimo ou do máximo;

- Escrita do resultado da operação em um arquivo de texto.

Pode-se notar que a estrutura descrita é a de um pipeline, composto pela leitura dos dados do HDFS, uma sequência de operações de transformação e a produção de uma saída. A primeira transformação gera resultados intermediários que são utilizados como entrada da seguinte.

Os resultados armazenados nos arquivos de saída gerados pelos dois arcabouços foram iguais aos resultados esperados. Os cenários executados estão listados na Tabela 7.4, enquanto a especificação do dataflow utilizando-se a interface está na Lista 7.4.

\begin{tabular}{|l|l|l|}
\hline $\begin{array}{l}\text { Conjunto de } \\
\text { dados (datasets) }\end{array}$ & $\begin{array}{l}\text { Mês da coleta } \\
\text { dos dados }\end{array}$ & $\begin{array}{l}\text { Quantidade } \\
\text { de registros }\end{array}$ \\
\hline 1 & Abril de 2019 & 1.008 .913 \\
\hline 2 & Maio de 2019 & 2.306 .336 \\
\hline 3 & Junho de 2019 & 1.877 .299 \\
\hline
\end{tabular}

Tabela 7.3: Número de registros dos três datasets utilizados no Experimento 2 


\begin{tabular}{|c|c|c|}
\hline Arcabouço & $\begin{array}{l}\text { Dataset } \\
\text { Utilizado }\end{array}$ & Operação \\
\hline Apex & \multirow{4}{*}{ 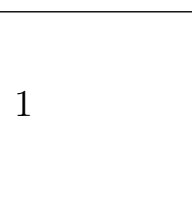 } & \multirow{2}{*}{ Min } \\
\hline Flink & & \\
\hline Apex & & \multirow{2}{*}{ Max } \\
\hline Flink & & \\
\hline Apex & \multirow{4}{*}{2} & \multirow{2}{*}{ Min } \\
\hline Flink & & \\
\hline Apex & & \multirow{2}{*}{ Max } \\
\hline Flink & & \\
\hline Apex & \multirow{4}{*}{3} & \multirow{2}{*}{ Min } \\
\hline Flink & & \\
\hline Apex & & \multirow{2}{*}{ Max } \\
\hline Flink & & \\
\hline
\end{tabular}

Tabela 7.4: Cenários de execução do Experimento 2

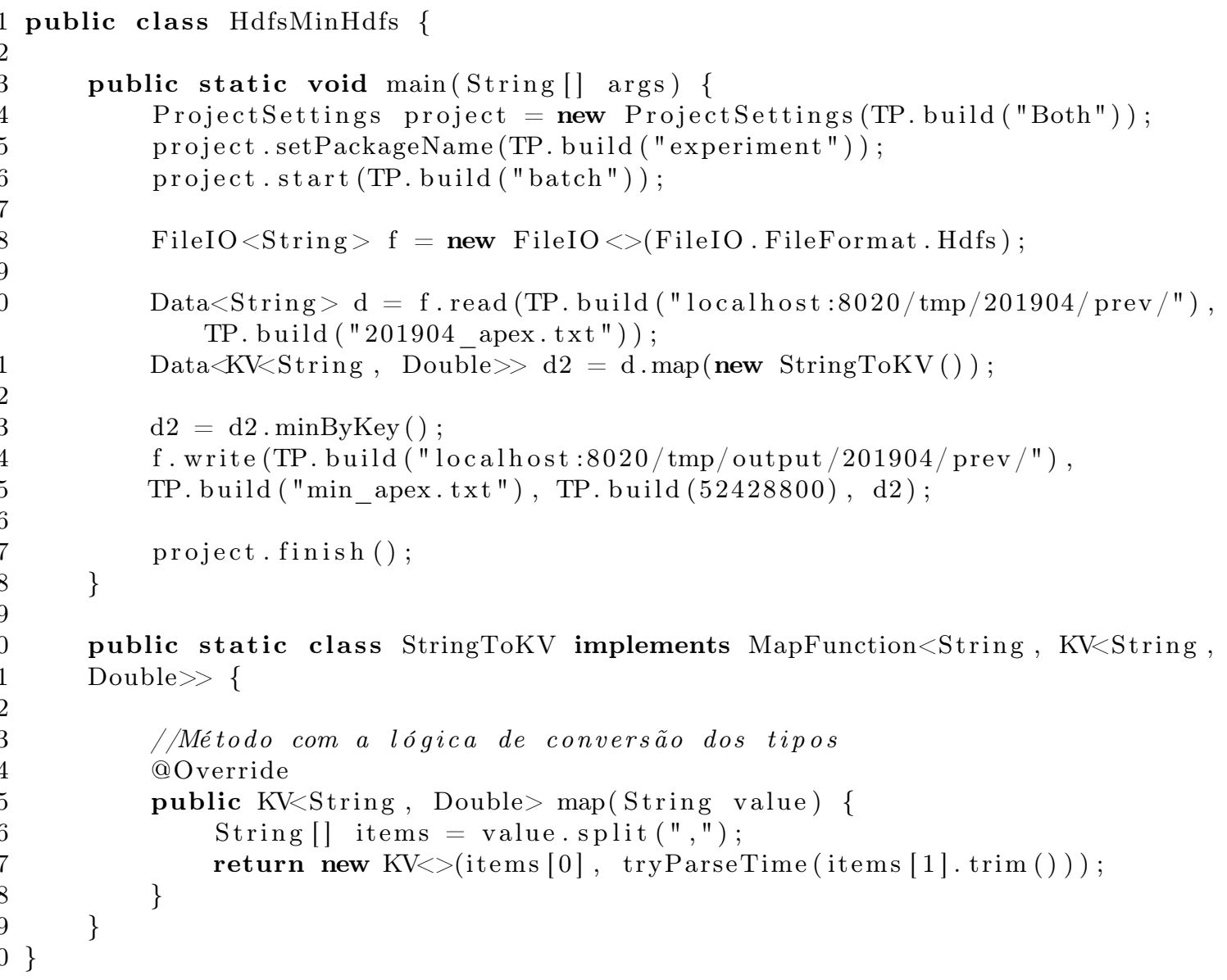

Lista 7.4: Dataflow do Experimento 2 especificado por meio da interface para cálculo dos mínimos

O Experimento 2 gerou como resultado os valores de máximo e mínimo de tempo que se levou entre cada par de paradas consecutivas das seis linhas analisadas. Para possibilitar a visualização parcial dos resultados deste experimento, três gráficos foram criados - um para cada mês analisado, de uma das seis linhas, a 1450. A escolha dessa linha se deve à sua quantidade de paradas de ônibus consecutivas analisadas, que totalizou 15. Para essa quantidade de paradas, o gráfico correspondente não é demasiadamente denso, nem contém pouca informação. Por outro lado, para a linha 1465, por exemplo, foram coletados dados de 35 paradas; seu gráfico correspondente é pouco legível. 
O objetivo das Figuras 7.3, 7.4 e 7.5 é mostrar que paradas diferentes podem ter maior ou menor tempo de espera, visto que diferentes circunstâncias podem afetá-las, como a distância entre as paradas consecutivas. Pode-se perceber que os valores máximos foram menores ou iguais a quinze minutos, exceto para o par 9-10 no mês de abril e pares 6-7 e 7-8 no mês de maio de 2019. Os valores mínimos se mantiveram constantes para os três meses, enquanto os valores médios foram bem similares, indicando que houve pouca variação de um mês para outro para os meses analisados.

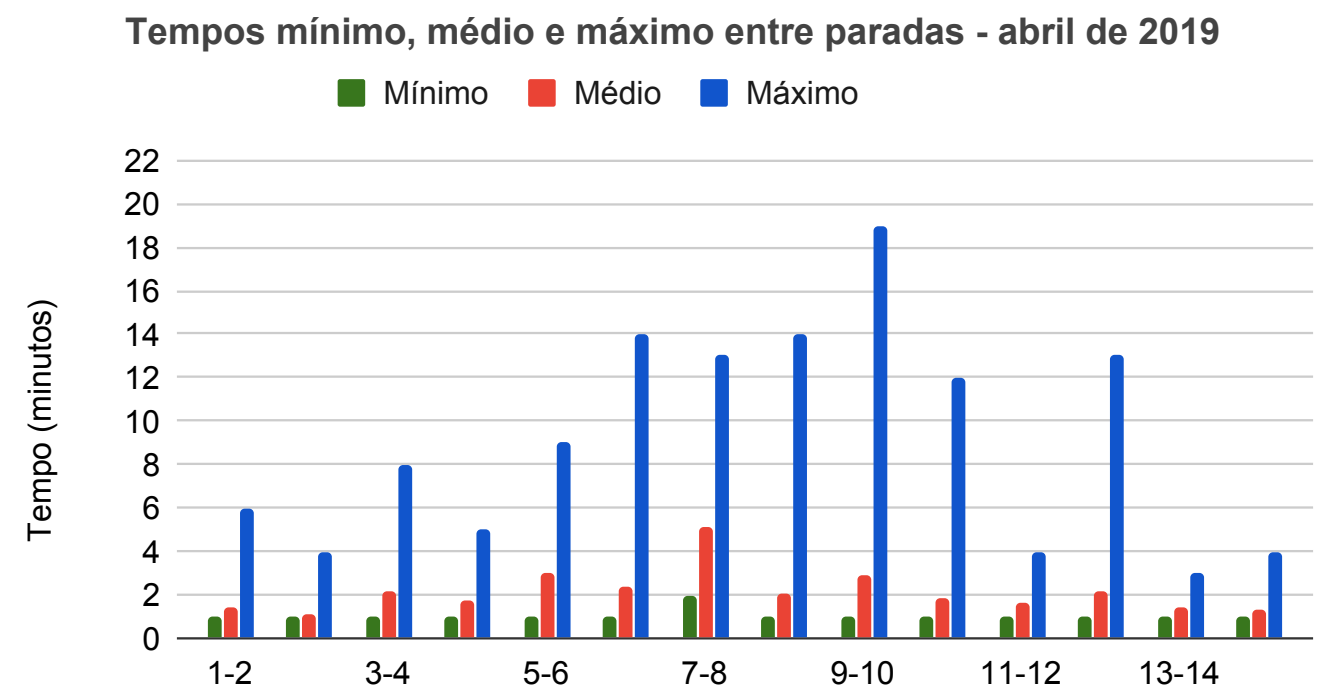

Par de paradas consecutivas

Figura 7.3: Tempos minimo, médio e máximo que os ônibus da linha 1450 levam entre duas paradas consecutivas, analisados com dados do mês de abril de 2019

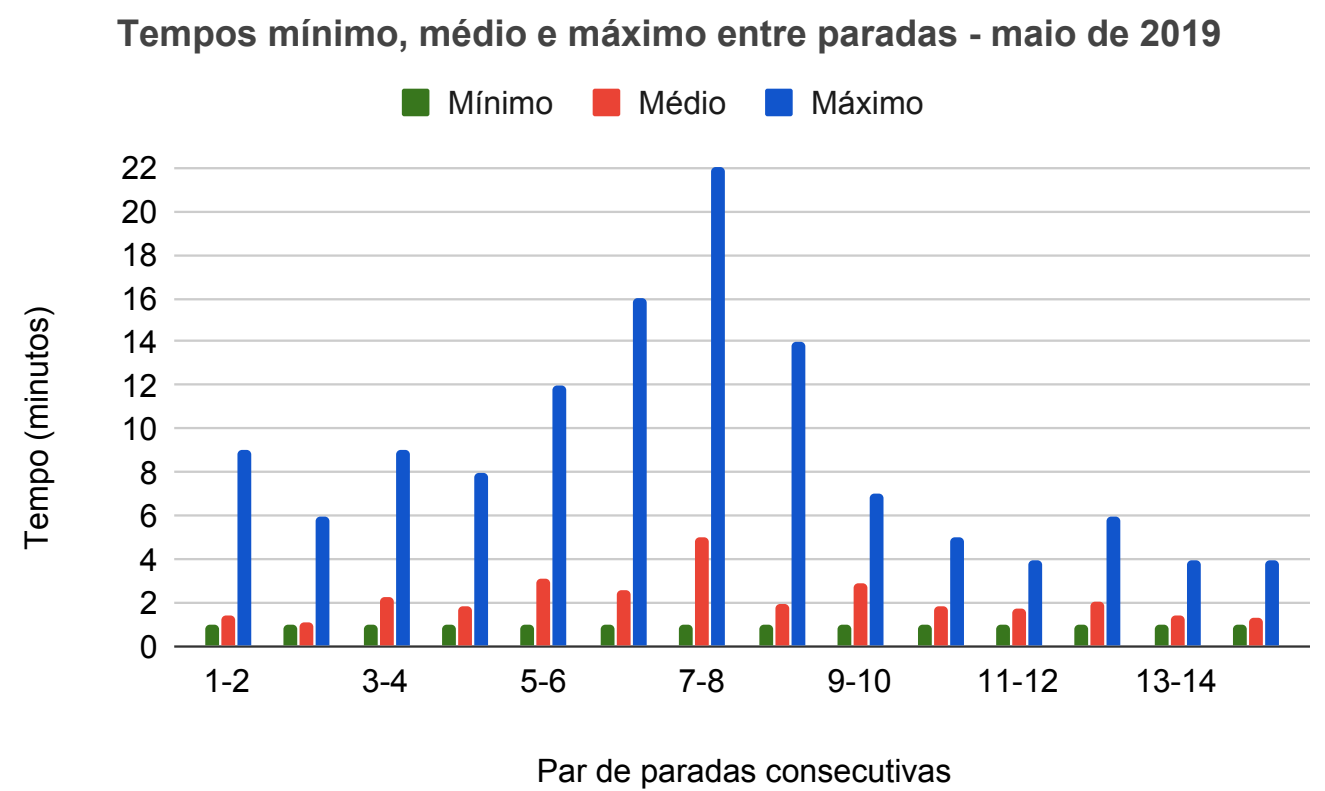

Figura 7.4: Tempos mínimo, médio e máximo que os ônibus da linha 1450 levam entre duas paradas consecutivas, analisados com dados do mês de maio de 2019 


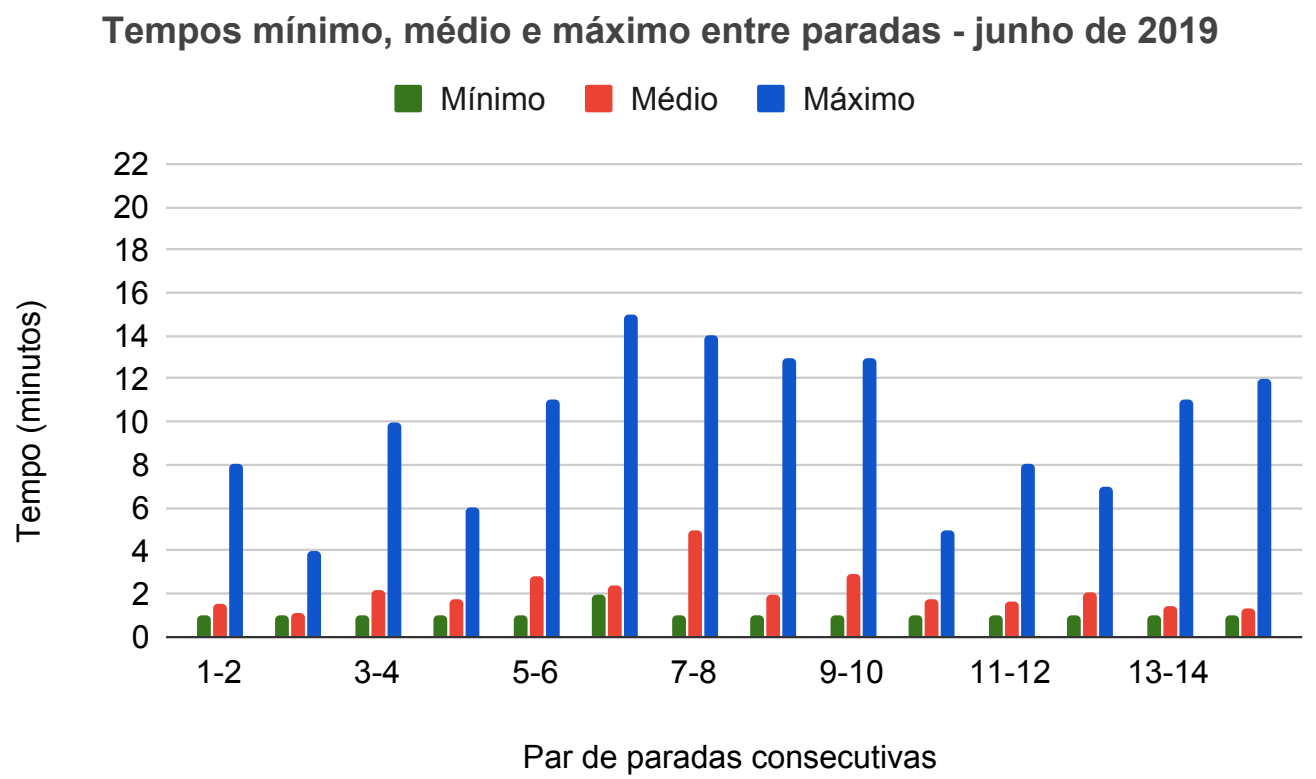

Figura 7.5: Tempos mínimo, médio e máximo que os ônibus da linha 1450 levam entre duas paradas consecutivas, analisados com dados do mês de junho de 2019

\subsection{Estudo de caso: sistema de previsão de horários de chegadas de ônibus}

A fim de testar o sistema de abstração desenvolvido neste trabalho em um cenário de uso mais complexo, desenvolveu-se como estudo de caso uma aplicação que fornece previsões de horários de chegada de ônibus às paradas em que os usuários do transporte público de São Paulo se encontram. A aplicação também fornece a quantidade de ônibus de uma dada linha que passam nas paradas escolhidas em um intervalo de tempo. Esse sistema precisa processar grandes volumes de dados em tempo real.

A Figura 7.6 é uma ilustração do dataflow desse sistema de previsões. Os retângulos representam operadores de processamento e as setas rotuladas representam fluxos de dados de stream, com os seus respectivos atributos.

A entrada de dados no sistema funciona da seguinte forma: a localização (latitude e longitude) dos ônibus é coletada via GPS e enviada para SPTrans, a qual disponibiliza uma API para o acesso aos dados. Por meio dessa API, um stream de dados é coletado e direcionado para o Kafka, utilizado como operador de entrada para o dataflow do estudo de caso.

Os retângulos numerados representam operadores de transformação sobre os dados. O primeiro (Operador 1 da Figura 7.6) recebe o fluxo de dados advindos do Kafka; ele atualiza a localização do respectivo ônibus sempre que um registro novo entra no sistema. A saída desse operador também é um stream, que funciona como entrada de dados para o Operador 2, responsável por identificar se o ônibus se encontra ou não em uma parada, realizando um filtro. Se não estiver em uma parada de ônibus, o operador não faz nada com os dados recebidos; contudo, caso esteja, algumas ações são executadas: atualização da estrutura de dados que contém informações das últimas paradas de ônibus, escrita dos dados no Kafka e envio dos mesmos para dois operadores subsequentes, o que atualiza a quantidade de ônibus em circulação em cada linha (Operador 3 na Figura 7.6) e o que atualiza a previsão de chegada dos ônibus (Operador 4).

O Operador 3 utiliza janelas de tempo e assim, sempre que o intervalo de tempo definido para ela é alcançado, o resultado da transformação é enviado para a saída padrão. O Operador 4 atualiza a previsão de chegada dos ônibus de uma linha nas paradas em que eles passam. Sempre que um ônibus de uma linha X encontra-se em alguma parada, isso funciona como um gatilho para o 


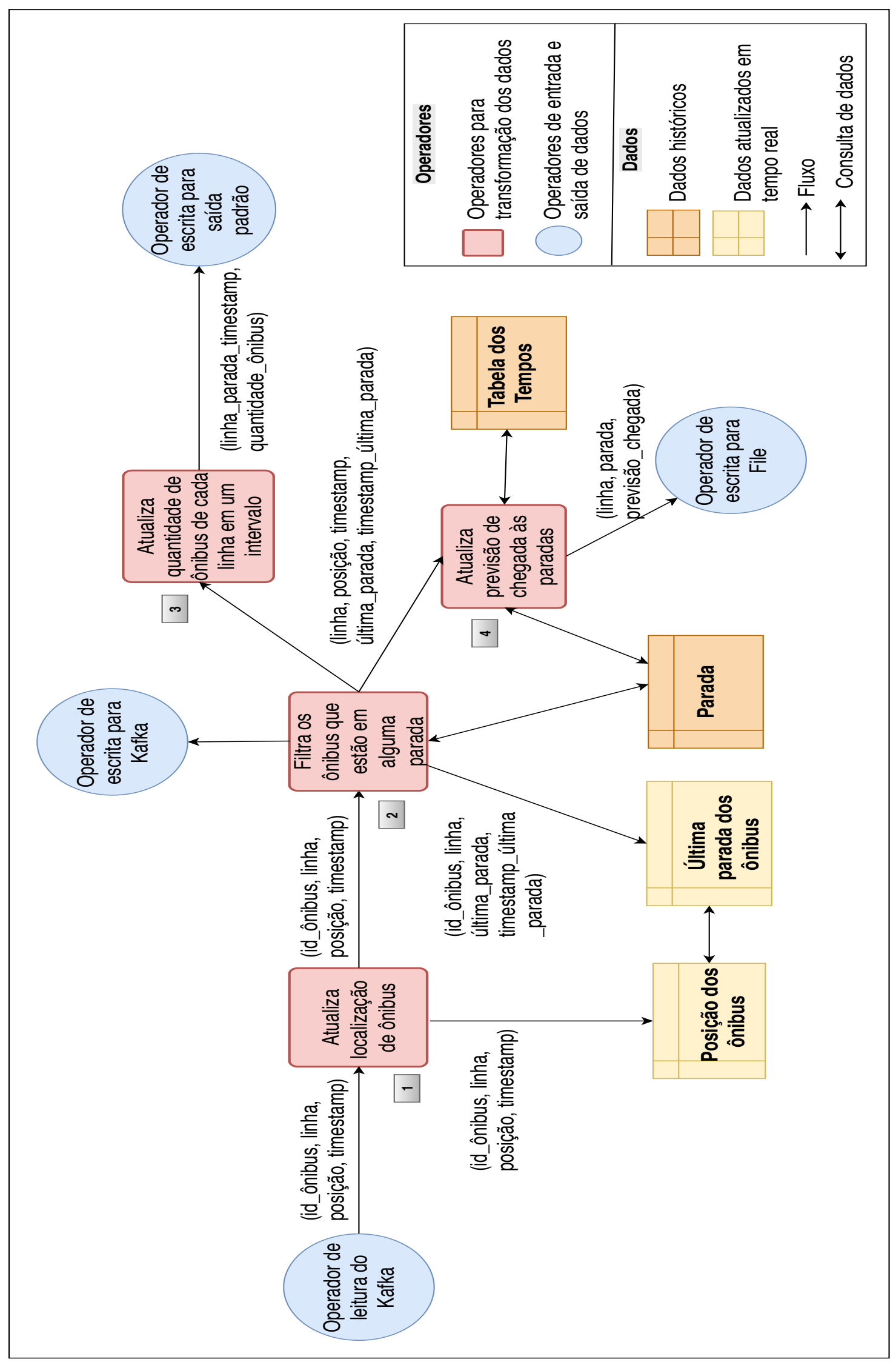

Figura 7.6: Dataflow do sistema servidor da aplicação de mobilidade urbana. 
Operador 4 calcular a previsão de chegada desse ônibus em suas paradas seguintes, escrevendo a previsão em um arquivo de saída.

Alguns operadores podem ser replicados, de modo a permitir paralelismo, como é o caso do Operador 2. Como o dataflow recebe um fluxo de dados, cada réplica identifica se o ônibus do stream atual está ou não em uma parada de ônibus. Os streams são analisados assim que chegam ao dataflow, independentemente de qual das seis linhas de ônibus os dados se refiram. As réplicas podem gerar entradas para os Operadores 3 e 4, os quais também podem ser replicados e desempenhar suas respectivas funções, de forma a tornar a execução mais eficaz. Dessa maneira, é viável explorar o potencial de paralelismo que as ferramentas de processamento de Big Data oferecem.

O dataflow do estudo de caso usa todos os tipos de recursos implementados na interface de abstração desenvolvida neste trabalho: entrada e saída de dados de diferentes conectores (Kafka, arquivos, console), transformações sobre dados de tempo real e históricos, utilizando-se Map, Reduce, janelas e funções definidas por usuário.

A Lista 7.5 mostra o dataflow especificado por meio da interface desenvolvida. O mesmo dataflow foi codificado usando-se diretamente as APIs das ferramentas de Big Data Flink e Apex, para que se pudesse comparar as especificações por meio de métricas de Engenharia de Software para análise de código. Com isso, foi possível analisar vantagens e desvantagens de se utilizar a interface desenvolvida, no lugar de implementar diretamente nos arcabouços de Big Data. Os resultados dessa análise são apresentados no Capítulo 8.

Os resultados da execução no Flink e no Apex dos códigos mapeados de forma automática a partir do dataflow especificado com a interface foram iguais aos da execução dos códigos escritos diretamente, indicando que o sistema de abstração funcionou corretamente no estudo de caso analisado. 


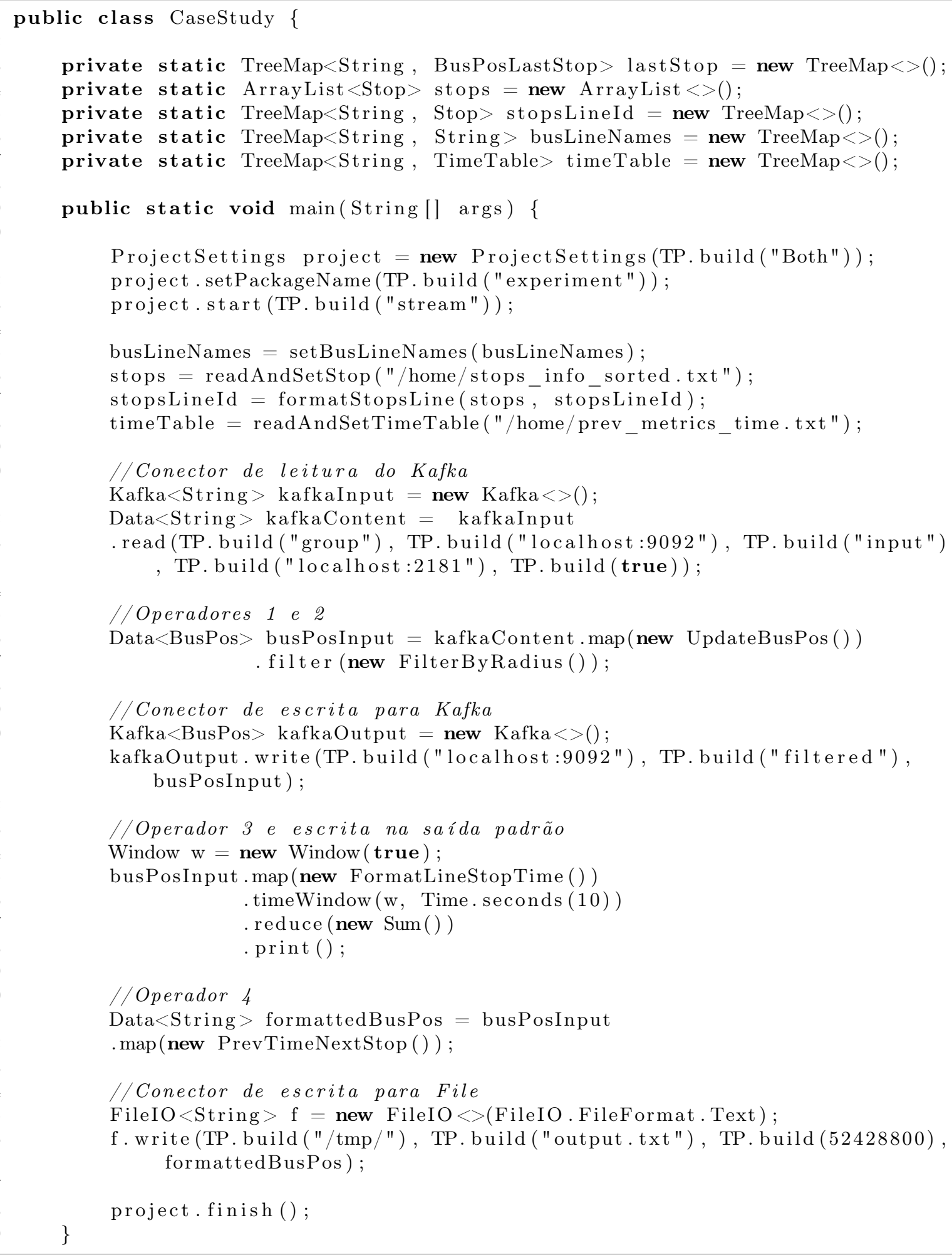

Lista 7.5: Dataflow do estudo de caso especificado por meio da interface 


\subsubsection{Análises dos resultados das execuções}

Os dados de saída do dataflow do estudo de caso são previsões de chegada dos ônibus das linhas analisadas, bem como a quantidade de ônibus em circulação de cada linha em um certo intervalo de tempo. Uma amostra da previsão de chegada encontra-se na Lista 7.6, enquanto resultados comparando as quantidades de ônibus por linha estão ilustrados nos gráficos das Figuras 7.7, 7.8 e 7.9 .

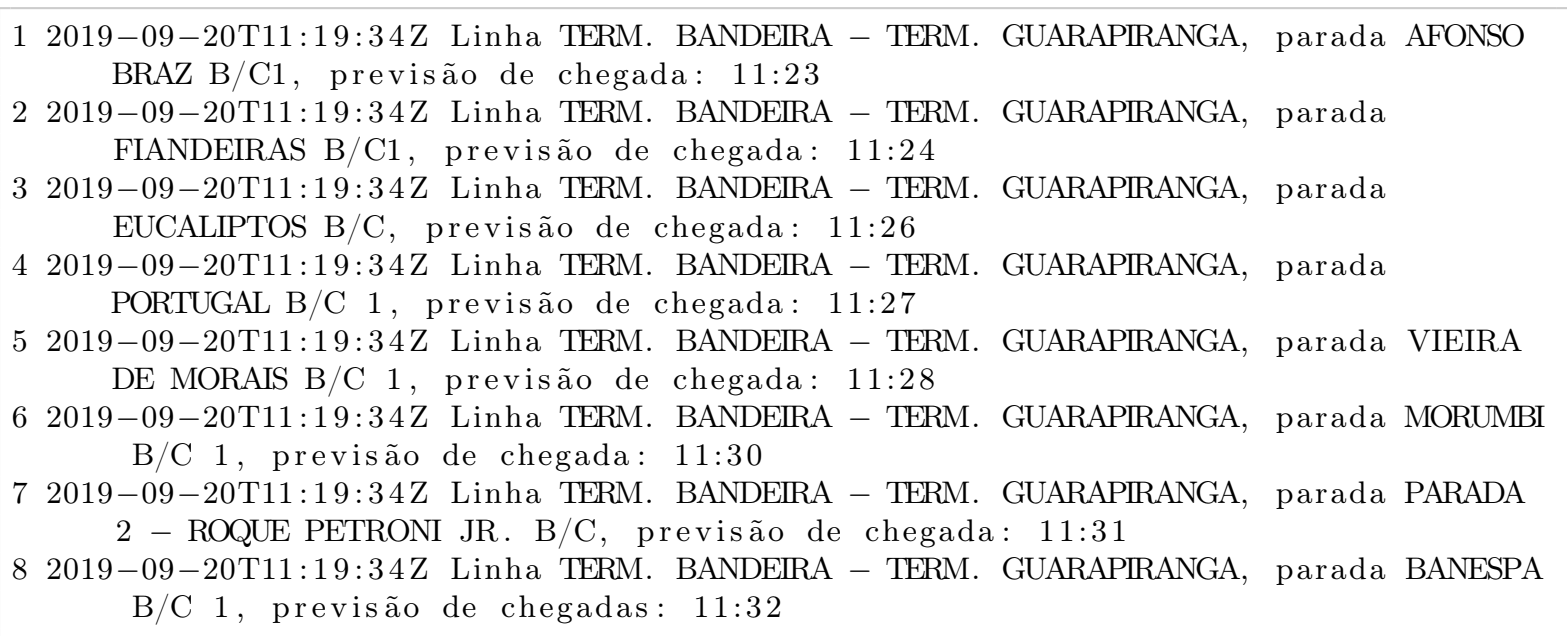

Lista 7.6: Amostra das previsões de chegada do próximo ônibus da Linha Terminal Bandeira - Terminal Guarapiranga

A Lista 7.6 contém uma amostra das previsões de chegada calculadas para as paradas da linha Terminal Bandeira - Terminal Guarapiranga para um usuário que estava à espera de um ônibus da linha no dia 20 de setembro às 11h19. A amostra também ilustra dados que poderiam ser exibidos em painéis eletrônicos nas paradas.

Os gráficos das Figuras 7.7 e 7.8 ilustram as quantidades médias de ônibus das seis linhas analisadas distribuídas ao longo do dia com dados do mês de setembro. Percebe-se que há uma clara diminuição na quantidade de ônibus aos finais de semana. Além disso, a linha 1651 tem quantidade de ônibus bem maior se comparada às quantidades das demais linhas.

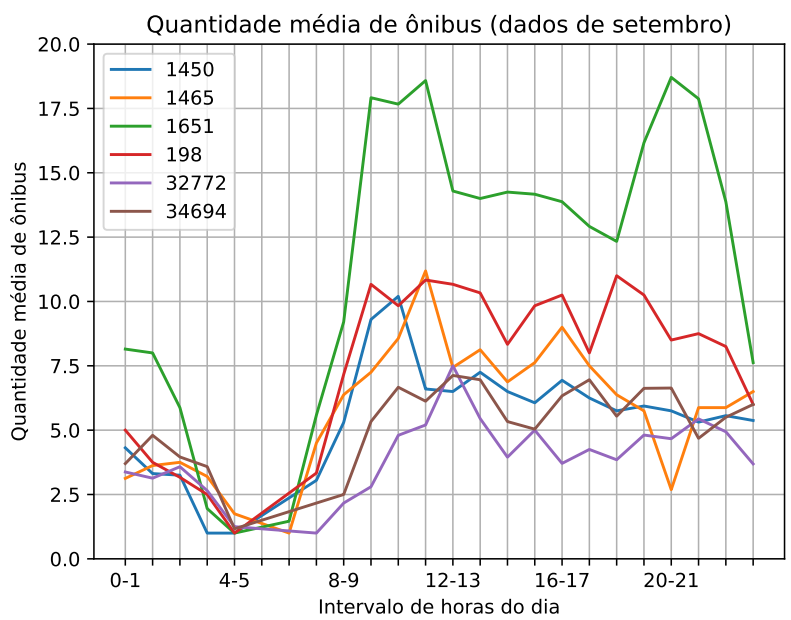

Figura 7.7: Quantidade média de ônibus ao longo do dia para seis linhas de ônibus em setembro de 2019, considerando-se apenas dias úteis

Nos gráficos da Figura 7.9, por questões de legibilidade, apenas três das seis linhas foram escolhidas para serem analisadas mais detalhadamente. Optou-se pela escolha das seguintes linhas por possuírem características diferentes entre si, como variação na duração da viagem completa 


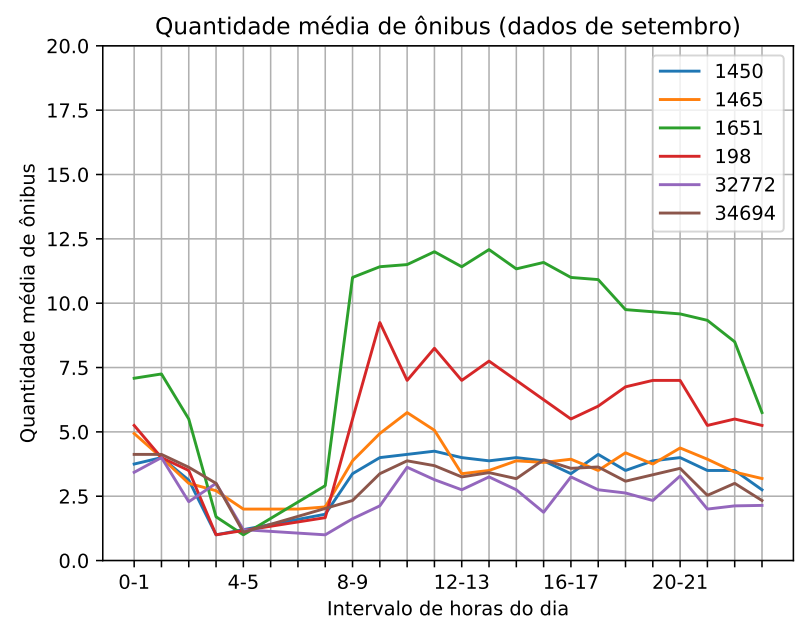

Figura 7.8: Quantidade média de ônibus ao longo do dia para seis linhas de ônibus em setembro de 2019, considerando-se apenas finais de semana e feriados

(estimativas obtidas no site da SPTrans (SPTrans, 2020)) e na região da cidade por onde passam:

- 1465: Terminal Bandeira - Terminal Varginha, o tempo estimado da viagem no entrepico é de 102 minutos, em dias de semana.

- 1651: Terminal Mercado - Terminal Sacomã, o tempo estimado de viagem é de 18 minutos, independentemente do horário e do dia da semana, por se tratar de uma linha expressa.

- 34694: Paraíso - Terminal Campo Limpo, leva o tempo estimado de 95 minutos no entrepico, em dias de semana. Passa por trechos de bastante movimento da cidade, como a Avenida Paulista.

Os três gráficos da Figura 7.9 evidenciam que há períodos do dia com maior quantidade de ônibus: nas faixas das $8 \mathrm{~h}$ às $12 \mathrm{~h}$, das $16 \mathrm{~h}$ às $18 \mathrm{~h}$ e, particularmente para a linha Terminal Mercado - Terminal Sacomã (1651), na faixa das 19h às 21h. Os horários mencionados são horários de pico ou próximos a eles e, portanto, espera-se que haja maior quantidade de ônibus nesses períodos. Os gráficos também indicam que o período com menor quantidade de ônibus é o da madrugada (das $3 \mathrm{~h}$ às $6 \mathrm{~h}$ ) como esperado. Das $12 \mathrm{~h}$ às $15 \mathrm{~h}$ também há uma queda na quantidade de ônibus, porém bem menos expressiva em comparação com os horários da madrugada. Os valores médios de ônibus calculados por intervalo de hora para as linhas Terminal Bandeira - Terminal Varginha e Paraíso Terminal Campo Limpo mantiveram-se similares para os três meses. Para a linha Terminal Mercado - Terminal Sacomã os valores também foram bem próximos, mas os valores mais altos foram cerca de dez em julho, treze em agosto e dezesseis em setembro. Essa diferença pode ser reflexo do período de férias escolares, que compreende julho e o começo de agosto. Para essa linha também, um outro ponto a se observar é que, por ser um expresso, com poucas paradas e sem trânsito no trajeto, um mesmo ônibus consegue fazer cerca de duas viagens completas no período de uma hora (ida e volta). Assim, mesmo se possuir menor quantidade de ônibus, essa linha consegue garantir frequência nas paradas de ônibus similar às de outras linhas mais extensas que tenham mais ônibus.

\subsection{Considerações sobre o capítulo}

Foram realizados experimentos e foi desenvolvido um estudo de caso para verificar o mapeamento automático e os resultados da execução de diferentes tipos de dataflows especificados por meio da interface desenvolvida. Esses dataflows usaram estruturas de processamento, pipeline e distribuição de dados. Os experimentos e o estudo de caso utilizaram diferentes tipos de conectores (arquivo, 

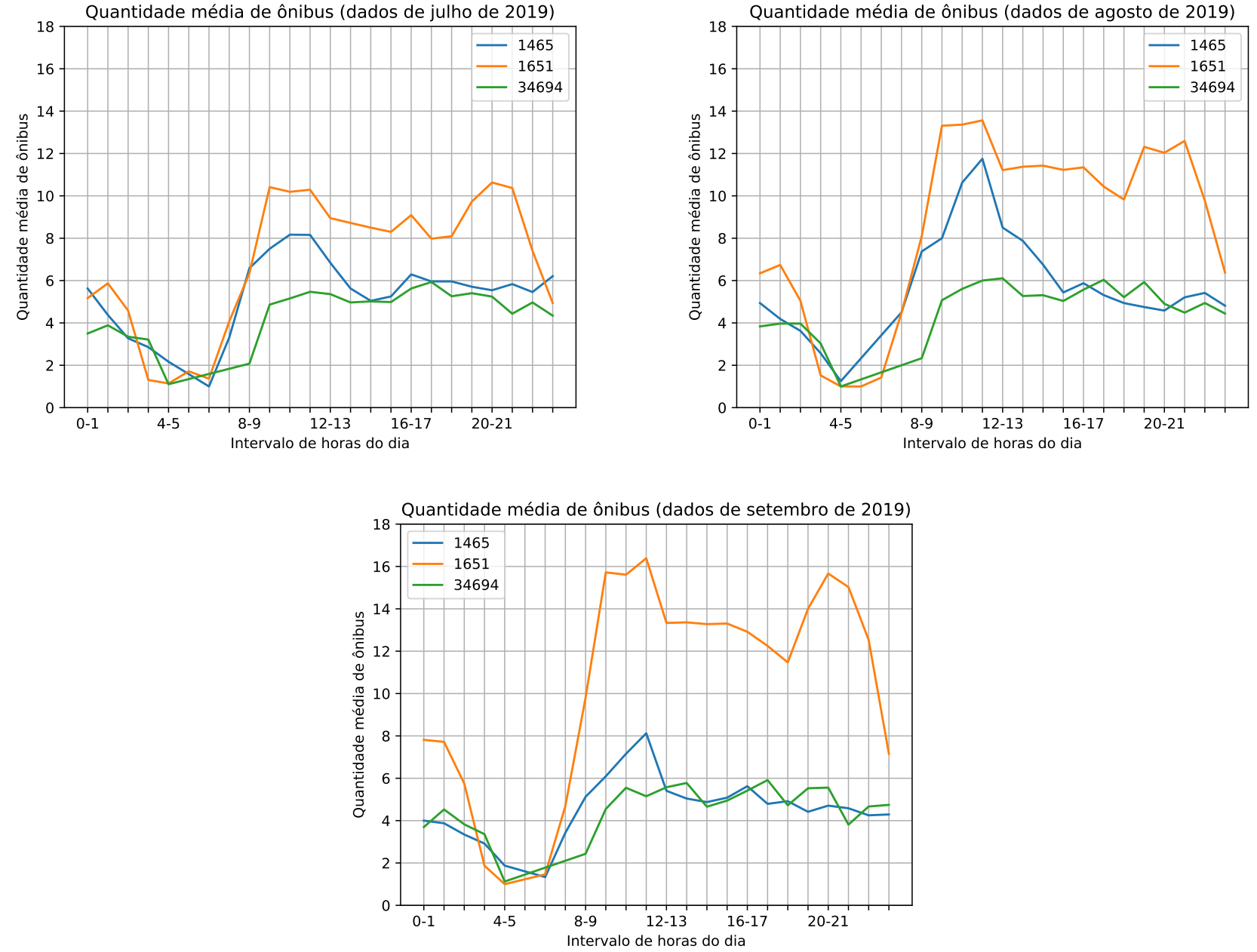

Figura 7.9: Quantidade média de ônibus que passam nas paradas ao longo do dia, para as três linhas analisadas, em julho, agosto e setembro de 2019 
HDFS, Kafka e saída padrão) e transformações (como filtro, mapeamento e redução). Em todos eles foram utilizados como entrada dados reais do sistema de transporte público da cidade de São Paulo, coletados por meio da API da SPTrans.

Os dados utilizados nos experimentos são referentes aos meses de abril, maio e junho de 2019, sendo que o mês de abril contém a menor quantidade de registros, pois a coleta foi iniciada na segunda metade do mês. Os dados gerados como saída nos dataflows dos experimentos foram usados no estudo de caso detalhado na Seção 7.4 como dados históricos. Além disso, foram usados dados de julho, agosto e setembro de 2019 no estudo de caso para simular a chegada de dados em tempo real.

O estudo de caso explorou um cenário mais complexo para fornecer previsões de horários de chegada de ônibus às paradas de seis linhas de ônibus do transporte público de São Paulo, bem como a quantidade de ônibus que passam por essas paradas em um intervalo de tempo. 


\section{Capítulo 8}

\section{Análise dos códigos-fonte do estudo de caso}

Como discutido no Capítulo 4, as ferramentas de Big Data disponibilizam APIs próprias para a especificação dos seus dataflows, que podem ser declarativas ou topológicas. Com uma API declarativa, os dataflows são expressos por uma álgebra de operadores que atuam sobre dados, enquanto que, com uma API topológica, eles são definidos explicitamente como grafos nos quais os nós de processamento são conectados por meio dos fluxos de dados. Assim, os códigos-fonte das especificações de um mesmo dataflow em diferentes APIs podem se diferenciar bastante uns dos outros tanto na sintaxe quanto no nível de abstração.

Este capítulo caracteriza e compara, por meio de métricas de análise de código-fonte, três especificações para o dataflow do estudo de caso apresentado na Seção 7.4: uma feita com a interface de abstração desenvolvida neste trabalho e as outras duas feitas diretamente nas APIs das ferramentas de Big Data de interesse (Apache Flink e Apache Apex). O objetivo dessa análise é evidenciar as vantagens que o uso da interface de abstração propiciou à especificação do dataflow.

\subsection{Métricas de código-fonte selecionadas}

As métricas de código-fonte são geralmente usadas para analisar a qualidade de softwares, havendo métricas para diferentes paradigmas de programação e que consideram diversas características do código, tais como complexidade, coesão, confiabilidade e usabilidade (para citar algumas).

Nuñez-Varela et al. (2017) fizeram uma revisão sistemática, selecionando 226 publicações referentes ao período de 2010 a 2015. Os autores concluíram que as métricas mais utilizadas são a de Chidamber e Kemerer, a quantidade de linhas de código e a complexidade ciclomática, sendo métricas bem conhecidas e consolidadas. Como o paradigma de orientação a objetos foi o utilizado para o desenvolvimento da interface e da biblioteca produzidos no presente trabalho, selecionou-se para as análises dos códigos do estudo de caso as dez métricas mais recorrentes para esse paradigma de programação, segundo Nuñez-Varela et al. (2017):

- Peso dos métodos por classe (WMC, de weighted methods for class)

- Acoplamento entre objetos (CBO, de coupling between objects)

- Falta de coesão nos métodos (LCOM, de lack of cohesion of methods)

- Profundidade da árvore de herança (DIT, de depth of inheritance tree)

- Linhas de código (LOC, de lines of code)

- Número de filhos (NOC, de number of children)

- Resposta de uma classe (RFC, de response for class) 
- Número de métodos (NOM, de number of methods)

- Complexidade Ciclomática (V(G))

- Número de atributos (NOA, de number of attributes)

A métrica Chidamber e Kemerer inclui seis das dez listadas: WMC, CBO, LCOM, DIT, NOC e RFC.

Duas ferramentas foram empregadas com a finalidade de se aplicar as métricas sobre os códigosfonte das três especificações do dataflow do estudo de caso: Analizo (Terceiro et al., 2010) e SonarQube (SonarQube, 2020).

\subsection{Métricas quantitativas}

A Tabela 8.1 compara os três códigos segundo a métrica de contagem do número de linhas. Na contagem, foram desconsiderados arquivos de configuração (pom.xml), que aumentariam o número de linhas, visto que neles foram incluídas dependências tanto para o Flink quanto para o Apex. Outras métricas quantitativas analisadas na Tabela 8.1 são as quantidades de atributos, métodos e classes.

\begin{tabular}{|l|c|c|c|}
\hline \multirow{2}{*}{$\begin{array}{c}\text { Métricas } \\
\text { analisadas } \\
\text { (em quantidade) }\end{array}$} & \multicolumn{3}{|c|}{ Código utilizando } \\
\cline { 2 - 4 } & A interface & $\begin{array}{c}\text { A sintaxe } \\
\text { do Flink }\end{array}$ & $\begin{array}{c}\text { A sintaxe } \\
\text { do Apex }\end{array}$ \\
\hline Número de linhas & 482 & 611 & 790 \\
\hline Linhas de código (LOC) & 339 & 433 & 558 \\
\hline Atributos (NOA) & 6 & 31 & 39 \\
\hline Métodos (NOM) & 13 & 74 & 83 \\
\hline Classes (NC) & 7 & 10 & 13 \\
\hline Arquivos & 2 & 6 & 8 \\
\hline
\end{tabular}

Tabela 8.1: Comparação da quantidade de linhas, atributos, métodos, classes e arquivos nos códigos-fonte

A diferença do número de linhas para as linhas de código é que o primeiro trata-se do número absoluto, enquanto o segundo refere-se a linhas que contenham pelo menos um caractere diferente de branco (espaços e tabulações) e que também não seja parte de um comentário. Comparando-se a quantidade de linhas de código, nota-se que para o código do Flink foram escritas quase cem linhas a mais, enquanto para o Apex o acréscimo passa de duzentas linhas. Isso exemplifica que quando se utiliza a interface desenvolvida, a quantidade de código escrito é bem menor que a quantidade de código implementada para executar diretamente nos arcabouços. A diferença na quantidade de atributos e métodos também é considerável. Por exemplo: foram escritos treze métodos usando-se a interface proposta, o que é um número bem menor se comparado a setenta e quatro para o Flink e oitenta e três para o Apex.

O tamanho do código também foi reduzido com o uso da interface quando os critérios analisados são o número de classes e de arquivos. Além disso, para todas as métricas quantitativas analisadas na Tabela 8.1, percebe-se que o valor na solução construída no Apex é maior em comparação à do Flink.

Essa redução ocorreu devido ao fato da interface permitir que seu usuário escreva menos código para expressar sua lógica. Um exemplo disso é que não é necessário criar um arquivo de propriedades, visto que estas são passadas por parâmetros com o uso da interface. A diferença quantitativa observada entre códigos do Flink e do Apex ocorre porque o segundo é mais verboso que o primeiro, já que para construir os dataflows no Apex é necessário entrar no nível de detalhe do grafo. 


\subsection{Métricas de complexidade}

Outras métricas importantes para análise de código são as complexidades ciclomática e a cognitiva. A primeira tem como base para o cálculo a quantidade de caminhos presentes no código. Por exemplo, cada divisão em um fluxo de controle incrementa em uma unidade a complexidade ciclomática do código. Cada método criado tem no mínimo complexidade um e, assim, quanto maior a quantidade de métodos, maior a complexidade ciclomática de um código. Visto que dois códigos com a mesma complexidade ciclomática não necessariamente são igualmente difíceis de se manter por um desenvolvedor, utiliza-se a complexidade cognitiva para conseguir mensurar, como o nome sugere, o esforço cognitivo necessário para a compreensão desses fluxos. Para o cálculo da pontuação considera-se para fins de incrementos: uso de estruturas de fluxo de controle encadeadas, uso de laços e condicionais, recursão, descontinuidades (break, goto, continue). A pontuação é incrementada para o primeiro if mas precisa ser analisada para else if, else e similares, porque entende-se que o custo de entendimento é pago no primeiro if, mas a análise é necessária pois depende da condição do else if, por exemplo. Portanto, a complexidade ciclomática segue bases matemáticas, enquanto a cognitiva considera também fatores humanos na contagem e análise da complexidade.

Embora a complexidade cognitiva tenha sido quase igual para os três códigos analisados, como pode ser visto na Tabela 8.2, a ciclomática teve diferença significativa: os códigos no Flink e Apex tiveram mais que o dobro da complexidade do código desenvolvido usando-se a interface.

\begin{tabular}{|c|c|c|c|}
\hline \multirow{2}{*}{$\begin{array}{c}\text { Métricas } \\
\text { analisadas } \\
\text { (complexidade) }\end{array}$} & \multicolumn{3}{|c|}{ Código } \\
\hline & A interface & $\begin{array}{l}\text { A sintaxe } \\
\text { do Flink }\end{array}$ & $\begin{array}{l}\text { A sintaxe } \\
\text { do Apex }\end{array}$ \\
\hline $\begin{array}{l}\text { Complexidade } \\
\text { ciclomática }\end{array}$ & 54 & 115 & 121 \\
\hline $\begin{array}{l}\text { Complexidade } \\
\text { cognitiva }\end{array}$ & 62 & 62 & 63 \\
\hline
\end{tabular}

Tabela 8.2: Comparação das complexidades ciclomática e cognitiva dos códigos-fonte

O código desenvolvido utilizando-se a interface apresenta menor complexidade ciclomática e, assim, possui menor quantidade de divisões nos fluxos de controle, o que facilita a manutenção do mesmo.

Outra métrica relacionada à complexidade de código é a WMC, que consiste na soma ponderada das complexidades de todos os métodos de uma classe. A métrica escolhida para mensurar a complexidade dos métodos impacta o valor da WMC, mas não há um consenso entre os pesquisadores sobre qual é a melhor métrica a utilizar (Subramanyam e Krishnan, 2003). Dentre as utilizadas para calcular o peso dos métodos estão o número de linhas de código e a complexidade ciclomática. Devido a isso, optou-se por não utilizar a WMC neste trabalho.

\subsection{Métricas de acoplamento e coesão}

A métrica CBO contabiliza a quantidade de classes acopladas a uma determinada classe, medindo, desse modo, o nível de acoplamento entre classes. O acoplamento ocorre, por exemplo, quando um método de uma classe utiliza métodos ou atributos de uma outra classe, indicando dependência entre classes. Assim, classes com alto acoplamento tendem a ser mais difíceis de compreender e manter. Portanto, quanto menor o acoplamento, melhor.

Pela Tabela 8.3 pode-se notar que o código Flink é o que apresenta maior acoplamento. Como o acoplamento médio nos três códigos é menor do que um e a quantidade de classes de cada um deles varia (o código que usa a interface possui 7, o do Flink possui 10 e o do Apex possui 13), foi incluída na tabela também a soma dos acoplamentos de todas as classes de cada código. O código 
Flink é o que possui o maior valor para essa métrica, mas o valor máximo atingido de acoplamento para uma classe é 2, o que mostra que os três códigos têm baixo acoplamento.

\begin{tabular}{|l|c|c|c|}
\hline \multirow{2}{*}{$\begin{array}{c}\text { Acoplamento } \\
\text { entre } \\
\text { objetos (CBO) }\end{array}$} & \multicolumn{3}{|c|}{ Código } \\
\cline { 2 - 4 } & A interface & $\begin{array}{c}\text { A sintaxe } \\
\text { do Flink }\end{array}$ & $\begin{array}{c}\text { A sintaxe } \\
\text { do Apex }\end{array}$ \\
\hline Mínimo & 0 & 0 & 0 \\
\hline Máximo & 1 & 2 & 1 \\
\hline Média & 0,43 & 0,70 & 0,31 \\
\hline Desvio Padrão & 0,53 & 0,95 & 0,48 \\
\hline Soma & 3 & 7 & 4 \\
\hline
\end{tabular}

Tabela 8.3: Comparação do acoplamento entre objetos nos códigos-fonte

Mensurar a coesão de métodos de uma classe relaciona-se à frequência de acesso aos atributos da classe. Quanto mais atributos em comum forem acessados pelos métodos da classe, mais coesa ela é. Uma vez que é desejado que as classes sejam coesas, é preferível números pequenos para a métrica LCOM. Para o cálculo dessa métrica é realizada a diferença entre a quantidade de pares de métodos que não compartilham atributos em comum pela quantidade de pares que compartilham. Uma vez que essa métrica está mais relacionada à forma como o código é escrito pelo desenvolvedor do que ao arcabouço em si, não foi utilizada como métrica comparativa.

\subsection{Métricas relacionadas a herança}

A profundidade da árvore de herança (métrica DIT) de uma classe trata-se da quantidade de níveis de herança em que as subclasses herdam os métodos e atributos em relação à raiz da árvore. Dessa forma, quanto maior a profundidade, mais complexa é a classe. Na Tabela 8.4, pode-se ver que os valores máximo e mínimo coincidem para os três códigos, indicando que há no máximo um nível de herança. O desvio padrão dos três é próximo, mas a média para o código desenvolvido usando-se a interface é um pouco maior. Fazendo-se o somatório das profundidades para todas as classes, o código Apex apresenta o maior valor (oito em detrimento de cinco nos demais).

\begin{tabular}{|l|c|c|c|}
\hline \multirow{2}{*}{$\begin{array}{c}\text { Profundidade da } \\
\begin{array}{c}\text { árvore de } \\
\text { herança (DIT) }\end{array}\end{array}$} & A interface & $\begin{array}{c}\text { A sintaxe } \\
\text { do Flink }\end{array}$ & $\begin{array}{c}\text { A sintaxe } \\
\text { do Apex }\end{array}$ \\
\cline { 2 - 4 } & 0 & 0 & 0 \\
\hline Mínimo & 1 & 1 & 1 \\
\hline Máximo & 0,71 & 0,50 & 0,62 \\
\hline Média & 0,49 & 0,53 & 0,51 \\
\hline Desvio Padrão & 5 & 5 & 8 \\
\hline Soma & & & \\
\hline
\end{tabular}

Tabela 8.4: Comparação da profundidade da árvore de herança dos códigos-fonte

\subsection{Métricas relacionadas a métodos e seus parâmetros}

A resposta para uma classe (RFC) é formada pela quantidade total e distinta de métodos que compõem uma classe, inclusive métodos herdados, ou que podem ser chamados diretamente por eles em resposta a uma mensagem recebida por um objeto da classe em questão (Arapidis, 2012).

A Tabela 8.5 indica que o código Flink apresenta o maior valor para essa métrica, seguido pelo código Apex, ambos atingindo o valor máximo de 51 chamadas para uma classe. Esse é um exemplo 
de que o uso da interface facilita o desenvolvimento da solução, visto que quanto maior a quantidade de métodos que podem ser chamados em uma classe, mais complexa ela é.

\begin{tabular}{|l|c|c|c|}
\hline \multirow{2}{*}{$\begin{array}{c}\text { Resposta para } \\
\text { uma classe (RFC) }\end{array}$} & A interface & $\begin{array}{c}\text { A sintaxe } \\
\text { do Flink }\end{array}$ & $\begin{array}{c}\text { A sintaxe } \\
\text { do Apex }\end{array}$ \\
\cline { 2 - 4 } & 1 & 1 & 1 \\
\hline Mínimo & 18 & 51 & 51 \\
\hline Máximo & 4,71 & 21,6 & 16,46 \\
\hline Média & 6,13 & 17,9 & 17,69 \\
\hline Desvio Padrão &
\end{tabular}

Tabela 8.5: Comparação da resposta para uma classe (RFC) dos códigos-fontes

A quantidade de parâmetros que um desenvolvedor precisa passar para uma função também é uma métrica indicadora de complexidade, pois quanto mais parâmetros se precisa passar, mais difícil é a memorização da assinatura do método.

O ANPM é o número médio de parâmetros por método e, assim, é calculado a partir da contagem total dos parâmetros dos métodos de cada classe dividida pelo número de métodos contidos nela. Desse modo, cada classe tem um valor de ANPM. Os valores mostrados na Tabela 8.6 são obtidos da seguinte forma: o mínimo (máximo) é o menor (maior) valor obtido de ANPM considerando-se todas as classes analisadas de um projeto, enquanto a média é obtida pela soma dos valores de ANPM de cada classe dividida pelo número de classes.

Pela Tabela 8.6 é possível notar que a média do código desenvolvido usando-se a interface é um pouco maior se comparada à dos demais. Isso se deve ao fato de serem necessários parâmetros adicionais em alguns métodos da interface para satisfazer os parâmetros solicitados pelos diferentes arcabouços para os quais se pode mapear o dataflow. Um exemplo disso, são propriedades que são requisitos para o Apex, mas que não são necessários para o Flink, como o endereço do servidor Zookeeper quando o conector Kafka é utilizado (vide Seção 5.3.3). Há outros cenários assim, então para diminuir o número de parametrizações e arquivos que o desenvolvedor teria que construir se usasse diretamente o arcabouço de Big Data, optou-se por aumentar quando necessário a quantidade de parâmetros nos métodos da interface de abstração.

\begin{tabular}{|l|c|c|c|}
\hline \multirow{2}{*}{$\begin{array}{c}\text { Número médio de } \\
\text { parâmetros por } \\
\text { método (ANPM) }\end{array}$} & A interface & $\begin{array}{c}\text { A sintaxe } \\
\text { do Flink }\end{array}$ & $\begin{array}{c}\text { A sintaxe } \\
\text { do Apex }\end{array}$ \\
\cline { 2 - 4 } & 1 & 0,73 & 0 \\
\hline Mínimo & 2 & 2 & 2 \\
\hline Máximo & 1,14 & 1,02 & 0,93 \\
\hline Média & 0,38 & 0,36 & 0,43 \\
\hline Desvio Padrão &
\end{tabular}

Tabela 8.6: Comparação da quantidade média de parâmetros dos métodos (ANPM) dos códigos-fonte

\subsection{Considerações sobre o capítulo atual}

As métricas consideradas neste capítulo abrangem diferentes perspectivas de análise de código: qualidade, legibilidade, manutenibilidade, usabilidade, evolutibilidade, entre outras.

Os resultados das métricas utilizadas evidenciam que é mais fácil escrever e manter códigos de dataflows por meio do uso da interface, no lugar de usar a sintaxe das APIs dos arcabouços.

As métricas quantitativas relativas a tamanho (linhas de código) e quantidade (atributos, métodos e classes) evidenciaram que para produzir código diretamente nos arcabouços com a mesma 
lógica do estudo de caso foi necessário escrever quase o dobro de linhas de código se comparado ao desenvolvimento que utiliza a interface proposta neste trabalho. A complexidade ciclomática dos códigos Flink e Apex também é maior que a do código que utiliza a interface.

O código Apex apresentou a menor coesão entre os três analisados, refletindo em maior dificuldade para realizar manutenções e alterações do mesmo. A resposta para classes foi maior no Flink, seguida pelo Apex, indicando também complexidade das classes. 


\section{Capítulo 9}

\section{Conclusões}

O presente trabalho visou a desenvolver uma interface para criação de dataflows que abstrai as especificidades de arcabouços de Big Data, bem como um sistema de software responsável por realizar o mapeamento de dataflows especificados com a interface em programas que podem ser executados nos arcabouços escolhidos. A interface juntamente com o sistema de software formam uma abstração cuja construção buscou ser a mais genérica possível, para viabilizar a expansão para outras ferramentas ou para a inclusão de outros componentes, como um novo operador de entrada e saída de dados.

Após uma comparação entre arcabouços de Big Data de código aberto, dois foram escolhidos como prova de conceito para o sistema de mapeamento: Apache Apex e Apache Flink. A escolha deles permitiu explorar aspectos diferentes no mapeamento, visto que são arcabouços distintos entre si, sendo o Flink de mais alto nível, enquanto o Apex entra no nível de topologia e idealização do grafo na especificação dos dataflows. Portanto, essa diversidade permitiu enriquecer o mapeamento implementado, de forma a possibilitar o seu uso como base para mapear outras ferramentas em alguma futura expansão da abstração desenvolvida.

No projeto da interface, buscou-se reunir as operações mais utilizadas nos arcabouços de Big Data e colocar o dado no centro de tudo, considerando-se que as ferramentas usam modelo de dataflows. Assim, os conectores de entrada e saída permitem ler e escrever dados, assim como as transformações e as janelas construídas também são aplicadas sobre os dados. Além desses quesitos, pensando-se em flexibilidade da interface, tipos genéricos para classes e métodos foram usados, para possibilitar reaproveitamento.

Para o mapeamento dos dataflows especificados por meio da interface em programas inteligíveis aos arcabouços de Big Data, foi necessário desenvolver um analisador de código para estruturas como declaração de variáveis, métodos e classes, com a finalidade de separar o código que usa a interface - que precisa ser mapeado - daquele que não a usa, mas que também é código Java. A etapa de mapeamento contempla não apenas a conversão dos métodos e chamadas, mas também a geração de arquivos de propriedades e adição de dependências.

Foram realizados experimentos para avaliar o funcionamento dos serviços de mapeamento implementados. Para os experimentos, foram criados programas que usaram a interface desenvolvida para especificar diferentes tipos de estruturas de dataflows. Os programas processaram dados reais do sistema de transporte público de ônibus de São Paulo, coletados nos meses de abril, maio e junho de 2019. Um outro dataflow mais complexo que o dos experimentos, também envolvendo o uso desses dados, foi implementado como estudo de caso, o qual permitiu validar a interface e o mapeamento desenvolvidos, por meio de uma aplicação de cidades inteligentes. Utilizou dados históricos e de tempo real, com a aplicação de diferentes tipos de transformações de dados.

Foram utilizadas algumas métricas para comparar o código-fonte de um dataflow especificado com o uso da interface e o código do mesmo dataflow especificado diretamente nas linguagens dos arcabouços. Foi notável a redução na quantidade de linhas, atributos, métodos e classes do código quando utilizou-se a interface. A complexidade ciclomática também foi reduzida, indicando mais um ganho com o uso da interface. 
Desse modo, foram respondidas às questões de pesquisa levantadas no Capítulo 1: os arcabouços de Big Data foram comparados no Capítulo 4, analisando-se características em comum às ferramentas, como operadores e representação de dataflows; como decorrência dessa análise, construiu-se a interface, apresentada no Capítulo 5, a qual é utilizada pelo usuário da abstração para exprimir seus dataflows; por fim, o mapeamento da API foi detalhado no Capítulo 6, no qual mostrou-se que, devido à forma como ele foi construído, pode ser usado como base para extensão para outras ferramentas.

\subsection{Pesquisas futuras}

Como trabalhos futuros, pode-se estender o mapeamento desenvolvido para outros arcabouços desejados, visto que foram construídos mapeamentos apenas para dois arcabouços, explorando o uso de APIs declarativas e topológicas. Além disso, a interface desenvolvida está em Java, uma linguagem orientada a objetos, e outra possível extensão seria ampliar a interface para utilizar outros paradigmas, como o funcional, por exemplo, já que esses arcabouços também reconhecem Scala além de Java.

A formalização das operações realizadas nesses arcabouços (mapeamento, redução, filtros, uso de janelas) por meio de um modelo matemático também seria uma contribuição relevante, similar à da Álgebra Relacional para a SQL. Uma semântica bem definida, que permite expressar as equivalências entre as operações existentes, traz maior segurança e flexibilidade no uso das transformações aplicadas.

Além disso, há linguagens de consulta para lidar com processamento em tempo real, mas não há uma padronização consolidada, como é a SQL para os bancos de dados relacionais. A proposição de uma padronização é um outro problema de pesquisa relevante, considerando-se a necessidade cada vez maior de processar dados em tempo real.

Por fim, outra possível contribuição relacionada ao presente trabalho seria a elaboração de outros estudos de caso, com dados de domínios diferentes do de mobilidade urbana e utilizar o sistema de software desenvolvido para gerar código voltado para benchmarks. Um exemplo seria explorar outros cenários de cidades inteligentes, integrando à plataforma do InterSCity, que possui microsserviços com suporte à conexão com diversos dispositivos IoT para obtenção de dados. Essa seria uma contribuição mútua aos sistemas integrados, visto que um dos trabalhos futuros para a plataforma seria a adição de suporte a processamento de Big Data. 


\section{Apêndice A}

\section{Mapeamento de código}

A Lista A.1 baseia-se no exemplo de dataflow utilizado no Capítulo 5. Os códigos resultantes do mapeamento desse dataflow para serem executados nos arcabouços Flink e Apex estão em seguida.

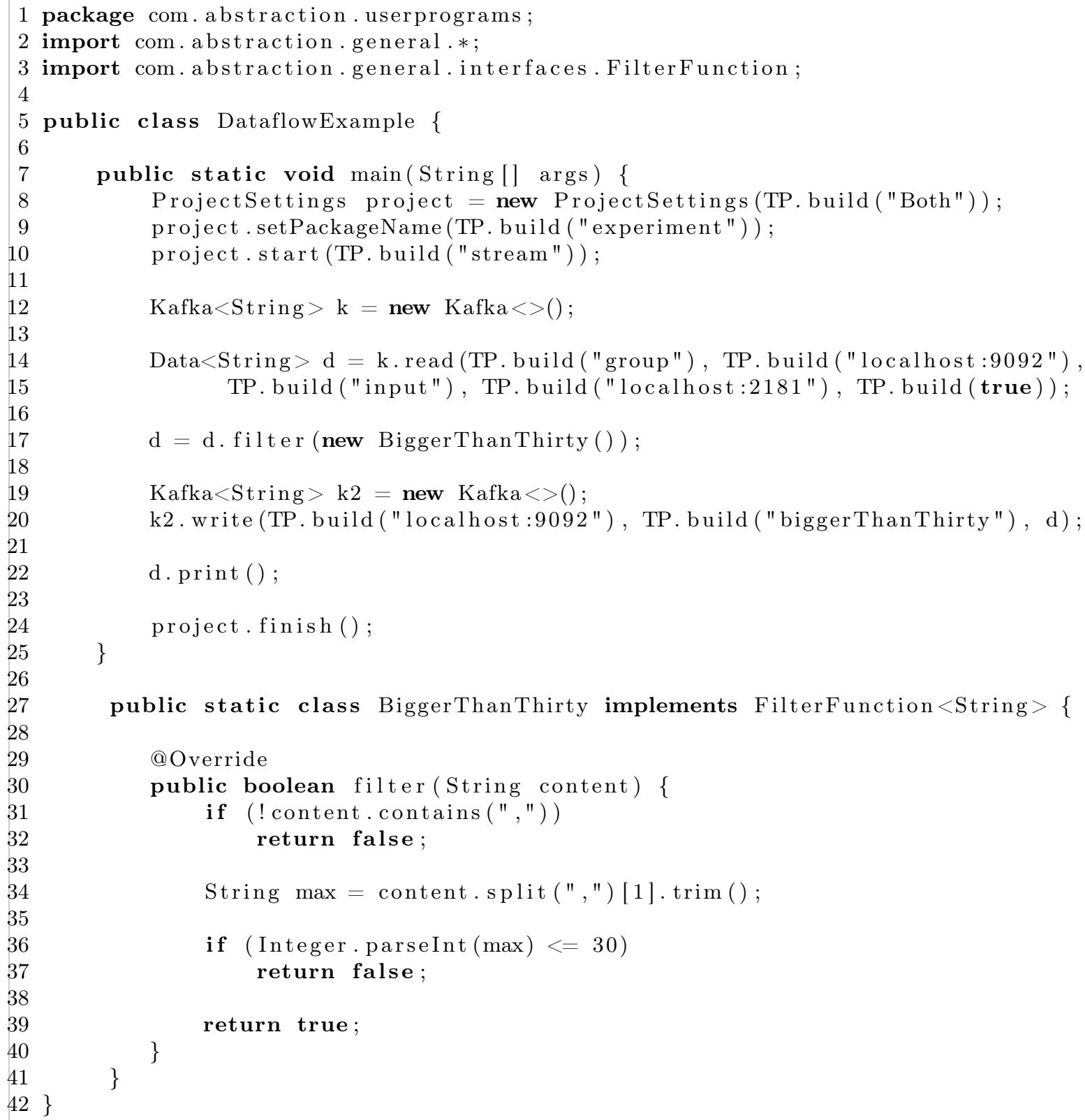

Lista A.1: Exemplo de dataflow definido com o uso da interface 
Na Lista A.1, pode-se notar na instanciação da classe Project Settings (linha 8) que desejase mapear o código para ambos os arcabouços, Flink e Apex. O código a ser gerado fica no pacote experiment e utiliza processamento de dados de tempo real. O Kafka é utilizado como conector de entrada e saída e precisa ser considerado no mapeamento. Assim, é necessário incluir dependências no arquivo pom.xml, tanto do projeto Apex quanto do Flink, como ilustrado nas Listas A.2 e A.5, respectivamente. Além disso, há propriedades definidas, como o tópico, zookeeper, entre outras associadas ao Kafka. No Apex elas são explicitadas em um arquivo .xml, conforme ilustrado na Lista A.4. No Flink, algumas das propriedades ficam em um arquivo separado (Lista A.7), enquanto outras ficam no próprio código. Os dataflows definidos para serem executados nos arcabouços Apex e Flink encontram-se nas Listas A.3 e A.6, respectivamente.

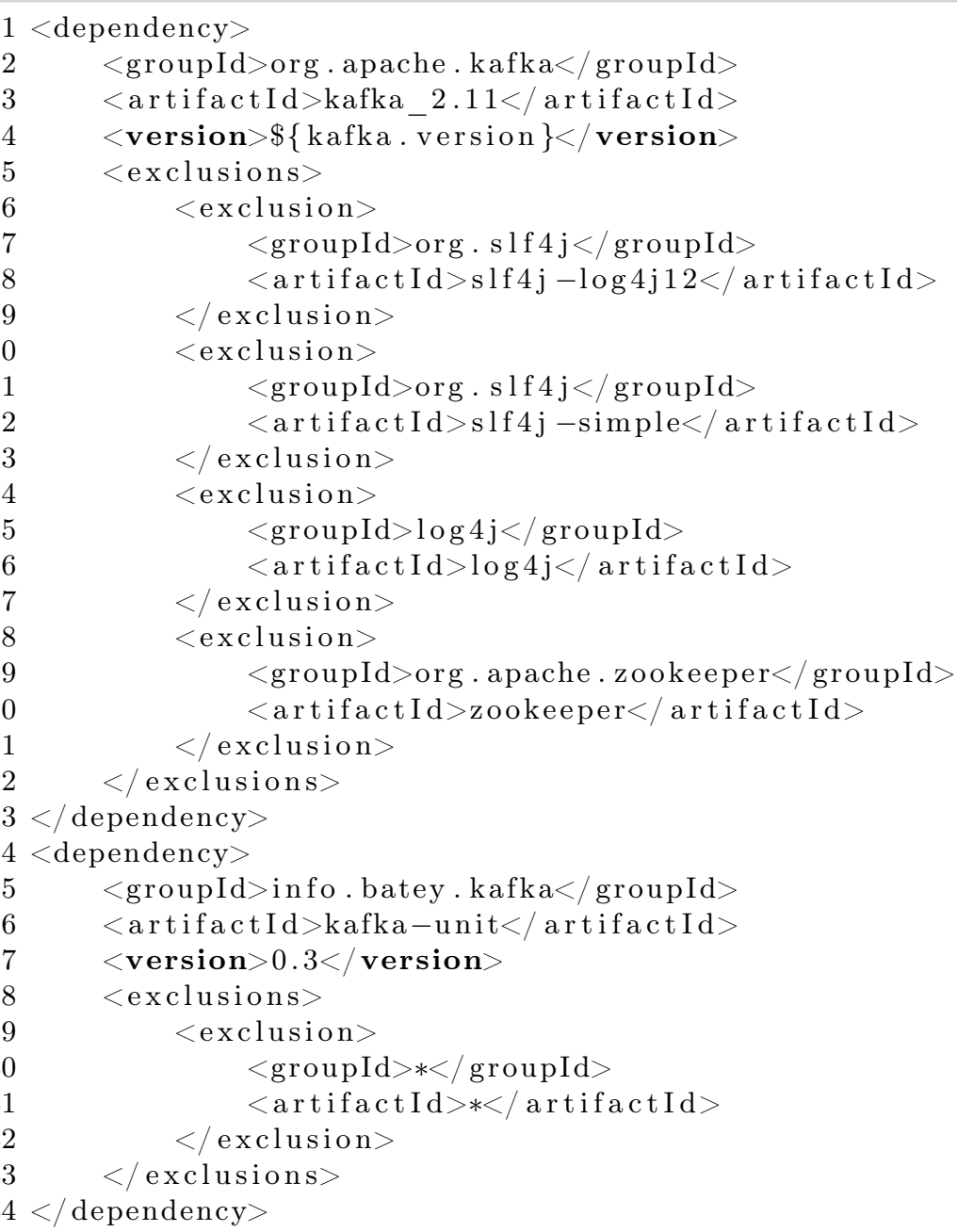

Lista A.2: Dependência adicionada ao pom.xml do código gerado para o Apex para o conector Kafka do DataflowExample 


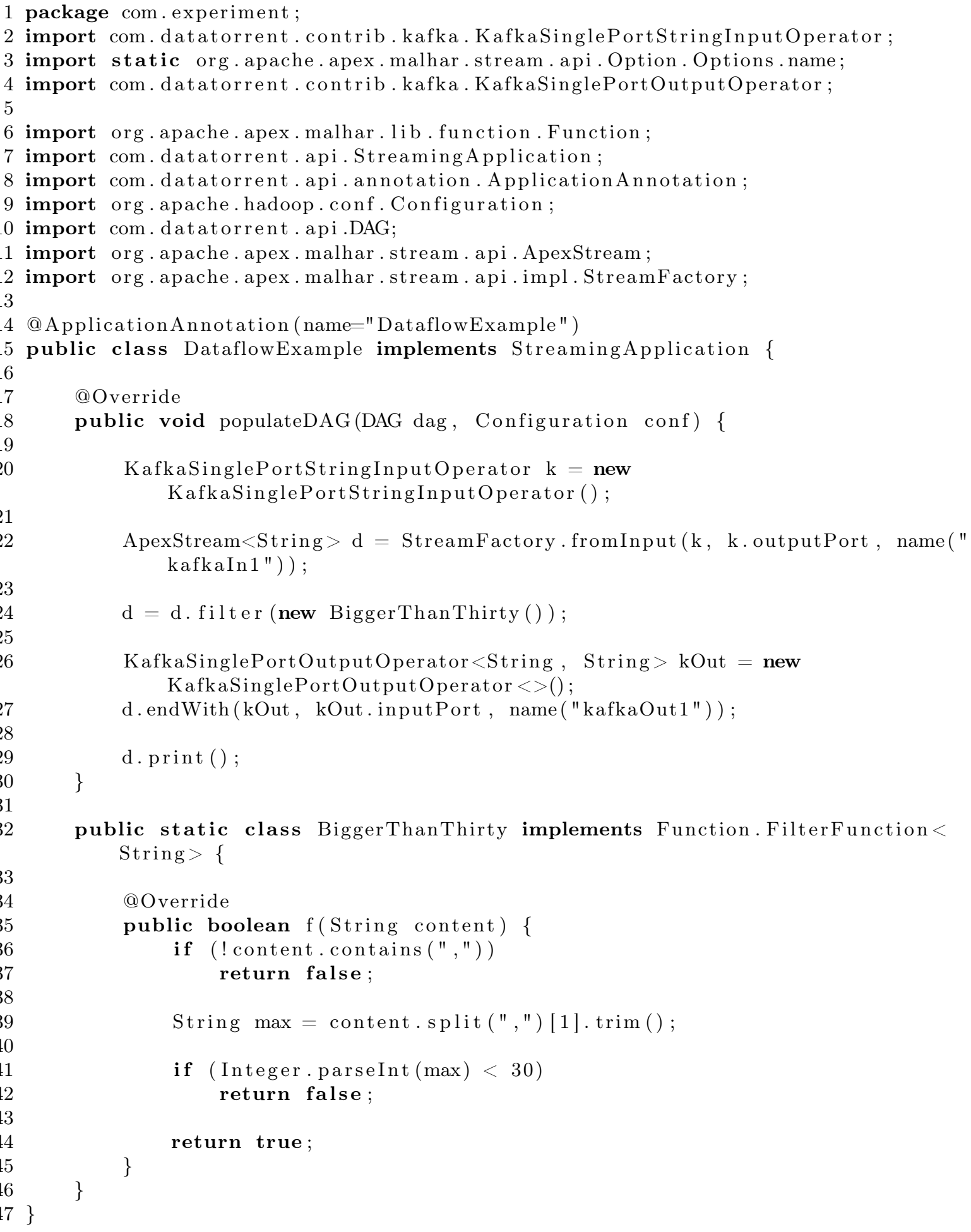

Lista A.3: Código gerado para o Apex pelo mapeamento do DataflowExample 


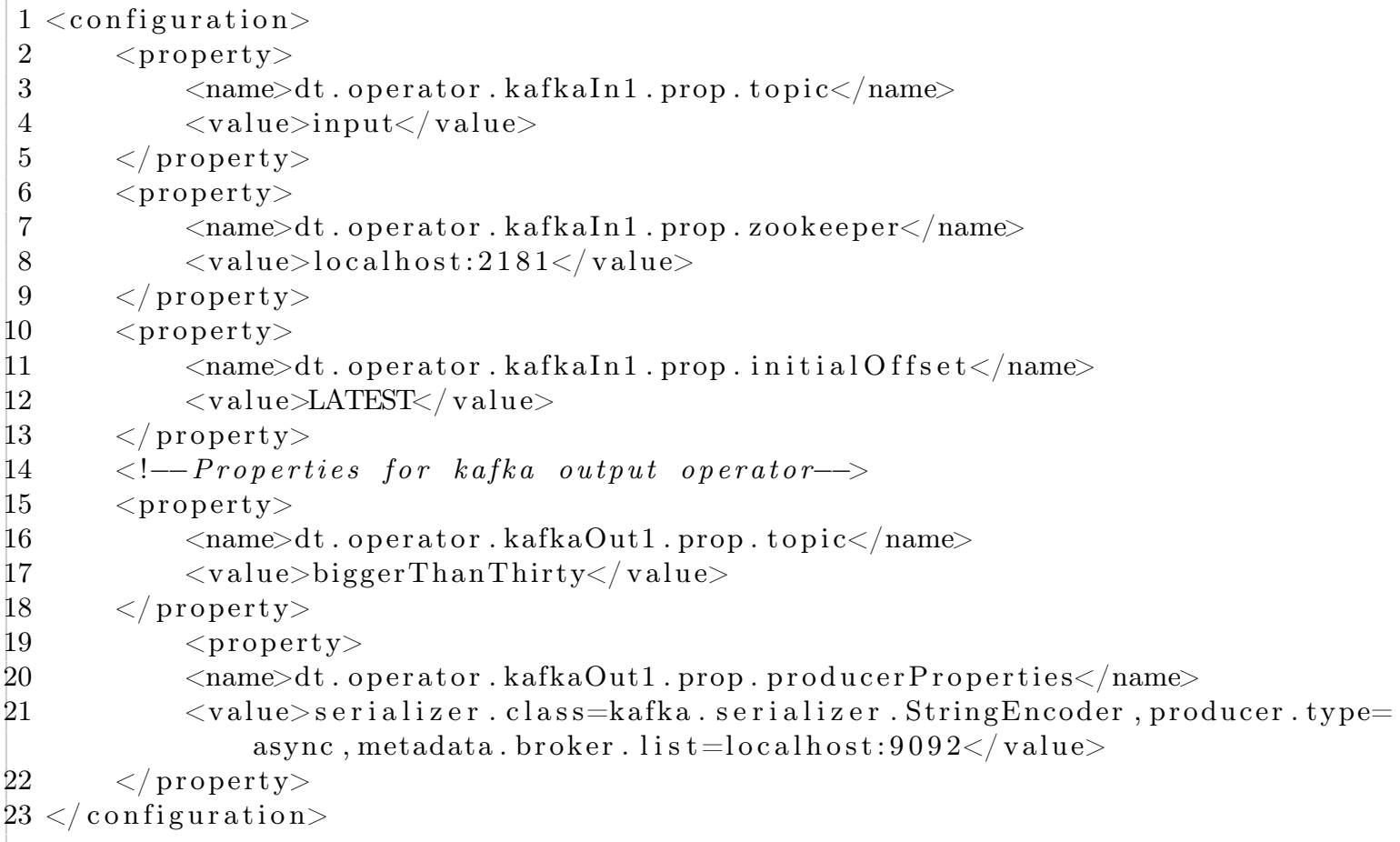

Lista A.4: Arquivo de propriedades geradas para o Apex para o conector Kafka do DataflowExample

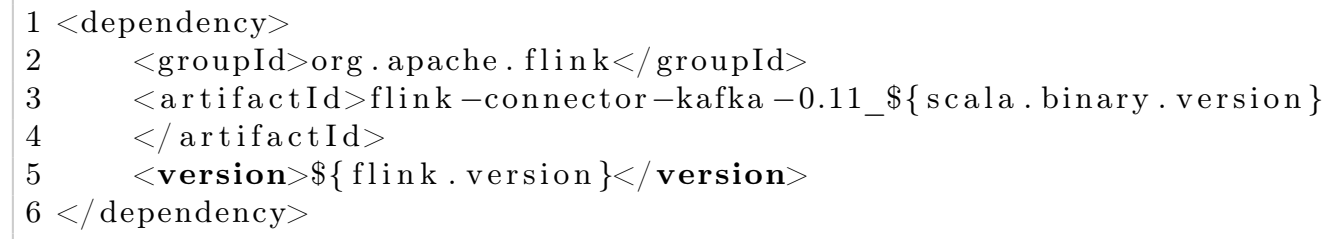

Lista A.5: Dependência adicionada ao pom.xml do código gerado para o Flink para o conector Kafka do DataflowExample 
1 package com.experiment;

2 import org.apache.flink.streaming.api.environment. StreamExecutionEnvironment;

3 import org.apache.flink.streaming.api.datastream. DataStream;

4 import org.apache.flink.api.java.utils. ParameterTool;

5 import java.io. InputStream;

6 import java.util. Properties;

7 import org.apache.flink. streaming.connectors.kafka. FlinkKafkaConsumer011;

8 import org.apache.flink.api.common. serialization. SimpleStringSchema;

9 import org.apache.flink.streaming.connectors.kafka. FlinkKafkaProducer011;

10 import org.apache.flink.api.common.functions. FilterFunction;

11

12 public class DataflowExample \{

13

14 getProperties ();

\}

d. print ( ) ;

@Override

return false;

return false;

return true;

\}

\} public static void main(String[] args) throws Exception \{

StreamExecutionEnvironment env $=$ StreamExecutionEnvironment. getExecutionEnvironment ();

InputStream inputStream = DataflowExample.class.getResourceAsStream (" DataflowExample.properties");

Properties prop $=$ ParameterTool.fromPropertiesFile(inputStream).

DataStream $<$ String $>d=$ env . addSource (new FlinkKafkaConsumer $011<>$ (" input", new SimpleStringSchema(), prop). setStartFromLatest ());

$\mathrm{d}=\mathrm{d}$.filter (new BiggerThanThirty ()$)$;

d.addSink (new FlinkKafkaProducer011<>("biggerThanThirty", new SimpleStringSchema (), prop));

public static class BiggerThanThirty implements FilterFunction $<$ String $>\{$

public boolean filter(String content) \{

if (! content.contains (","))

String $\max =$ content.split (",")[1].trim ();

if (Integer.parseInt $(\max )<30$ )

Lista A.6: Código gerado para o Flink pelo mapeamento do DataflowExample

1 bootstrap. servers=localhost:9092

2 group.id=group

Lista A.7: Arquivo de propriedades geradas para o Flink para o conector Kafka do DataflowExample 


\section{Apêndice B}

\section{Tempo de execução de dataflows mapeados}

Para a execução dos experimentos do Capítulo 7 foi utilizado um computador com processador i5 e 8GB de memória RAM. O sistema operacional utilizado foi o Ubuntu 14.04.6 LTS.

Quando se usa a interface e o serviço de mapeamento presentes na abstração desenvolvida neste trabalho, são gerados códigos a serem executados diretamente nos arcabouços de Big Data. Dessa forma, o tempo de execução dos programas gerados dependem da eficiência e características dos arcabouços em questão, isto é, a abstração não interfere na velocidade de execução. Entretanto, apenas para exemplificar e comparar os tempos de execução das duas ferramentas escolhidas na prova de conceito, escolheu-se o Experimento 1 apresentado na Seção 7.3 do Capítulo 7 para realizar medições do tempo de execução, repetindo-se trinta vezes cada cenário a fim de calcularmos algumas estatísticas, como média, desvio padrão e intervalo de confiança.

Pelo Teorema Central do Limite, considerando-se uma população de tamanho $N$ com média $\mu$ e desvio padrão $\sigma$, seja a uma amostra de tamanho $n$ para variáveis aleatórias independentes, a distribuição das médias das amostras tende a uma Normal $N\left(\mu, \frac{\sigma}{\sqrt{n}}\right)$. Na prática, é comum utilizar uma amostra aleatória no lugar de várias, desde que contenha um número $n<<N$ suficientemente grande de observações (tamanho maior ou igual a 30). O desvio padrão da distribuição é o $\sigma_{S E M}$, chamado de erro padrão da média, isto é: $\sigma_{S E M}=\frac{\sigma}{\sqrt{n}}$.

Assim, pode ser usado o modelo Normal de probabilidades para fazer inferências sobre a média da população, bem como para o cálculo do intervalo de confiança. Para o cálculo deste último, aplicando-se o Teorema Central do Limite para uma amostra simples e aleatória de tamanho $n$, pode-se utilizar a fórmula $C I=\bar{X} \pm z * \frac{\sigma}{\sqrt{n}}=\bar{X} \pm z * \sigma_{S E M}$, sendo CI o intervalo de confiança e $z$ o $z$-score. Como o desvio padrão da população é desconhecido e a amostra tem tamanho igual a trinta observações, é utilizado o erro padrão estimado da média da amostra, dado pela fórmula: $s_{\bar{x}}=\frac{S}{\sqrt{n}}$.

Os conjuntos de dados utilizados são os mesmos representados pela Tabela 7.1, ou seja, os conjuntos 1, 2 e 3 referem-se aos dados coletados dos meses de abril, maio e junho, respectivamente. Para cada conjunto de dados e ferramenta foram executados trinta vezes o experimento. Dessa forma, para representar todas as combinações da Figura B.1 foram realizadas $3 * 2 * 30=180$ execuções, sendo três o número de datasets, dois arcabouços (Apex e Flink) e trinta as repetições do experimento, respectivamente. O intervalo de confiança calculado é de $99 \%$ e os tempos indicados estão em segundos.

Pelo gráfico da Figura B.1 pode-se notar estabilidade nos tempos de execução do experimento observado, apresentando intervalos de confiança com pequena variação para ambos os arcabouços: por volta de dois segundos e meio para o Apex e pouco mais de um segundo para o Flink. A execução do código no Flink foi mais eficiente em comparação com o Apex, mesmo para diferentes quantidades de registros de entrada.

Portanto, ao comparar-se os tempos de execução do primeiro experimento para os arcabouços Apex e Flink, concluiu-se que a execução do Flink é mais rápida que a do Apex, com o uso de um 


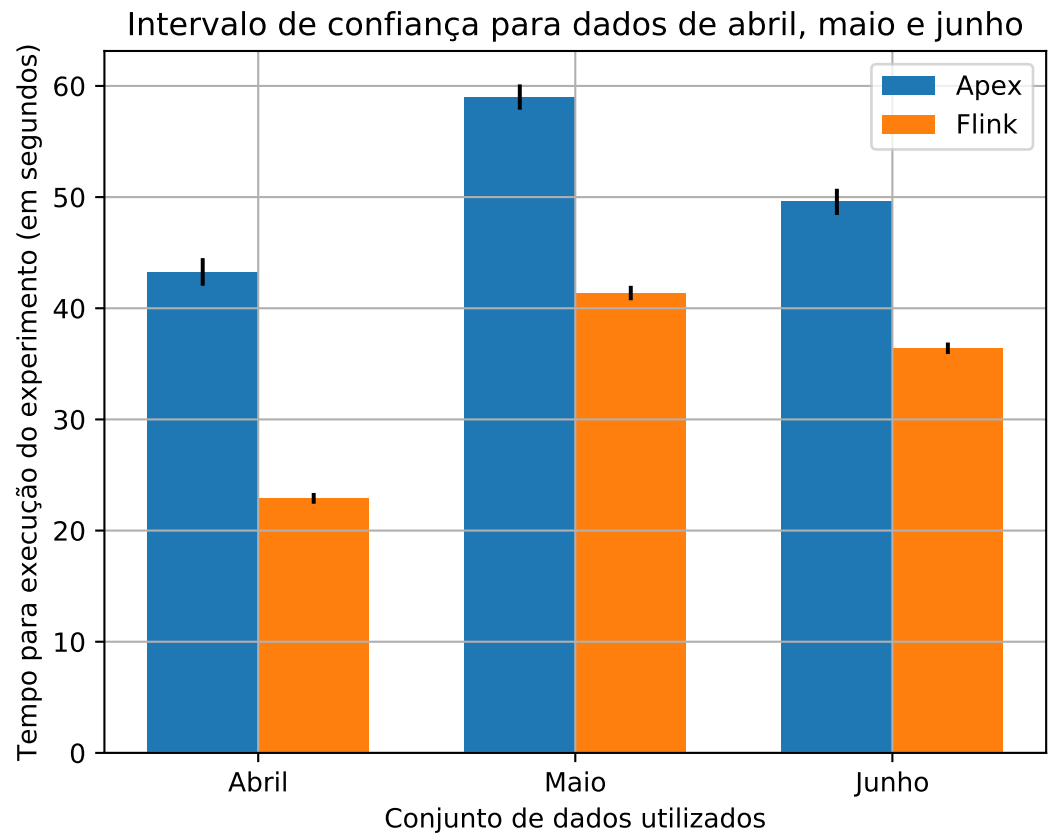

Figura B.1: Tempo médio de execução (com intervalo de confiança de 99\%) do Experimento 1 nos arcabouços Apex e Flink

intervalo de confiança de $99 \%$ para a distribuição Normal de probabilidade. 


\title{
Referências Bibliográficas
}

\author{
Ajerla et al.() Dharmitha Ajerla, Sazia Mahfuz e Farhana Zulkernine. A real-time patient mo- \\ nitoring framework for fall detection. Wireless Communications Mobile Computing, 2019:1-13. \\ Citado na pág. 26
}

Akidau(2015) Tyler Akidau. The world beyond batch: Streaming 101. https://www.oreilly.com/ ideas/the-world-beyond-batch-streaming-101, Agosto 2015. Acesso em: 20/01/2020. Citado na pág. $6,7,13$

Al Nuaimi et al.(2015) Eiman Al Nuaimi, Hind Al Neyadi, Nader Mohamed e Jameela Al-Jaroodi. Applications of big data to smart cities. Journal of Internet Services and Applications, 6(1):25. Citado na pág. 1, 5

Aldinucci et al.(2014) Marco Aldinucci, Marco Danelutto, Peter Kilpatrick e Massimo Torquati. Fastflow: high-level and efficient streaming on multi-core. Em Sabri Pllana e Fatos Xhafa, editors, Programming Multi-core and Many-core Computing Systems, Parallel and Distributed Computing, chapter 13. Wiley. URL http://calvados.di.unipi.it/storage/paper_files/2011_FF_ tutorial-draft.pdf. Citado na pág. 21

Aldinucci et al.(2018) Marco Aldinucci, Maurizio Drocco, Claudia Misale e Guy Tremblay. Languages for Big Data analysis, páginas 1-12. Springer International Publishing, Cham. Citado na pág. 18, 19

Apex(2020) Apache Apex. https://apex.apache.org/docs/apex/, 2020. Acesso em: 20/01/2020. Citado na pág. $3,7,28$

Arapidis(2012) Charalampos Arapidis. Sonar Code Quality Testing Essentials. Packt Publishing. Citado na pág. 79

Attic(2020) Apache Attic. https://attic.apache.org/projects/apex.html, 2020. Acesso em: 20/01/2020. Citado na pág. 56

Avro(2020) Avro. https://avro.apache.org/docs/current/, 2020. Acesso em: 20/01/2020. Citado na pág. 11

Beach et al.(2010) Aaron Beach, Mike Gartrell, Xinyu Xing, Richard Han, Qin Lv, Shivakant Mishra e Karim Seada. Fusing mobile, sensor, and social data to fully enable context-aware computing. Em Proceedings of the Eleventh Workshop on Mobile Computing Systems 85 Applications, páginas 60-65. ACM. Citado na pág. 1

Bharathi et al.(2008) Shishir Bharathi, Ann Chervenak, Ewa Deelman, Gaurang Mehta, Mei-Hui Su e Karan Vahi. Characterization of scientific workflows. Em 2008 third workshop on workflows in support of large-scale science, páginas 1-10. IEEE. Citado na pág. xiii, 13, 15

Cassandra(2020) Cassandra. http://cassandra.apache.org/, 2020. Acesso em: 20/01/2020. Citado na pág. 56 
Cho et al.(2016) Hirotoshi Cho, Hiroaki Shiokawa e Hiroyuki Kitagawa. Jsflow: Integration of massive streams and batches via json-based dataflow algebra. Em 2016 19th International Conference on Network-Based Information Systems (NBiS), páginas 188-195. IEEE. Citado na pág. 18, 19,20

Crankshaw et al.(2017) Daniel Crankshaw, Xin Wang, Guilio Zhou, Michael J Franklin, Joseph E Gonzalez e Ion Stoica. Clipper: A low-latency online prediction serving system. Em Proceedings of the 14th USENIX Symposium on Networked Systems Design and Implementation, páginas 613-627. Citado na pág. 18, 19, 20

de Camargo Magano e Braghetto(2018) Fernanda de Camargo Magano e Kelly Rosa Braghetto. Abstracting big data processing tools for smart cities. Em 2018 IEEE 37th International Symposium on Reliable Distributed Systems Workshops (SRDSW), páginas 14-17. IEEE. Citado na pág. 4

Dean e Ghemawat(2008) Jeffrey Dean e Sanjay Ghemawat. MapReduce: simplified data processing on large clusters. Communications of the ACM, 51(1):107-113. Citado na pág. xiii, 8, 9

Dissanayake e Jayasena(2017) DMC Dissanayake e KPN Jayasena. A cloud platform for big IoT data analytics by combining batch and stream processing technologies. Em 2017 National Information Technology Conference (NITC), páginas 40-45. IEEE. Citado na pág. 18, 19

Dobbelaere e Esmaili(2017) Philippe Dobbelaere e Kyumars Sheykh Esmaili. Kafka versus RabbitMQ: A comparative study of two industry reference publish/subscribe implementations: Industry paper. Em Proceedings of the 11th ACM International Conference on Distributed and Event-based Systems, páginas 227-238. ACM. Citado na pág. 10

Especificação - Linguagem Java(2020) Especificação - Linguagem Java. https://docs.oracle. $\mathrm{com} /$ javase $/$ specs $/ \mathrm{jls} / \mathrm{se} 7 / \mathrm{html} / \mathrm{jls}-18 . \mathrm{html}, 2020$. Acesso em: 20/01/2020. Citado na pág. 48

Eugster et al.(2003) Patrick Th Eugster, Pascal A Felber, Rachid Guerraoui e Anne-Marie Kermarrec. The many faces of publish/subscribe. ACM computing surveys (CSUR), 35(2):114-131. Citado na pág. 10

Filgueira et al.(2016) Rosa Filgueira, Rafael Ferreira da Silva, Amrey Krause, Ewa Deelman e Malcolm Atkinson. Asterism: Pegasus and dispel4py hybrid workflows for data-intensive science. Em Proceedings of the 7th International Workshop on Data-Intensive Computing in the Cloud, páginas 1-8. IEEE Press. Citado na pág. 18, 20, 21

Flink(2020) Apache Flink. https://flink.apache.org/, 2020. Acesso em: 20/01/2020. Citado na pág. $3,7,26$

Friedman e Tzoumas(2016) Ellen Friedman e Kostas Tzoumas. Introduction to Apache Flink: Stream Processing for Real Time and Beyond. O'Reilly Media, Inc. Citado na pág. 6, 9, 10, 12, 27

Gandomi e Haider(2015) Amir Gandomi e Murtaza Haider. Beyond the hype: Big Data concepts, methods, and analytics. International Journal of Information Management, 35(2):137-144. Citado na pág. 5,11

HBase(2020) HBase. https://hbase.apache.org/, 2020. Acesso em: 20/01/2020. Citado na pág. 24

HDFS(2020) HDFS. https://hadoop.apache.org/docs/r1.2.1/hdfs_design.html, 2020. Acesso em: 20/01/2020. Citado na pág. 12, 24

Hirzel e Baudart(2018) Martin Hirzel e Guillaume Baudart. Stream processing languages and abstractions. Em 2018 Springer International Publishing, Encyclopedia of Big Data Technologies. Springer Nature. Citado na pág. 17 
Hive(2020) Hive. https://hive.apache.org/, 2020. Acesso em: 20/01/2020. Citado na pág. 24

Inoubli et al.(2018) Wissem Inoubli, Sabeur Aridhi, Haithem Mezni, Mondher Maddouri e Engelbert Mephu Nguifo. An experimental survey on big data frameworks. Future Generation Computer Systems, 86:546-564. Citado na pág. 2

InterSCity(2020) InterSCity. INCT InterSCity: Enabling the future internet for smart cities. http://interscity.org/, 2020. Acesso em: 20/01/2020. Citado na pág. 3

Java Parser(2020) Java Parser. https://javaparser.org, 2020. Acesso em: 20/01/2020. Citado na pág. 48,55

JDBC(2020) JDBC. http://www.oracle.com/technetwork/java/javase/jdbc/index.html, 2020. Acesso em: 20/01/2020. Citado na pág. 24

Kafka(2020) Kafka. https://kafka.apache.org/, 2020. Acesso em: 20/01/2020. Citado na pág. 10, 24

Kamburugamuve et al.(2018) Supun Kamburugamuve, Pulasthi Wickramasinghe, Saliya Ekanayake e Geoffrey C Fox. Anatomy of machine learning algorithm implementations in mpi, spark, and flink. The International Journal of High Performance Computing Applications, 32(1):61-73. Citado na pág. 26

Kanhere(2011) Salil S Kanhere. Participatory sensing: Crowdsourcing data from mobile smartphones in urban spaces. Em 12th IEEE International Conference on Mobile Data Management (MDM), volume 2, páginas 3-6. IEEE. Citado na pág. 1

Kappa(2016) Arquitetura Kappa. https://www.oreilly.com/ideas/ applying-the-kappa-architecture-in-the-telco-industry, 2016. Acesso em: 20/01/2020. Citado na pág. xiii, 7,8

Kiran et al.(2015) Mariam Kiran, Peter Murphy, Inder Monga, Jon Dugan e Sartaj Singh Baveja. Lambda architecture for cost-effective batch and speed big data processing. Em Big Data (Big Data), 2015 IEEE International Conference on, páginas 2785-2792. IEEE. Citado na pág. 7, 18

Lambda(2020) Arquitetura Lambda. http://lambda-architecture.net, 2020. Acesso em: 20/01/2020. Citado na pág. xiii, 7

Lee e Parks(1995) Edward A Lee e Thomas M Parks. Dataflow process networks. Proceedings of the IEEE, 83(5):773-801. Citado na pág. 15, 34

Lin et al.(2009) Cui Lin, Shiyong Lu, Xubo Fei, Artem Chebotko, Darshan Pai, Zhaoqiang Lai, Farshad Fotouhi e Jing Hua. A reference architecture for scientific workflow management systems and the view soa solution. IEEE Transactions on Services Computing, 2(1):79-92. Citado na pág. 16

Lopez et al.(2016) Martin Andreoni Lopez, Antonio Gonzalez Pastana Lobato e Otto Carlos MB Duarte. A performance comparison of open-source stream processing platforms. Em 2016 IEEE Global Communications Conference (GLOBECOM), páginas 1-6. IEEE. Citado na pág. 5, 6, 12

Marz e Warren(2015) Nathan Marz e James Warren. Big Data: Principles and best practices of scalable real-time data systems. New York; Manning Publications Co. Citado na pág. 5

Maven(2020) Apache Maven. https://maven.apache.org, 2020. Acesso em: 20/01/2020. Citado na pág. 31

Misale et al.(2017) Claudia Misale, Maurizio Drocco, Marco Aldinucci e Guy Tremblay. A comparison of big data frameworks on a layered dataflow model. Parallel Processing Letters, 27(01): 1740003. Citado na pág. 8, 12, 13, 15, 16, 18, 19, 20 
Misale et al.(2018) Claudia Misale, Maurizio Drocco, Guy Tremblay, Alberto R Martinelli e Marco Aldinucci. Pico: High-performance data analytics pipelines in modern $\mathrm{C}++$. Future Generation Computer Systems, 87:392-403. Citado na pág. 18, 21

MongoDB(2020) MongoDB. https://docs.mongodb.com/, 2020. Acesso em: 20/01/2020. Citado na pág. 24

Neophytou et al.(2011) Panayiotis Neophytou, Panos K Chrysanthis e Alexandros Labrinidis. CONFLuEnCE: Continuous workflow execution engine. Em Proceedings of the 2011 ACM SIGMOD International Conference on Management of Data, páginas 1311-1314. ACM. Citado na pág. $18,20,21$

Nuñez-Varela et al.(2017) Alberto S Nuñez-Varela, Héctor G Pérez-Gonzalez, Francisco E Martínez-Perez e Carlos Soubervielle-Montalvo. Source code metrics: A systematic mapping study. Journal of Systems and Software, 128:164-197. Citado na pág. 76

Olho Vivo(2018) Olho Vivo. Monitoramento Olho Vivo. https://www.prefeitura.sp.gov. br/cidade/secretarias/upload/transportes/edital2018/001_ESTRUTURAL/ANEXO-VII_ SISTEMA-MONITORAMENTO/Anexo-VII.pdf, 2018. Acesso em: 20/01/2020. Citado na pág. 57

RabbitMQ(2020) RabbitMQ. https://www.rabbitmq.com/, 2020. Acesso em: 20/01/2020. Citado na pág. 10

Redis(2020) Redis. https://redis.io/, 2020. Acesso em: 20/01/2020. Citado na pág. 12, 24

Samosir et al.(2016) Jonathan Samosir, Maria Indrawan-Santiago e Pari Delir Haghighi. An evaluation of data stream processing systems for data driven applications. Procedia Computer Science, 80:439-449. Citado na pág. 2, 18, 19

Samza(2020) Apache Samza. https://samza.apache.org/learn/documentation/latest/, 2020. Acesso em: 20/01/2020. Citado na pág. 7

SonarQube(2020) SonarQube. https://www.sonarqube.org, 2020. Acesso em: 20/01/2020. Citado na pág. 77

Spark(2020) Apache Spark. http://spark.apache.org/docs/2.1.1/, 2020. Acesso em: 20/01/2020. Citado na pág. 7

SPTrans(2020) SPTrans. SPTrans: Dados da frota de ônibus em São Paulo. http://www.sptrans. com.br/sptrans/, 2020. Acesso em: 20/01/2020. Citado na pág. 1, 3, 73

SPTrans - Olho Vivo(2020) SPTrans - Olho Vivo. SPTrans. http://www.sptrans.com. $\mathrm{br} /$ desenvolvedores/api-do-olho-vivo-guia-de-referencia/documentacao-api/, 2020. Acesso em: 20/01/2020. Citado na pág. 57

Stonebraker et al.(2005) Michael Stonebraker, Uğur Çetintemel e Stan Zdonik. The 8 requirements of real-time stream processing. ACM Sigmod Record, 34(4):42-47. Citado na pág. 18, 19, 60

Storm(2020) Apache Storm. http://storm.apache.org/, 2020. Acesso em: 20/01/2020. Citado na pág. 7

Subramanyam e Krishnan(2003) Ramanath Subramanyam e Mayuram S. Krishnan. Empirical analysis of CK metrics for object-oriented design complexity: Implications for software defects. IEEE Transactions on software engineering, 29(4):297-310. Citado na pág. 78

Talia(2013) Domenico Talia. Workflow systems for science: Concepts and tools. ISRN Software Engineering, 2013. Citado na pág. 16 
Terceiro et al.(2010) Antonio Terceiro, Joenio Costa, João Miranda, Paulo Meirelles, Luiz Romário Rios, Lucianna Almeida, Christina Chavez e Fabio Kon. Analizo: an extensible multi-language source code analysis and visualization toolkit. Em Brazilian conference on software: theory and practice (Tools Session). Citado na pág. 77

Vydyanathan et al.(2007) Nagavijayalakshmi Vydyanathan, Umit V Catalyurek, Tahsin M Kurc, Ponnuswamy Sadayappan e Joel H Saltz. Toward optimizing latency under throughput constraints for application workflows on clusters. Em European Conference on Parallel Processing, páginas 173-183. Springer. Citado na pág. 6

Weise et al.(2017) Thomas Weise, David Yan, Munagala Ramanath e Kenneth Knowles. Learning Apache Apex: Real-time streaming applications with Apex. Packt Publishing. Citado na pág. 29, 30

Wingerath et al.(2016) Wolfram Wingerath, Felix Gessert, Steffen Friedrich e Norbert Ritter. Real-time stream processing for big data. it-Information Technology, 58(4):186-194. Citado na pág. 6

YARN(2020) YARN. https://yarnpkg.com/en/, 2020. Acesso em: 20/01/2020. Citado na pág. 12

Yu e Buyya(2005) Jia Yu e Rajkumar Buyya. A taxonomy of scientific workflow systems for grid computing. ACM Sigmod Record, 34(3):44-49. Citado na pág. 3, 13

Zanella et al.(2014) Andrea Zanella, Nicola Bui, Angelo Castellani, Lorenzo Vangelista e Michele Zorzi. Internet of things for smart cities. IEEE Internet of Things journal, 1(1):22-32. Citado na pág. 1

Zhang(2016) Bingjing Zhang. A collective communication layer for the software stack of big data analytics. Em 2016 IEEE International Conference on Cloud Engineering Workshop (IC2EW), páginas 204-206. IEEE. Citado na pág. 18, 19, 20

Zhang et al.(2016) Yunquan Zhang, Ting Cao, Shigang Li, Xinhui Tian, Liang Yuan, Haipeng Jia e Athanasios V Vasilakos. Parallel processing systems for big data: a survey. Proceedings of the IEEE, 104(11):2114-2136. Citado na pág. 1, 2, 6, 8 